ORNL/TM-2001/262

\section{OAK RIDGE}

\section{NATIONAL LABORATORY}

MANAGED BY UT-BATTELLE

FOR THE DEPARTMENT OF ENERGY

\section{Investigations and Recommendations on the Use of Existing Experiments in Criticality Safety Analysis of Nuclear Fuel Cycle Facilities for Weapons-Grade Plutonium}

B. T. Rearden

K. R. Elam 


\section{DOCUMENT AVAILABILITY}

Reports produced after January 1, 1996, are generally available free via the U.S. Department of Energy (DOE) Information Bridge.

Web site http://www.osti.gov/bridge

Reports produced before January 1, 1996, may be purchased by members of the public from the following source.

National Technical Information Service

5285 Port Royal Road

Springfield, VA 22161

Telephone 703-605-6000 (1-800-553-6847)

TDD 703-487-4639

Fax 703-605-6900

E-mail info@ntis.fedworld.gov

Web site http://www.ntis.gov/support/ordernowabout.htm

Reports are available to DOE employees, DOE contractors, Energy Technology Data Exchange (ETDE) representatives, and International Nuclear Information System (INIS)

representatives from the following source.

Office of Scientific and Technical Information

P.O. Box 62

Oak Ridge, TN 37831

Telephone 865-576-8401

Fax 865-576-5728

E-mail reports@adonis.osti.gov

Web site http://www.osti.gov/contact.html

This report was prepared as an account of work sponsored by an agency of the United States government. Neither the United States government nor any agency thereof, nor any of their employees, makes any warranty, express or implied, or assumes any legal liability or responsibility for the accuracy, completeness, or usefulness of any information, apparatus, product, or process disclosed, or represents that its use would not infringe privately owned rights. Reference herein to any specific commercial product, process, or service by trade name, trademark, manufacturer, or otherwise, does not necessarily constitute or imply its endorsement, recommendation, or favoring by the United States government or any agency thereof. The views and opinions of authors expressed herein do not necessarily state or reflect those of the United States government or any agency thereof. 


\title{
Investigations and Recommendations on the Use of Existing Experiments in Criticality Safety Analysis of Nuclear Fuel Cycle Facilities for Weapons-Grade Plutonium
}

\author{
B. T. Rearden and K. R. Elam \\ Oak Ridge National Laboratory, \\ PO Box 2008, \\ Oak Ridge, TN 37831-6370
}

Date Published: June 2002

Prepared by the

OAK RIDGE NATIONAL LABORATORY

Oak Ridge, Tennessee 37831

managed and operated by

UT-Battelle, LLC

for the

U.S. DEPARTMENT OF ENERGY

under contract DE-AC05-00OR22725 



\section{CONTENTS}

Page

LIST OF FIGURES

LIST OF TABLES . vii

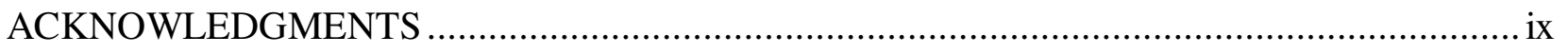

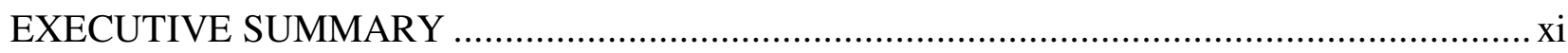

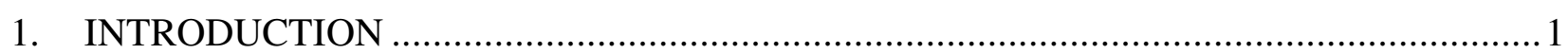

2. SENSITIVITY AND UNCERTAINTY BASED CRITICALITY VALIDATION TECHNIQUES

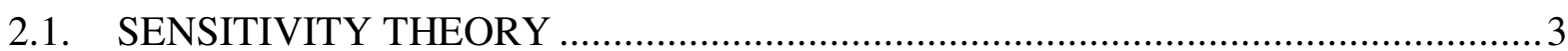

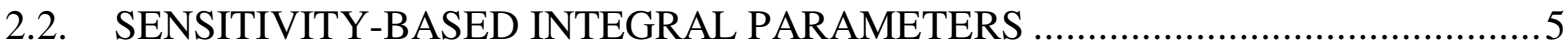

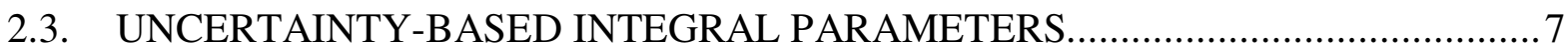

2.4. AREA OF APPLICABILITY USING INTEGRAL PARAMETER TECHNIQUES ...9

2.5. SUMMARY OF S/U ANALYSIS TECHNIQUES................................................. 10

3. PROTOTYPICAL SENSITIVITY AND UNCERTAINTY ANALYSIS CODES FOR CRITICALITY SAFETY WITH THE SCALE CODE SYSTEM.......................................13

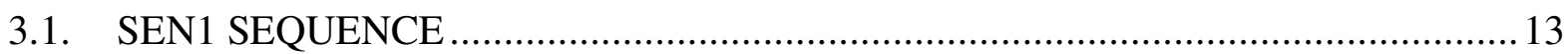

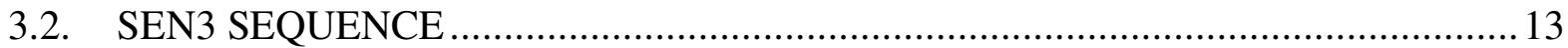

3.3. SENSITIVITY TO RESONANCE-SHIELDED MULTIGROUP

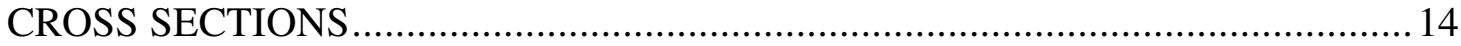

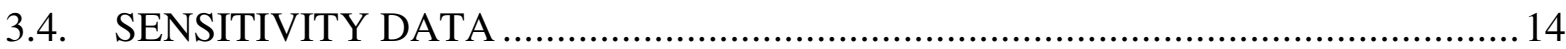

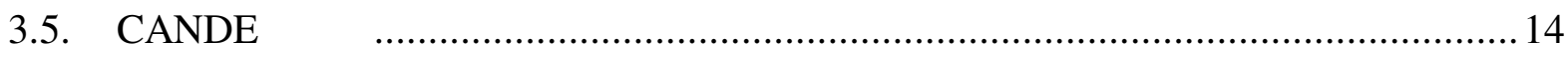

4. SAMPLE DESIGN APPLICATIONS FOR THE MIXED-OXIDE FUEL FABRICATION FACILITY...

5. DEVELOPMENT OF CRITICAL EXPERIMENT DATABASE .......................................19

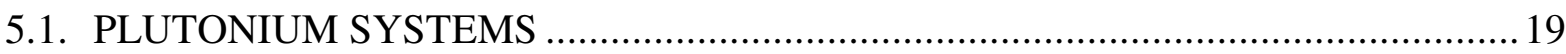

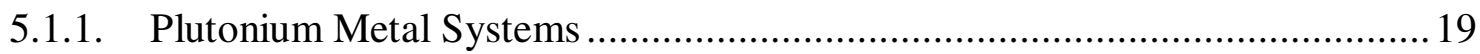

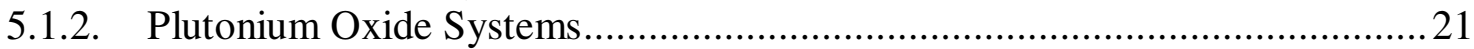

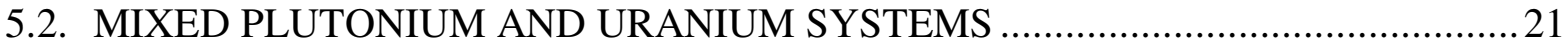

5.2.1. $\quad$ Mixed Plutonium and Uranium Solution Systems .........................................21

5.2.2. $\quad$ Mixed Plutonium and Uranium Fuel Pin Lattices...........................................22

5.2.3. $\quad$ Mixed Plutonium and Uranium Solid Systems ............................................2 23

5.2.4. $\quad$ Mixed Plutonium and Uranium Metal System .......................................24

5.3. LOW-ENRICHED URANIUM OXIDE SYSTEMS ..................................................2

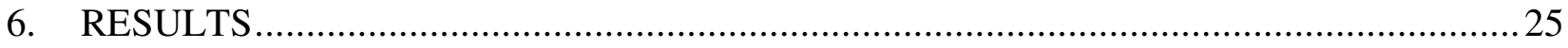

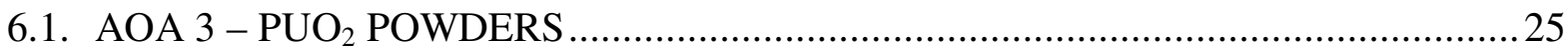




\section{CONTENTS (continued)}

$\underline{\text { Page }}$

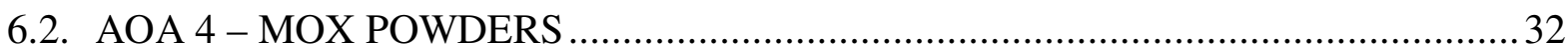

6.2.1. Nuclide-Reaction-Specific Analysis of AOA 4-2 _.....................................4 45

6.2.2. Analysis of Mass Variations for AOA 4-4 ..............................................48

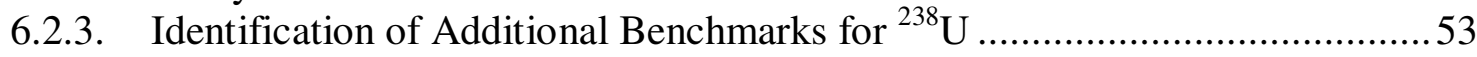

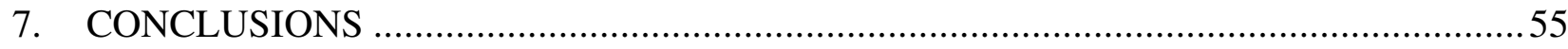

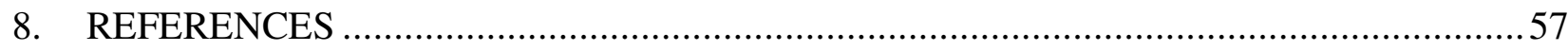

APPENDIX A — COMPLETENESS PARAMETER .............................................................. 61

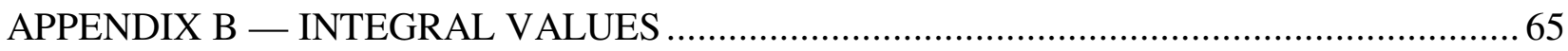




\section{LIST OF FIGURES}

Figure

$\underline{\text { Page }}$

1. Energy-dependent-sensitivity profiles for ${ }^{239} \mathrm{Pu}$ fission for AOA 4-2, Experiment 4 from Table 5 of NSE55, and Experiment 1 from Table 4 of NSE55.

2. Energy-dependent-sensitivity profiles for ${ }^{239} \mathrm{Pu}$ fission for AOA 4-2 and AOA 4-4.............49

3. Energy-dependent-sensitivity profiles for ${ }^{239} \mathrm{Pu}$ fission for varying mass cases of AOA 4-4 and benchmark experiment PU-29-1

4. Energy-dependent-sensitivity profiles for ${ }^{238} \mathrm{U}$ capture for varying mass cases of AOA 4-4 and benchmark experiment PU-29-1.

5. Energy-dependent-sensitivity profiles for ${ }^{238} \mathrm{U}$ capture for AOA 4-4, AOA 4-4-P8, PU-29-1 and LEU-COMP-THERM-049-01.. 


\section{LIST OF TABLES}

$\underline{\text { Table }}$

$\underline{\text { Page }}$

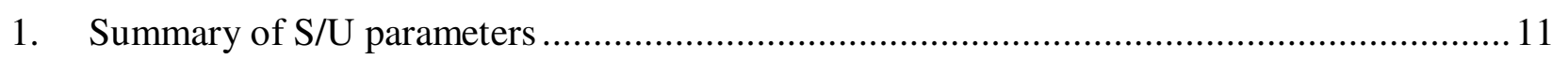

2. Proposed design application specification for $\mathrm{AOA} 3\left(\mathrm{PuO}_{2}\right.$ powders) of MFFF.................. 17

3. Proposed design application specification for AOA 4 (MOX powders) of MFFF .................18

4. Summary description of benchmark experiments ......................................................... 20

5. Calculated characteristics of design systems from AOA 3 ...........................................25

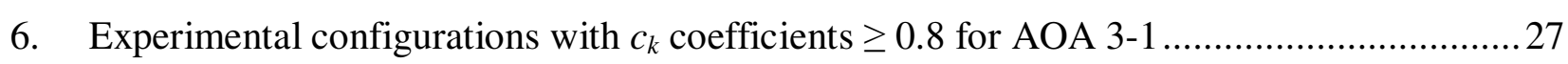

7. $\quad$ Experimental configurations with $c_{k}$ coefficients $\geq 0.8$ for AOA $3-2 \ldots \ldots \ldots \ldots \ldots \ldots \ldots \ldots \ldots \ldots \ldots . .28$

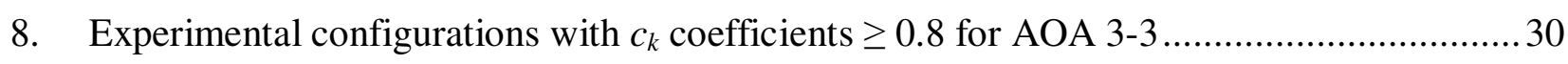

9. Calculated characteristics of design systems from AOA 4 ............................................. 32

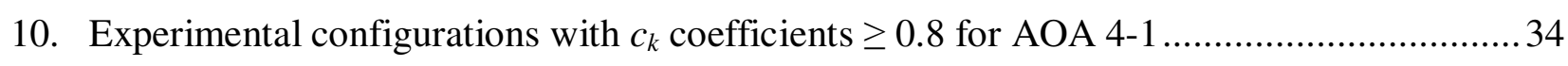

11. Experimental configurations with $c_{k}$ coefficients $\geq 0.8$ for AOA 4-2 ….......................... 36

12. Experimental configurations with $c_{k}$ coefficients $\geq 0.8$ for AOA 4-3 …........................... 38

13. Experimental configurations with $c_{k}$ coefficients $\geq 0.7$ for AOA $4-4 \ldots \ldots \ldots \ldots \ldots \ldots \ldots \ldots \ldots \ldots \ldots . .40$

14. Experimental configurations with $c_{k}$ coefficients $\geq 0.7$ for AOA 4-4-P163 ........................ 41

15. Experimental configurations with $c_{k}$ coefficients $\geq 0.8$ for AOA 4-4-P40.......................... 42

16. Experimental configurations with $c_{k}$ coefficients $\geq 0.8$ for AOA 4-4-P8 …....................... 43

17. Properties of systems considered for nuclide-reaction-specific analysis of AOA 4-2 ..........45

18. Nuclide-reaction-specific-sensitivity data for AOA 4-2 with $T\left(c_{k}\right)$ values for benchmarks NSE55T4-01 and NSE55T5-04 .

19. Nuclide-reaction-specific-sensitivity data for the various masses analyzed for AOA 4-4 with $T\left(c_{k}\right)$ values for benchmark PU-29-1. 


\section{LIST OF TABLES (continued)}

Table

$\underline{\text { Page }}$

A.1. Completeness parameter $(R)$ for each design system using the 318-benchmarkexperiment set .

B.1 Tabulated $c_{k}$ values and calculated parameters for design systems and benchmark experiments ...

B.2 Tabulated $E_{\text {sum }}$ values and calculated parameters for design systems and benchmark experiments 


\section{ACKNOWLEDGMENTS}

The authors acknowledge B. L. Broadhead, C. M. Hopper and C. V. Parks of the Oak Ridge National Laboratory for providing guidance in the preparation of this report and for carefully reviewing the draft manuscript. The authors are grateful to W. C. Carter for her preparation of the final report. 


\section{EXECUTIVE SUMMARY}

Sensitivity and uncertainty (S/U) methodologies under development at Oak Ridge National Laboratory (ORNL) were applied to evaluate critical experiment applicability to a range of Mixed Oxide Fuel Fabrication Facility (MFFF) design systems. Duke, Cogema, Stone and Webster (DCS) provided ORNL with compositions and dimensions for critical systems used to establish preliminary mass limits for facility powder and fuel pellet handling areas. Data for seven distinct critical configurations were provided. Three of the design applications evaluated in this report are $\mathrm{PuO}_{2}$ powder systems and four are mixed-oxide (MOX) powder systems.

Using traditional criticality analysis validation techniques, a number of benchmark quality critical experiments were identified by DCS as applicable to the seven design systems evaluated in this report. These experiments were identified by DCS in a preliminary criticality code validation document supplied to ORNL at the inception of this work. ORNL analyzed each of these experimental configurations, along with a wide range of additional plutonium, uranium, and mixed plutonium and uranium experiments using the sensitivity analysis sequence SEN3, which will be included in the next release of the SCALE $^{1}$ code system. This sensitivity data and crosssection uncertainty data were then processed with the S/U analysis code $\mathrm{CANDE}^{2}$ to determine the correlation of each application to each experiment in the benchmarking set. The criterion for the applicability of an experiment for use in the criticality code validation of design systems is established by the value of the correlation coefficient, $c_{k}$, of 0.8 or higher. This criterion is based

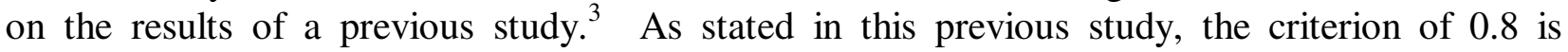
somewhat arbitrary and may be re-evaluated in future studies. For the current report, only the $\mathrm{S} / \mathrm{U}$-based correlation coefficient, $c_{k}$, is considered. Previous studies have demonstrated that the use of sensitivity-only based integral parameters, $E_{\text {sum, }}$ may be inappropriate for systems containing plutonium due to the anti-correlation of certain components of the cross-section data.

Of 318 benchmark experiments evaluated in this study, 91 were determined to satisfy the criteria used to define applicability to $\mathrm{PuO}_{2}$ powder systems. For the MOX powder design systems evaluated, 67 of the 318 experiments were identified as applicable. Of the 46 experiments identified as applicable to $\mathrm{PuO}_{2}$ powder systems by preliminary DCS work using traditional validation selection techniques, 38 were confirmed as applicable by $\mathrm{S} / \mathrm{U}$ analysis. Similarly, all 14 experiments identified by DCS as applicable to MOX powder design systems were confirmed by S/U techniques to be applicable. One MOX powder design system appeared to be outside the area of applicability of the selected benchmark experiments based on traditional validation techniques. However, the $\mathrm{S} / \mathrm{U}$ methods demonstrated that 54 of the 318 benchmark experiments exceeded the applicability criterion for this design system.

Other insights provided by the S/U studies performed in this work include the inability to cover the entire area of applicability of MOX design systems with the 318 experiments evaluated. When evaluated separately using S/U techniques, none of the 318 experiments satisfied the applicability criteria for a high-density (i.e., > $10 \mathrm{gm} / \mathrm{cc}$ ) subset of MOX design applications. However, as many as 20 experiments could be shown to satisfy a slightly relaxed acceptance criteria and it was shown that the applicability measures were substantially improved as the MOX powder mass was reduced from the critical condition for this design system subset. For example, 
46 benchmark experiments met the applicability criteria for the smallest reduced mass subcritical system.

Upon further investigation of the critical configuration of the high-density MOX powder application, it was determined that this system exhibits unique energy-dependent sensitivities in the fast energy range for several important reactions including ${ }^{239} \mathrm{Pu}$ fission and ${ }^{238} \mathrm{U}$ capture. It is these particular reactions that are likely responsible for the lower correlation between the critical experiments and the design application. For the reduced mass configurations, the energydependent sensitivities in these reactions are similar to those of the benchmark experiments, resulting in improved correlation. 


\section{INTRODUCTION}

Sensitivity and Uncertainty (S/U) methods, recently developed at Oak Ridge National Laboratory (ORNL) have been demonstrated to determine the applicability of critical benchmark experiments to the criticality code validation of design systems. These methods, although still under development, have been recently published in several sources. ${ }^{2-9}$ Development of the techniques used in this report was conducted through joint support from the United States Department of Energy (U.S. DOE) and the Nuclear Regulatory Commission (NRC) to provide a physics-based approach for the establishment of the area of applicability of critical experiments per the requirements of ANSI/ANS-8.1. ${ }^{10}$ Use of these methods may allow users to interpolate and extrapolate the traditional area of applicability (AOA) of a given set of critical experiments to include new application areas that may not have been anticipated during the experiment design.

The new S/U analytical tools include the SEN1 and SEN3 sensitivity analysis sequences,

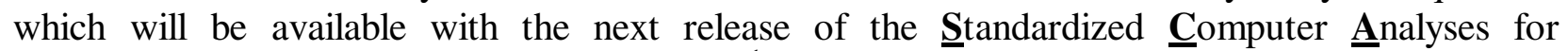
Licensing Evaluation (SCALE) code system. 1 These analysis sequences compute the relative change in the system neutron multiplication factor, $k_{\text {eff }}$, which would be observed for perturbations in the group-wise neutron cross-section data for each reaction of each nuclide in the system. The CANDE code uses sensitivity data determined separately for the design system applications and the individual experiments, along with the cross-section-covariance data, to calculate integral parameters which give a measure of the similarity between a particular design system and an experimental benchmark. A high-valued integral parameter for an experimentapplication pair indicates that the experiment demonstrates similar properties to the application. Thus, the experiment is applicable for the criticality code validation of the design system. A theoretical basis for the S/U techniques applied in this report is given in Sect. 2.

This report pertains to two of the five AOAs identified by the licensee [Duke, Cogema, Stone and Webster (DCS)] for the validation of criticality codes in the design of the Mixed-Oxide Fuel Fabrication Facility (MFFF). The five AOAs are as follows:

1. Pu-nitrate aqueous solutions (homogeneous systems),

2. Mixed-oxide (MOX) pellets, fuel rods and fuel assemblies (heterogeneous systems),

3. $\mathrm{PuO}_{2}$ powders,

4. MOX powders, and

5. Aqueous solutions of $\mathrm{Pu}$ compounds (Pu-oxalate solutions).

This report addresses a $\mathrm{S} / \mathrm{U}$ analysis pertaining to $\mathrm{AOA} 3, \mathrm{PuO}_{2}$ powders, and $\mathrm{AOA} 4$, MOX powders. AOA 3 and AOA 4 are the subject of this report since the other AOAs (solutions and heterogeneous systems) appear to be well represented in the documented benchmark experiments used in the criticality safety community. Prior to this work, DCS used traditional criticality validation techniques to identify numerous experimental benchmarks that are applicable to AOAs 3 and 4. Traditional techniques for selection of applicable benchmark experiments essentially consist of evaluating the area of applicability for important design parameters (e.g., $\mathrm{Pu}$ content or average neutron energy) and ensuring experiments have similar characteristics that bound or nearly bound the range of conditions requiring design analysis. DCS provided ORNL 
with compositions and dimensions for critical systems used to establish preliminary mass limits for facility powder and fuel pellet handling areas corresponding to AOAs 3 and 4.

ORNL has reviewed existing critical experiments to identify those, which, in addition to those provided by DCS, may be applicable to the criticality code validation for AOAs 3 and 4 . A $\mathrm{S} / \mathrm{U}$ analysis was then performed to calculate the integral parameters used to determine the similarity of each critical experiment to each design system provided by DCS.

This report contains a review of the S/U theory, a description of the design systems, a brief description of the critical experiments evaluated for applicability, and the results of the S/U analysis determining the applicability of each experiment to each application. 


\section{SENSITIVITY AND UNCERTAINTY BASED CRITICALITY VALIDATION TECHNIQUES}

This section describes the development of S/U methods to gauge the similarity of systems. A theoretical development of the calculation of the sensitivity coefficients and development of sensitivity-only and S/U based integral parameters to quantitatively assess the similarity of systems are given below. The development of the current limiting values to determine system similarity is reviewed, and a summary of the $\mathrm{S} / \mathrm{U}$ analysis parameters is presented.

\subsection{SENSITIVITY THEORY}

Sensitivity coefficients are defined physically such that they represent the percentage effect on some response due to a percentage change in an input parameter. For fissionable material systems, one of the appropriate responses is the system $k_{\text {eff }}$ value, relative to input parameters of interest (i.e., the nuclear reaction probabilities or cross sections). These sensitivity coefficients are typically presented as "profiles," where the change in $k_{\text {eff }}$ due to cross sections is given as a function of the energy of the cross section. These sensitivity profiles can be generated for each material in the system and may include various nuclear reactions (e.g., scatter, absorption, fission) as well as the neutron energy distribution from fission, $\chi$, and average number of neutrons emitted per fission, $\bar{v}$.

The techniques used in this work to generate sensitivity information are based on the widely used adjoint-based perturbation theory approach. ${ }^{[1-14}$ The full derivation of the general procedure will not be given here; however, the specific theory for the generation of $k_{\text {eff }}$ sensitivities is given below. For the full derivation of the general sensitivity equations the reader is referred to Ref. 15.

Considering the Boltzmann transport equation written in the form:

$$
[A-\lambda B] \phi=0,
$$

where $A$ and $B$ are loss and production operators, $\phi$ is the neutron flux, and $\lambda$ is $1 / k_{\text {eff }}$, and a perturbed system

$$
\left[A^{\prime}-\lambda^{\prime} B^{\prime}\right] \phi^{\prime}=0,
$$

the equation adjoint to Eq. (1) is

$$
\left[A^{*}-\lambda B^{*}\right] \phi^{*}=0,
$$

where $\phi^{*}$ is the adjoint flux or importance function and $A^{*}$ and $B^{*}$ are the adjoint operators corresponding to $A$ and $B$. 
Mulitplying Eq. (2) by $\phi^{*}$, and integrating over all phase space yields

$$
\left\langle\phi^{*}\left(A^{\prime}-\lambda^{\prime} B^{\prime}\right) \phi^{\prime}\right\rangle=0
$$

Defining:

$$
\begin{aligned}
& A^{\prime}=A+d A \\
& B^{\prime}=B+d B \\
& \lambda^{\prime}=\lambda+d \lambda
\end{aligned}
$$

and using the property of adjointness for the operators $A, A^{*}$ and $B, B^{*}$, it can be shown that

$$
\left\langle\phi^{*}(d A-\lambda d B-B d \lambda-d \lambda d B) \phi^{\prime}\right\rangle=0
$$

Ignoring second-order terms $(d \lambda d B)$, substituting $\phi^{\prime}$ with $\phi$, and solving for the inverse $k_{\text {eff }}$ perturbation yields

$$
d \lambda / \lambda=\left\langle\phi^{*}(d A-\lambda d B) \phi\right\rangle /\left\langle\phi^{*}(\lambda B) \phi\right\rangle
$$

Hence, the sensitivity of $\lambda$, with respect to the reaction $x$ cross section, $\Sigma_{x}$, becomes

$$
\frac{d \lambda / \lambda}{d \Sigma_{x} / \Sigma_{x}}=\frac{\Sigma_{x}}{\lambda} \frac{\left\langle\phi^{*}\left(d A / d \Sigma_{x}-\lambda d B / d \Sigma_{x}\right) \phi\right\rangle}{\left\langle\phi^{*}(B) \phi\right\rangle} .
$$

Note that since $\lambda=1 / k_{\text {eff }}$, then $d \lambda \lambda=-d k_{\text {eff }} / k_{\text {eff }}$ such that the above equation is essentially the defining equation for the $k_{\text {eff }}$ sensitivity, $S_{x}$, where

$$
S_{x}=\frac{d k_{e f f} / k_{e f f}}{d \Sigma_{x} / \Sigma_{x}}=\frac{-d \lambda / \lambda}{d \Sigma_{x} / \Sigma_{x}} .
$$

In practice, the $d A$ and $d B$ terms in Eq. (8) are simple functions of the scattering, capture, and fission cross-section data. The evaluation of Eq. (8) then becomes an integration of the forward and adjoint fluxes and the cross sections over the entire phase space.

Typically, the energy dependence of the cross-section data is represented by averaging the $S_{x}$ quantities over an energy group $i$, represented as $\Sigma_{x_{i}}$. Insertion of these group quantities into Eq. (9) yields the definition of a sensitivity "profile," $S_{x_{i}}=\left(d k_{\text {eff }} / k_{\text {eff }}\right) /\left(d \Sigma_{x_{i}} / \Sigma_{x_{i}}\right)$, where $i$ is varied to obtain the sensitivity for all groups, which span the energy range of interest. 


\subsection{SENSITIVITY-BASED INTEGRAL PARAMETERS}

The sensitivity profiles provide a great deal of information about the particular system, because they predict the effect on $k_{\text {eff }}$ for differential changes in each of the cross-section data components. However, the amount of information is too large to be of general use. Some type of automated method for representing these sensitivities is necessary to reduce the amount of information to a few easily interpreted parameters. The development of a number of different sensitivity-based integral parameters has been studied and reported in Refs. 3, 5 and 6. The objective was to produce a single parameter that would quantify the similarities between two systems, such that this single parameter could be used for determination of system similarity and as a trending parameter to support interpolation and extrapolation.

An integral parameter to measure the similarity of systems based on the magnitude and shape of the sensitivity profiles for two systems has been demonstrated to quantitatively measure the applicability of one system for the validation of the other. ${ }^{5}$ These sensitivity-based parameters, denoted as $E$, correspond to the summation of the product of the sensitivity coefficients for two systems over energy groups and nuclides, normalized such that when summed over nuclides and reactions, an $E$ value of 0 indicates the systems are totally dissimilar, and an $E$ value of 1 indicates the two systems are precisely the same. The $E$ values are defined as:

$$
\begin{aligned}
& E_{f}=M^{-1} \sum_{j=1}^{N} \sum_{i=1}^{g} S_{f a i j} S_{f e i j}, \\
& E_{c}=M^{-1} \sum_{j=1}^{N} \sum_{i=1}^{g} S_{c a i j} S_{c e i j}, \\
& E_{s}=M^{-1} \sum_{j=1}^{N} \sum_{i=1}^{g} S_{s a i j} S_{s e i j},
\end{aligned}
$$

where

$$
M=\sum_{x}\left\{\sum_{j=1}^{N} \sum_{i=1}^{g}\left(S_{x a i j}\right)^{2} \sum_{j=1}^{N} \sum_{i=1}^{g}\left(S_{x e i j}\right)^{2}\right\}^{1 / 2}
$$

and $S$ is the sensitivity of $k_{\text {eff }}$ for the design system application, $a$, or experimental configuration, $e$, to the fission, capture and scattering cross sections ( $f, c$ and $s$ respectively) for energy group $i$ and nuclide $j$;

$$
E_{\text {sum }}=E_{f}+E_{c}+E_{s} .
$$

Mathematically, an $E_{\text {sum }}$ value as low as -1 could be generated, but this would be the result of a rare combination of system sensitivities. As with the case of an $E$ value of 0 , this would indicate 
that the systems are dissimilar. Thus, two systems exhibiting comparable integral responses in $k_{\text {eff }}$ due to differential changes in the cross-section data, are considered to be similar.

The $E_{\text {sum }}$ parameter is considered "global" in nature, in that a single quantity identifies similarity between two systems based only on the magnitude and shape of the sensitivity profiles for fission, capture and scatter. It is also possible and sometimes desirable to produce analogous values for each isotope-reaction pair, such that similarity information can be computed on a differential level. For this purpose, an additional parameter $d E$ is defined from the equations above by omitting the nuclide and reaction summations in the numerator and the reaction summation in the denominator. Thus, the $d E$ value for reaction $x$ of nuclide $j$ between the application $a$ and the experiment $e$ is defined as:

$$
d E_{x e a j}=\frac{\sum_{i=1}^{g} S_{x a i j} S_{x e i j}}{\left(\sum_{j=1}^{N} \sum_{i=1}^{g}\left(S_{x a i j}\right)^{2} \sum_{j=1}^{N} \sum_{i=1}^{g}\left(S_{x e i j}\right)^{2}\right)^{1 / 2}} .
$$

The $d E$ values relate, on a system-to-system basis, the similarity of various nuclidereaction pairs. These values are normalized such that, when an application is compared to itself, the sum over isotopes for a given reaction-type (i.e., capture, fission, scatter) is unity. This allows for similarity determinations for that reaction among various isotopes.

With the $d E$ parameter, a detailed analysis of the physics of the systems can be conducted. The magnitudes of the $d E$ values show the relative contribution to $E$ for each nuclide with respect to its capture, fission, or scattering reactions. In addition, since the normalization requires that the sum over a given reaction will only be unity if the two systems are exactly the same, the sum over the $d E$ values for each reaction gives an additional indicator of the systems' similarity. A method of utilizing this information in a simple manner is to define a $T(E)$ value, which is the ratio of the $d E$ value relating the two systems to the $d E$ value of the application system to itself. Thus, the $T(E)$ value relating application $a$ to experiment $e$ for reaction $x$ of nuclide $j$ is

$$
T(E)_{x e a j}=\frac{d E_{x e a j}}{d E_{x a a j}} .
$$

This $T(E)$ quantity has a value less than unity if the nuclide/reaction pair is less important in the benchmark experiment than the application. $T(E)$ is greater than or equal to unity if the importance of the nuclide-reaction pair in the benchmark experiment is equal to or greater than the importance in the application. Thus, the number of benchmark systems with $T$ values near or greater than unity is a good indicator of benchmark coverage for a given nuclide-reaction pair. Interestingly, this test is appropriate even if the material is not an important material in the application. 


\subsection{UNCERTAINTY-BASED INTEGRAL PARAMETERS}

An alternative and complementary approach to exploring the similarity of systems based solely on the use of sensitivity data is the use of uncertainty analyses. The procedure presented here is the same as that developed in Ref. 3 and is included here for the convenience of the reader. This procedure involves the propagation of estimated cross-section uncertainty information to the calculated $k_{\text {eff }}$ value of a given system via the sensitivity coefficients. Mathematically, this is accomplished by a quadratic product of the group-wise sensitivity profile vectors by isotope and reaction type with the cross-section uncertainty matrices by nuclide and reaction type. The result of this procedure is not only an estimate of the uncertainty in the system $k_{\text {eff }}$ due to cross sections, but also an estimate of the correlated uncertainty between systems. These correlated uncertainties can be represented by correlation coefficients, which represent the degree of correlation in the uncertainties between the two systems. This parameter, denoted as $c_{k}$, not only has the desirability of a single quantity relating the two systems, but also measures the similarity of the systems in terms of uncertainty, not just sensitivity. These correlation coefficients are particularly useful when used in traditional trending analyses for criticality safety validation. When used as a trending parameter in these analyses, the correlation coefficient should relate to the degree in which the uncertainties in the critical benchmarks are coupled with the uncertainties in the application of interest. This coupling with the common uncertainties in the various systems is expected to closely mimic the coupling in predicted biases between the various systems, since they should both be related to the cross-section uncertainties. The underlying assumption in this approach is that the cross-section uncertainty data for all nuclides and reactions of interest are tabulated and processed for use by these procedures. However, tabulated cross-sectioncovariance data are not available for all nuclide-reaction pairs. Nuclide-reaction pairs without tabulated data are omitted from this analysis, but it is assumed that the cross-section data values from these pairs are well known, and thus, they present a negligible contribution to the uncertainty-based analysis.

Two steps are required in the determination of the uncertainties in the calculated values of the system multiplication factor: (1) the estimation/processing of uncertainties in the crosssection data and (2) the propagation of those uncertainties to the system $k_{\text {eff }}$ value. The techniques for processing cross-section uncertainty data are well known ${ }^{16,17}$ and will not be discussed here. It should be noted that covariance data in $\mathrm{ENDF} / \mathrm{B}-\mathrm{V}$ is limited to select isotopes. However, those data that are available have been processed for use with these techniques.

Once uncertainty information for the cross sections for all nuclides and reaction processes that are important to the systems become available for analysis, it is possible to estimate the uncertainty in the calculated system multiplication factor due to these data uncertainties. Previous investigations of the propagation of cross-section uncertainties to computed values for uranium systems have demonstrated that the uncertainty in $k_{\text {eff }}$ ranges from $<1 \%$ for well moderated systems to nearly $2 \%$ for dry systems. 
When the matrix of uncertainty information for all of the cross sections is denoted as $C_{\alpha \alpha}$, and the sensitivity matrix relating changes in each constituent material and process to the system $k_{\text {eff }}$ is labeled as $S_{k}$, the uncertainty matrix for the system $k_{\text {eff }}$ values, $C_{k k}$, is given as

$$
C_{k k}=S_{k} C_{\alpha \alpha} S_{k}^{\dagger}
$$

where + indicates a transpose.

The $S_{k}$ is $I \times N$ matrix, where $I$ is the number of critical systems being considered, $N$ is the number of nuclear data parameters in the problem. Typically, $N$ is the number of nuclide-reaction processes times the number of energy groups. The $C_{\alpha \alpha}$ matrix is an $N \times N$ matrix, with the resulting $I \times I C_{k k}$ matrix. The $C_{k k}$ matrix consists of variance values $\sigma_{i}^{2}$ for each of the critical systems under consideration (the diagonal elements), as well as the so-called "covariance" between systems $\sigma_{i j}^{2}$ (the off-diagonal elements). These off-diagonal elements represent the shared or common variance, hence the term covariance, between any two systems. For presentation, these off-diagonal elements are typically divided by the square root of the corresponding (same row) diagonal elements (i.e., the respective standard deviations) to generate a correlation coefficient matrix. Thus, the $c_{k}$ coefficients are defined as

$$
c_{k}=\sigma_{i j}^{2} /\left(\sigma_{i} \sigma_{j}\right)
$$

such that each $c_{k}$ value represents the correlation coefficient between uncertainties in system $i$ and system $j$.

These correlations arise due to the fact that the uncertainties in the $k_{\text {eff }}$ values for two different systems are related, since they contain the same materials. Cross-section uncertainties will propagate to all systems containing these materials. Systems with the same materials and similar spectra would be correlated, while systems with different materials or differing spectra would not be correlated. The interpretation of the correlation matrix is the following: a value of 0 represents no correlation between the systems, a value of 1 represents full correlation between the systems, and a value of -1 represents a full anti-correlation.

Similar to the $d E$ values defined in Sect. 2.2, $d c_{k}$ values, the individual components of $c_{k}$, are defined for comparison of specific nuclide-reaction pairs between a given application and experiment. However, it should be noted that the $d c_{k}$ parameter does not utilize the cross-sectioncovariance data to the fullest extent. The covariance between reactions of the same nuclide is utilized, but any covariance relating one nuclide to another is ignored in the $d c_{k}$ calculation. These covariances are accounted for in the system-wide $c_{k}$ parameter. A $T\left(c_{k}\right)$ parameter, shown in Eq. (15) is defined as the ratio of the $d c_{k}$ value for an experiment compared to an application to the $d c_{k}$ value of the application compared to itself. Thus, a $T\left(c_{k}\right)$ value of 1.0 or higher indicates 
that for a given nuclide reaction, the variance of the experiment is as great or greater than that of the application.

$$
T\left(c_{k}\right)_{x e a j}=\frac{d c_{k_{x a j i}}}{d c_{k_{\text {xaaj }}}}
$$

\subsection{AREA OF APPLICABILITY USING INTEGRAL PARAMETER TECHNIQUES}

In a previous report, 3 the criterion for the acceptance of a benchmark for the validation of a design system was established such that experiments exhibiting a $c_{k}$ value of 0.8 or higher could be used for the validation of the design system. This criterion was chosen based on two methods of evaluation. The first was objectively viewing the sensitivity profiles to determine which systems appear to exhibit similar properties. The systems that exhibited the most similarities were those with a $c_{k}$ value of 0.8 or higher. The second method for establishing the criterion was the divergence of the computational bias predicted by the Generalized Linear Least Squares Methodology (GLLSM) procedure. Through this procedure, the GLLSM code was used to predict the computational bias of a system based on differing sets of experimental benchmarks. First, a large number of critical systems, with a wide range of $c_{k}$ values, were included in the evaluation, and a bias was computed. Next, systems with $c_{k}$ values of 0.9 or greater were removed from the experimental set, thus the experiment set included only those experiments with $c_{k}$ values of 0.89 or lower. No change in the computational bias calculated by GLLSM was observed. A third GLLSM evaluation was performed using only experiments exhibiting a $c_{k}$ value of 0.79 or lower. In this case, the computational bias computed by GLLSM varied from the previous two calculations by approximately $0.5 \%$. A similarly skewed bias was found when only including systems with a $c_{k}$ of 0.69 or lower. Thus, it is concluded in Ref. 3, there is a clear break in the behavior of systems at a $c_{k}$ value of 0.8 , and this should be used as the criterion for applicability.

The procedures for determining the applicability of a benchmark dataset for a particular design application using $c_{k}$ and an outmoded parameter, $D_{\text {sum }}$, which was an early sensitivity-only based integral parameter, are clearly outlined in Ref. 3. Currently, the $E$ parameter is recommended for the supersession of the $D$ parameter. The trending values of $E$ have proven very similar to those of $c_{k}$, and thus the recommended limits for validation are the same as those developed for $c_{k}$. Two systems are considered to be similar if the $c_{k}$ or $E_{\text {sum }}$ value relating the two systems is 0.8 or higher. 
Thus, the recommended procedure for ensuring the applicability of the benchmark dataset in criticality safety validation problems is as follows:

1. Produce sensitivity coefficients for all benchmark experiments and design systems,

2. Quantify values of $c_{k}, d c_{k}, T\left(c_{k}\right), E, d E$, and $T(E)$ relating each application to the entire benchmark set,

3. Count the number of systems with $c_{k}$ and/or $E$ values $>0.8(\sim 15-20$ systems are needed for validation), and

4. For important nuclide-reaction pairs, count the number of systems with $T\left(c_{k}\right)$ and/or $T(E)$ values $>0.95$ ( 5-10 systems are needed).

The number of systems and the acceptance criterion for $T\left(c_{k}\right)$ and $T(E)$ values are not rigorously defined. These values are based on experience with other parameters and may change over time with additional experience with these parameters.

A previous application of the $\mathrm{S} / \mathrm{U}$ methods for systems containing plutonium revealed that the $c_{k}$ correlation coefficient provides a more accurate measure of system similarity than does the $E$ parameter ${ }^{4}$ The difference in the performance of $c_{k}$ and $E_{\text {sum }}$ is attributed to anti-correlation in the cross-section data for some plutonium isotopes. As a result of these anti-correlations, differences observed in the sensitivity data that would result in lower $E_{\text {sum }}$ values will not reduce the value $c_{k}$ by the same magnitude. Thus, in this study, only the $c_{k}$ values will be reported.

\subsection{SUMMARY OF S/U ANALYSIS TECHNIQUES}

Several methods of using $\mathrm{S} / \mathrm{U}$ analysis to establish system similarity are presented in this section. The integral parameter techniques are used to generate relational parameters based only on the sensitivity data. The $E_{\text {sum }}$ parameter is used to assess system similarity on a system-wide basis. Related to $E_{\text {sum }}$, the $d E$ and $T(E)$ parameters are used to assess nuclide-reaction-specific coverage of an application by an experiment. In addition to the sensitivity data, use of crosssection uncertainty data is also employed in the generation of the $c_{k}$ parameter. As with $E_{\text {sum }}$, the $c_{k}$ parameter is used to assess similarity on a system-wide basis. However, the similarity assessment is based on the sensitivity-weighted cross-section uncertainties common to the two systems. Also, the $d c_{k}$ and $T\left(c_{k}\right)$ parameters can be used to determine nuclide-reaction-specific coverage. Each of these parameters is summarized in Table 1. 
Table 1. Summary of S/U parameters

\begin{tabular}{|c|c|c|c|c|c|}
\hline Parameter & Description & $\begin{array}{c}\text { Recommended } \\
\text { value for } \\
\text { coverage }\end{array}$ & $\begin{array}{c}\text { Sensitivity } \\
\text { based }\end{array}$ & $\begin{array}{c}\text { Uncertainty } \\
\text { based }\end{array}$ & $\begin{array}{l}\text { Reaction } \\
\text { specific }\end{array}$ \\
\hline$E_{\text {sum }}$ & $\begin{array}{l}\text { Normalized sum of the product of the } \\
\text { group-wise sensitivity coefficients for a } \\
\text { given application and experiment } \\
\text { summed for fission, capture and } \\
\text { scattering. }\end{array}$ & $\begin{array}{c}\geq 0.8 \\
\text { for } 15-20 \\
\text { systems }\end{array}$ & $\sqrt{ }$ & & \\
\hline$d E$ & $\begin{array}{l}\text { Nuclide-reaction-specific normalized } \\
\text { sum of the product of group-wise } \\
\text { sensitivity coefficients for a given } \\
\text { application and experiment. Allows for } \\
\text { similarity determinations for specific } \\
\text { nuclide-reaction pairs. Available for } \\
\text { scatter, capture and fission reactions. }\end{array}$ & & $\sqrt{ }$ & & $\sqrt{ }$ \\
\hline$T(E)$ & $\begin{array}{l}\text { Ratio of a particular } d E \text { value for a given } \\
\text { application-experiment pair to the } d E \\
\text { value of the application as compared to } \\
\text { itself. Indicates the validation coverage } \\
\text { for the particular nuclide-reaction pair } \\
\text { for the application by the experiment. }\end{array}$ & $\begin{array}{c}\geq 0.95 \\
\text { for } 5-10 \\
\text { systems }\end{array}$ & $\sqrt{ }$ & & $\sqrt{ }$ \\
\hline$c_{k}$ & $\begin{array}{l}\text { Correlation coefficient relating the } \\
\text { uncertainty in } k_{\text {eff }} \text { due to uncertainties in } \\
\text { the cross-section data common to the } \\
\text { application and the experiment. }\end{array}$ & $\begin{array}{c}\geq 0.8 \\
\text { for } 15-20 \\
\text { systems }\end{array}$ & $\sqrt{ }$ & $\sqrt{ }$ & \\
\hline$d c_{k}$ & $\begin{array}{l}\text { Nuclide-reaction-specific correlation } \\
\text { coefficient relating the uncertainty in } k_{\text {eff }} \\
\text { due to uncertainties in the nuclide- } \\
\text { reaction-specific-cross-section data } \\
\text { common to the application and } \\
\text { experiment. Allows for similarity } \\
\text { determinations for specific nuclide- } \\
\text { reaction pairs. Available for scatter, } \\
\text { capture and fission reactions. }\end{array}$ & & $\sqrt{ }$ & $\sqrt{ }$ & $\sqrt{ }$ \\
\hline$T\left(c_{k}\right)$ & $\begin{array}{l}\text { Ratio of a particular } d c_{k} \text { value for a } \\
\text { given application-experiment pair to the } \\
d c_{k} \text { value of the application as compared } \\
\text { to itself. Indicates the validation } \\
\text { coverage for the particular nuclide- } \\
\text { reaction pair for the application by the } \\
\text { experiment. }\end{array}$ & $\begin{array}{c}\geq 0.95 \\
\text { for } 5-10 \\
\text { systems }\end{array}$ & $\sqrt{ }$ & $\sqrt{ }$ & $\sqrt{ }$ \\
\hline
\end{tabular}




\section{PROTOTYPICAL SENSITIVITY AND UNCERTAINTY ANALYSIS CODES FOR CRITICALITY SAFETY WITH THE SCALE CODE SYSTEM}

Two prototypical sensitivity analysis sequences for criticality safety have recently been developed for the SCALE code system at ORNL. The need for modern tools to produce the sensitivity data necessary for the $\mathrm{S} / \mathrm{U}$ analysis techniques described in Sect. 2 of this report motivated the development of these sequences. Both of these sequences are applications of the first-order linear perturbation theory as was used in the one-dimensional (1-D) FORSS code system. ${ }^{15}$ The SEN1 ${ }^{18}$ sequence involves 1-D deterministic neutron transport calculations using XSDRNPM. The SEN3 ${ }^{19}$ sequence involves three-dimensional (3-D) Monte Carlo neutron transport calculations using KENO V.a. Each of these sequences and the types of results they produce are described below. As these analysis sequences have been documented in the references noted above, this section will only provide a brief overview of their capabilities, with special emphasis on previously unpublished capabilities. The SEN1 and SEN3 analysis sequences are expected to be publicly available with the release of SCALE-5.

\subsection{SEN1 SEQUENCE}

Using the SCALE philosophy and/or protocol as a guide, a 1-D sensitivity sequence, SEN1, was produced. It generates sensitivity coefficients which represent the percentage change in the system $k_{\text {eff }}$ for a percentage change in the cross-section value in a given energy group for each nuclide-reaction pair. The SEN1 sequence performs standard resonance processing tasks, and then determines, using 1-D transport theory, the forward and adjoint angular fluxes and flux moments needed for sensitivity coefficient generation. The XSDRNPM code, which is used extensively within the SCALE system, is used for the forward and adjoint neutron transport calculations. The sequence then calls the Sensitivity Analysis Module of SCALE (SAMS), which computes the sensitivity coefficients.

The user input to SEN1 is very similar to the user input of the SCALE shielding analysis sequence, SAS1, except that, since $k_{\text {eff }}$ sensitivities do not require a fixed source, a source input is not required. The SEN1 input contains the standard composition description that is common to all SCALE modules, followed by a simple geometry model for the problem. SEN1 uses any of the types of resonance shielding calculations available in SCALE including INFHOMMEDIUM, LATTICECELL and MULTIREGION. For the first option, no resonance shielding is performed; the second technique treats resonance-shielding effects in pin-lattice geometry cases; the third technique gives the user more flexibility in defining the geometry in which the resonance calculations are performed. The SEN1X sequence calculates cell-weighted cross sections with XSDRNPM prior to performing the 1-D criticality calculations.

\subsection{SEN3 SEQUENCE}

The SEN3 sequence calculates sensitivity coefficients using 3-D Monte Carlo neutral particle transport with KENO V.a. The input for SEN3 is very similar to the CSAS25 sequence 
of SCALE commonly used for criticality safety analysis. SEN3 performs resonance-shielding calculations using the same options as SEN1. Forward and adjoint angular neutron fluxes are obtained from an enhanced version of KENO V.a that employs a novel approach to produce the angular fluxes necessary for sensitivity analysis. Once the fluxes are obtained, the SAMS module calculates the sensitivity coefficients from this data and the problem dependent cross-section data. The SAMS module also propagates the uncertainty in the sensitivity coefficients due to the Monte Carlo uncertainties.

A significant advantage in using SEN3 is that the input is very similar to that of CSAS25. Thus, with only minor modifications, existing criticality models used for CSAS25 analyses can be used for sensitivity analysis using SEN3.

\subsection{SENSITIVITY TO RESONANCE-SHIELDED MULTIGROUP CROSS SECTIONS}

Previous verification results of SEN1 and SEN3 demonstrated that the sensitivity coefficients could be over predicted, especially for scattering-type reactions for well-moderated systems. ${ }^{18,19}$ This effect is due to changes in the self-shielded multigroup neutron cross-section data caused by changes in the fine-structured neutron energy spectrum resulting from perturbations in nuclide concentrations. ${ }^{20}$ Updated versions of BONAMI and NITAWL-II have recently been developed for use with SEN1 and SEN3 to account for these effects. The documentation of this work is beyond the scope of this report but will be the subject of future publications. All sensitivity data used in this report was calculated with the use of these new techniques through the enhanced resonance processing code BONAMIST and NITAWLST.

\subsection{SENSITIVITY DATA}

The standard output files from both SEN1 and SEN3 contain sensitivity coefficients presented as a total sensitivity, which is integrated over all cross-section energies for a particular reaction type of an isotope. These are presented on a region-dependent basis as well as regionintegrated, which provides a single sensitivity coefficient for each reaction of a particular isotope integrated over the entire system. Each code also generates a text file containing the sensitivity profiles in which the relative change in $k_{\text {eff }}$ is displayed for each reaction type of each isotope for each energy group. Sensitivities are generated for a wide variety of nuclear reactions including scattering, fission, capture, absorption, $\bar{v}, \chi$ and the total of all reactions.

\subsection{CANDE}

The CANDE ( $c$ and $E$ ) code was created to perform the integral parameter analyses using the sensitivity data generated from the SEN1 and/or SEN3 sequences. CANDE produces the $c_{k}$, $E, d E, d c_{k}, T(E)$ and $T\left(c_{k}\right)$ parameters described in Sect. 2 for one or more applications in reference to an experimental database chosen by the code user. CANDE also computes the completeness parameter $R$, which assesses the coverage of each application by the entire benchmark suite. The development and use of the completeness parameter is given in Appendix A. 


\section{SAMPLE DESIGN APPLICATIONS FOR THE MIXED-OXIDE FUEL FABRICATION FACILITY}

As indicated in Sect. 1, the MFFF licensee, DCS, has identified five AOAs for the validation of criticality codes in the design of the facility. This report addresses a $\mathrm{S} / \mathrm{U}$ analysis pertaining to $\mathrm{AOA} 3, \mathrm{PuO}_{2}$ powders, and AOA 4, MOX powders. DCS provided the following data corresponding to AOA 3 and AOA 4. The data is representative of the expected bounding compositions encountered in MFFF design applications.

Many MFFF design applications involve process units and areas where mass and moderation limits are imposed. Mass limits are established based on simple homogeneous powder-form systems with simple geometry (i.e., single reflected and unreflected slabs, cylinders and spheres). Three oxide media in homogeneous form are considered for evaluation as follows:

- $\mathrm{PuO}_{2}(100 \%)$, included in $\mathrm{AOA} 3$,

- MOX with 22 wt \% $\mathrm{PuO}_{2}$, included in AOA 4,

- $\mathrm{MOX}$ with $6.3 \mathrm{wt} \% \mathrm{PuO}_{2}$, included in AOA 4.

The $\mathrm{Pu}$ isotopic composition assumed in all design applications under AOAs 3 and 4 is 96 wt $\%{ }^{239} \mathrm{Pu}$ and $4 \mathrm{wt} \%{ }^{240} \mathrm{Pu}$. This isotopic distribution is considered to bound the actual expected range of $\mathrm{Pu}$ isotopic distributions summarized as follows:

- ${ }^{236} \mathrm{Pu}<1 \mathrm{ppb}$,

- ${ }^{238} \mathrm{Pu}<0.05$ wt $\%$,

- $90 \mathrm{wt} \%<{ }^{239} \mathrm{Pu}<95 \mathrm{wt} \%$,

- 5 wt $\%<{ }^{240} \mathrm{Pu}<9$ wt $\%$,

- ${ }^{241} \mathrm{Pu}<1$ wt $\%$,

- ${ }^{242} \mathrm{Pu}<0.1 \mathrm{wt} \%$.

In addition to $\mathrm{Pu}$ isotopes, $\mathrm{PuO}_{2}(100 \%)$ received and handled at the MFFF will also contain up to $2 \mathrm{wt} \% \mathrm{U}$ enriched up to $93.2 \mathrm{wt} \%{ }^{235} \mathrm{U}$ and $0.7 \mathrm{wt} \%{ }^{241} \mathrm{Am}$ in addition to chemical impurities not explicitly modeled in fissile systems.

Powder density assumptions vary from process to process. Design assumptions for maximum powder density generally range from $3.5 \mathrm{~g} / \mathrm{cm}^{3}$ to $7.0 \mathrm{~g} / \mathrm{cm}^{3}$ (possibly $8.3 \mathrm{~g} / \mathrm{cm}^{3}$ ).

Moderator content in powder handling areas is typically limited to $<5 \mathrm{wt} \% \mathrm{H}_{2} \mathrm{O}$. Although other moderator content conditions are evaluated $(0,1$ and $3 \mathrm{wt} \%)$, the $5 \mathrm{wt} \%$ value is generally evaluated as a worst-case moderator content assumption.

The fuel compositions and reflector specifications of seven design applications are given below. The applicability of critical experiments to each design system is evaluated in subsequent sections of this report. Three applications shown in Table 2 are critical configurations representative of $\mathrm{AOA} 3, \mathrm{PuO}_{2}$ powders. Four material specifications, shown in Table 3, are 
representative of AOA 4, MOX powders. Each of the four material compositions given in Table 3 has a critical radius listed. The fourth material, high-density MOX powder, also has three subcritical configurations listed. Although modeled as a homogeneous sphere, the actual design system with the material specified as AOA 4-4 will involve loose pellets, which will be under strict mass controls. Mass limits, based on the total $\mathrm{Pu}$ content, have been used to develop subcritical models consisting of this high-density MOX material. Thus the three subcritical configurations are given identifiers denoting the mass of $\mathrm{Pu}$ in the system in kilograms (e.g., AOA 4-4-P163 contains $163 \mathrm{~kg}$ of $\mathrm{Pu}$ ). 


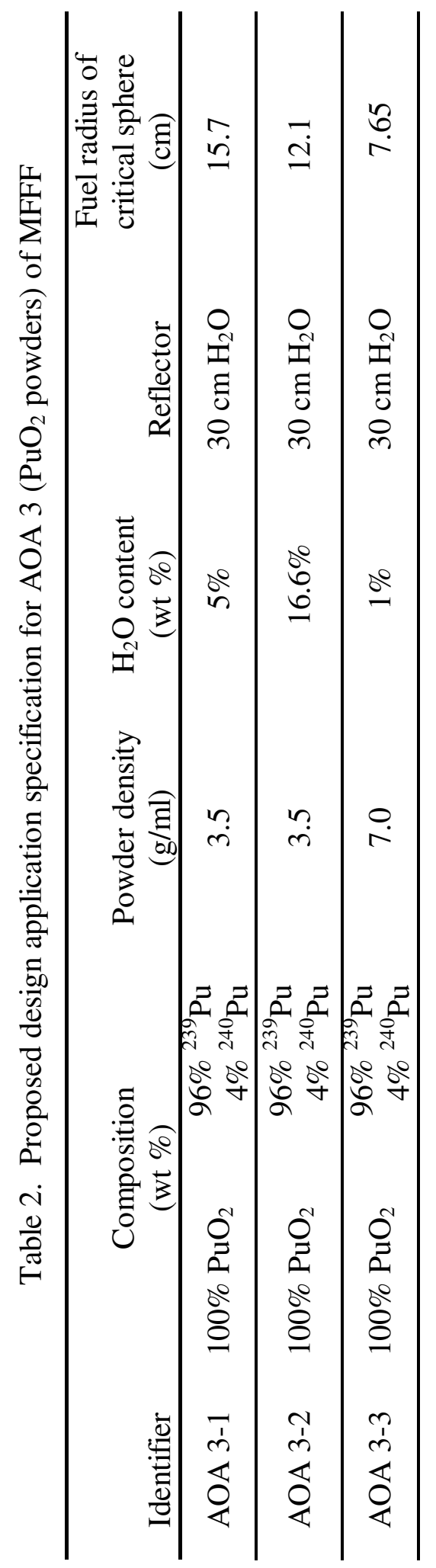




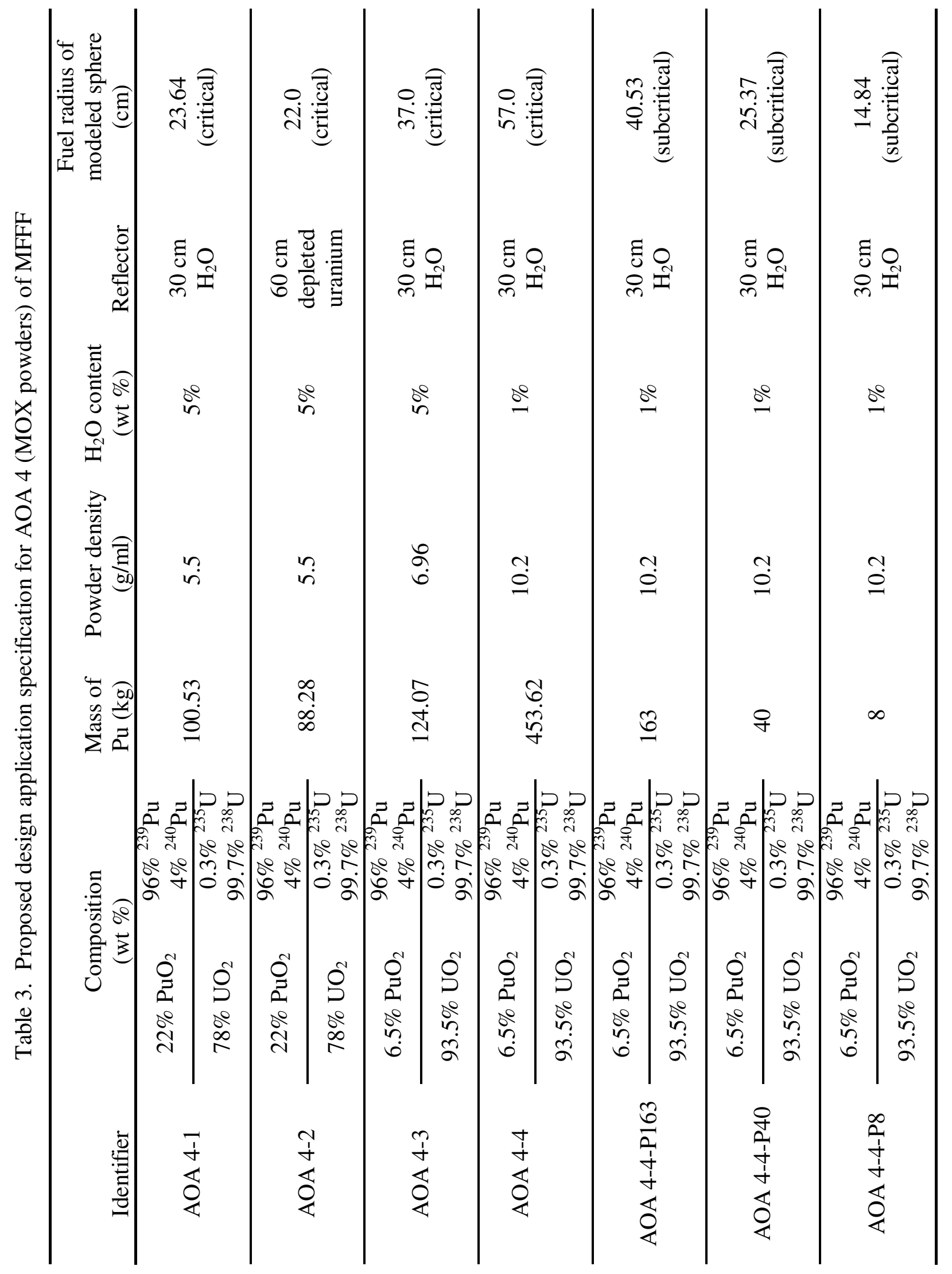




\section{DEVELOPMENT OF CRITICAL EXPERIMENT DATABASE}

The key to any criticality safety validation procedure is the generation of a database of critical benchmark experiments that covers a broad range of systems that are in some way similar to the particular application(s) of interest. At the onset of this work, DCS introduced a database of critical experiments for each AOA evaluated in this study. Based on the expert judgment of criticality safety practitioners and traditional trending methods, DCS recommended 46 critical benchmarks for AOA 3 and 14 for AOA 4. With the anticipation that the S/U analysis would extend the area of applicability of existing experiments, ORNL used more relaxed criteria in the selection of critical benchmarks. Thus, 318 experiments, including the 60 initially identified by DCS, have been complied into an experimental database for use with this study. A summary description of each set of experiments is given in Table 4, and experiment-specific data are tabulated in Appendix B. The number of benchmark experiments from each experimental series identified by DCS, as applicable to either AOA 3 or AOA 4, is also give in Table 4. In the $\mathrm{S} / \mathrm{U}$ analyses presented in subsequent sections of this report, integral parameters for each application of interest are generated to determine the similarity of each application to each of these 318 benchmark experiments. The experiments were chosen because of similarity to the design applications described in the previous section, either in material type or in fission energy spectrum. Other experiments were also analyzed; however, they were not included in this database because they were not applicable to either AOA 3 or AOA 4 . The benchmark experiments in this database include both plutonium systems, mixed plutonium and uranium systems, and one set of low-enriched uranium systems with low moderation. The benchmark descriptions for the majority of these experiments are provided in the International Handbook of Evaluated Criticality Safety Benchmark Experiments (IHECSBE), ${ }^{21}$ which is a product of the International Criticality Safety Benchmark Evaluation Program.* Experiments from the IHECSBE are noted with the parenthetical comment of their handbook designation. Experiments compiled from other sources are specifically noted.

\subsection{PLUTONIUM SYSTEMS}

Sixty-one plutonium benchmarks are included in the experiment database used for this study. These include metal systems and oxide systems.

\subsubsection{Plutonium Metal Systems}

Twenty-six plutonium metal experiments are included in this set of benchmarks. Two bare metal spheres are included: one with a low ${ }^{240} \mathrm{Pu}$ content $\left(4.5\right.$ at. \%), designated ${ }^{239} \mathrm{Pu}$ Jezebel (PU-MET-FAST-001), and another with a higher ${ }^{240} \mathrm{Pu}$ content $(20.1$ at. \%) designated as ${ }^{240} \mathrm{Pu}$ Jezebel (PU-MET-FAST-002). A set of five experiments using arrays of unmoderated

\footnotetext{
* The International Criticality Safety Benchmark Evaluation Program (ICSBEP) is an ongoing effort to identify and evaluate a comprehensive set of critical benchmark data for use by the worldwide criticality safety community. The project involves criticality safety experts and experimental data from several national laboratories in the United States, as well as the United Kingdom, France, Japan, the Russian Federation, Hungary, Korea, Slovenia, Yugoslavia, Spain, and Israel. The work of the ICSBEP is documented as an International Handbook of Evaluated Criticality Safety Benchmark Experiments, which is updated annually.
} 


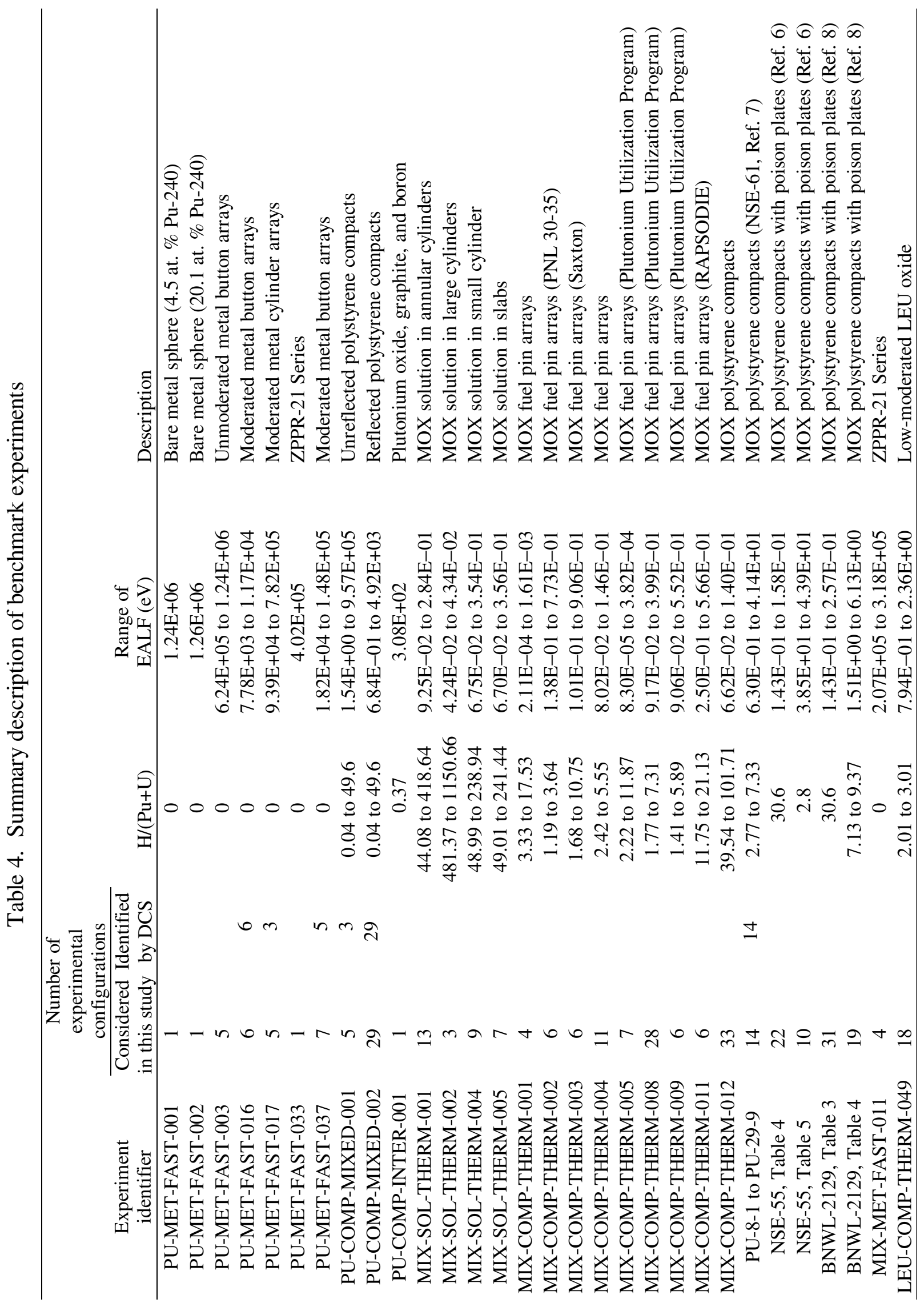


plutonium metal buttons, either bare or with one side reflected by polyethylene, were included (PU-MET-FAST-003). A group of 13 experiments using plutonium metal in cans, and placed in $3 \times 3 \times 3$ or $2 \times 2 \times \mathrm{N}$ arrays with water moderation and reflection are taken from PU-METFAST-016 and PU-MET-FAST-037. Five experiments using moderated arrays of plutonium metal cylinders are included from PU-MET-FAST-017. The final plutonium metal experiment is from PU-MET-FAST-033, and is part of the ZPPR-21 series of experiments, which also include MIX-MET-FAST-011 and HEU-MET-FAST-061. The ZPPR-21 series began with a fissile core containing only plutonium, and gradually substituted highly-enriched uranium metal for some of the plutonium metal until the final configuration contained only uranium.

\subsubsection{Plutonium Oxide Systems}

A set of 34 experiments involves plutonium oxide that has been mixed with various quantities of polystyrene, and then compacted into cubes. These cubes are stacked in arrays to form critical configurations with or without Plexiglas reflection. Five unreflected experiments are taken from PU-COMP-MIXED-001, and 29 experiments from PU-COMP-MIXED-002. The $\mathrm{H} / \mathrm{Pu}$ ratios in these compacts range from 0.04 to 49.6, giving a range of fission neutron spectra from fast to thermal.

One benchmark using plutonium oxide, graphite, and boron was included from PU-COMP-INTER-001. This benchmark describes a system with a $k_{\text {inf }}$ of 1 , and is interpolated from measured reactivity worths for a number of fuel samples with varied boron content. With energy of average lethargy causing fission (EALF) of $\sim 300 \mathrm{eV}$, this benchmark was chosen to represent the dry plutonium oxide powders in applications 1 through 3.

\subsection{MIXED PLUTONIUM AND URANIUM SYSTEMS}

Two hundred and thirty-nine mixed plutonium and uranium systems are included in this set of benchmarks. These experiments involve solution systems, fuel pin lattices, solid mixedoxide systems moderated by polystyrene, and mixed metal systems.

\subsubsection{Mixed Plutonium and Uranium Solution Systems}

Thirteen experiments with mixed plutonium and uranium solution in annular cylinder geometry are taken from MIX-SOL-THERM-001. The ratio of $\mathrm{Pu} /(\mathrm{Pu}+\mathrm{U})$ is 0.22 or 0.97 , and the concentration of the solution in the annular region is varied from 61 to $489 \mathrm{~g}(\mathrm{Pu}+\mathrm{U}) / \mathrm{liter}$. All experiments use a water reflector.

Three experiments with similar solution in large cylindrical geometry are from MIX-SOLTHERM-002. The objective of these experiments was to obtain data on the minimum fissile concentration for criticality in an effectively infinite cylindrical geometry. The reaction vessel has an inside diameter of $68.68 \mathrm{~cm}$. The concentrations of the solution are 23 and $53 \mathrm{~g}$ $(\mathrm{Pu}+\mathrm{U}) /$ liter with a ratio of $\mathrm{Pu} /(\mathrm{Pu}+\mathrm{U})$ of 0.52 and 0.23 , respectively. All three experiments are water reflected.

Nine experiments from this same series that use small cylindrical geometry are also included from MIX-SOL-THERM-004. The reaction tank has an inside diameter of $35.39 \mathrm{~cm}$ 
and inside height of $106.60 \mathrm{~cm}$. The concentrations of the solution are 105, 293, and $435 \mathrm{~g}$ $(\mathrm{Pu}+\mathrm{U}) /$ liter with a ratio of $\mathrm{Pu} /(\mathrm{Pu}+\mathrm{U})$ of 0.4 for all nine experiments. Three measurements have a water reflector, three have a concrete reflector, and three have no reflector.

Seven experiments with mixed plutonium and uranium solution in slab geometry are taken from MIX-SOL-THERM-005. The solution concentration ranged from 105 to $435 \mathrm{~g}$ $(\mathrm{Pu}+\mathrm{U}) /$ liter with a ratio of $\mathrm{Pu} /(\mathrm{Pu}+\mathrm{U})$ of 0.4 . Four experiments were water reflected, and four were bare.

\subsubsection{Mixed Plutonium and Uranium Fuel Pin Lattices}

Four experiments using natural $\mathrm{UO}_{2}-20 \mathrm{wt} \% \mathrm{PuO}_{2}\left(11.5 \mathrm{wt} \%{ }^{240} \mathrm{Pu}\right)$ fuel pins in a square lattice were analyzed (MIX-COMP-THERM-001). These experiments used water reflection, and incorporated polypropylene grid plates to minimize the effect of the grids on the reactivity of the core. The pitch was varied from 0.95 to $1.9 \mathrm{~cm}$.

Six experiments with natural $\mathrm{UO}_{2}-2$ wt $\% \mathrm{PuO}_{2}\left(8 \%{ }^{240} \mathrm{Pu}\right)$ fuel include square-pitched lattices, with 0.70-in., 0.87-in., or 0.99-in. pitch, in borated or pure water moderator (MIXCOMP-THERM-002). These experiments are also referred to as PNL 30-35 in NUREG/CR-0210 in the CSEWG Thermal Reactor Benchmarks (BNL-19302).

Six more experiments with natural $\mathrm{UO}_{2}-6.6 \mathrm{wt} \% \mathrm{PuO}_{2}$ fuel include square-pitched, partial-moderator-height lattices with five lattice pitches of 0.52 in., 0.56 in., 0.735 in., 0.792 in., and 1.04 in. (MIX-COMP-THERM-003). The purpose of these experiments was to verify the nuclear design of the Saxton partial plutonium core, which consisted of MOX assemblies in the central region with peripheral enriched $\mathrm{UO}_{2}$ assemblies. The experiments with 0.56-in.-pitched lattices were performed with borated or pure water moderator, but the other pitched-lattice experiments were performed only with pure water moderator.

Eleven experiments conducted at the Tokai Research Establishment of JAERI in Japan used natural $\mathrm{UO}_{2}-3.01 \mathrm{wt} \% \mathrm{PuO}_{2}$ rods in square arrays of varying pitch (MIX-COMPTHERM-004). The plutonium in the fuel pins contained $24 \mathrm{wt} \%{ }^{240} \mathrm{Pu}$.

Forty-one experiments from the Plutonium Utilization Program at Pacific Northwest Laboratories are included (MIX-COMP-THERM-005, MIX-COMP-THERM-008, and MIXCOMP-THERM-009). These experiments were performed using $\mathrm{MOX}$ fuel with $\mathrm{PuO}_{2}$ enrichments varying from 1.5- to $4-\mathrm{wt} \% \mathrm{PuO}_{2}$, and the ${ }^{240} \mathrm{Pu}$ isotopic composition of the plutonium was varied from $8 \%$ to $24 \%$. The fuel pins are arranged in hexagonal lattices with varying pitches with the rods uniformly arrayed in such a manner that the core is a right circular cylinder.

Six benchmark experiments using MOX fuel designed for the RAPSODIE fast breeder reactor in Cadarache, France are included from MIX-COMP-THERM-011. The uranium was enriched to $60 \mathrm{wt} \%{ }^{235} \mathrm{U}$, and the plutonium content of the MOX fuel was $25.8 \mathrm{wt} \%$, with $9.72 \mathrm{wt} \%$ of the plutonium being ${ }^{240} \mathrm{Pu}$. The pitch was triangular, and measured either $1.9 \mathrm{~cm}$ or $2.5 \mathrm{~cm}$. 


\subsubsection{Mixed Plutonium and Uranium Solid Systems}

Several experiments using various combinations of plutonium oxide, depleted uranium oxide and polystyrene, which had been pressed into compacts and stacked into arrays, are included in the database used in this study. They are included in MIX-COMP-THERM-012 and three other published references that have not yet been included in the IHECSBE. The configurations are similar to those in PU-COMP-THERM-001 and -002, but with MOX instead of plutonium oxide. There are both reflected and unreflected arrays, and some of the stacked arrays contain neutron poison plates.

There are 33 experiments included from MIX-COMP-THERM-012. These configurations contain mixtures of plutonium and depleted uranium oxides containing between 7.6 and 30-wt \% plutonium, with $\mathrm{H} / \mathrm{X}$ ratios from 19.5 to 51.8. Six experiments with 7.6 -wt $\%$ plutonium used plutonium that contains $23 \mathrm{wt} \%{ }^{240} \mathrm{Pu}$. The other experiments use plutonium with $8 \mathrm{wt} \%{ }^{240} \mathrm{Pu}$. Twenty-seven experiments are Plexiglas reflected, while six are bare.

Fourteen other experiments were performed with a similar range of plutonium oxide concentrations, but with much lower moderation levels (NSE-61). ${ }^{22}$ These experiments also utilize compacts with between 7.6 and $30 \mathrm{wt} \%$ plutonium, and H/X ratios ranging from 3 to 7 . The plutonium contained $11.5 \mathrm{wt} \%{ }^{240} \mathrm{Pu}$. Only the plexiglas-reflected configurations from this reference are included. (These experiments have been tentatively assigned to evaluation number MIX-COMP-INTER-001 in the IHECSBE, but have not been published in the Handbook.) In the attached tables, these experiments are labeled PU-8-1 through -4, PU-15-1, and PU-29-1 through -9 .

Thirty-two experiments were performed with MOX-polystyrene compacts in arrays that contained either one or two copper, copper/cadmium, or aluminum plates of varying thickness within the stack. ${ }^{23}$ All of these experiments were fully reflected with Plexiglas. Two types of fuel were used in these experiments. The first contained MOX with a plutonium content of 14.6 wt \%, of which 7.97 wt \% was ${ }^{240} \mathrm{Pu}$, and with an $\mathrm{H} / \mathrm{X}$ of 30.6. The second type of fuel contained MOX with a plutonium content of $30.3 \mathrm{wt} \%$, of which $11.5 \mathrm{wt} \%$ was ${ }^{240} \mathrm{Pu}$, and with an $\mathrm{H} / \mathrm{X}$ of 2.8. Twenty-two experiments contained the fuel with an $\mathrm{H} / \mathrm{X}$ of 30.6 , and ten experiments used the fuel with an $\mathrm{H} / \mathrm{X}$ of 2.8. These experiments are labeled NSE55T $x-x x$ in subsequent sections of this report.

Fifty experiments were performed using these same two fuel compositions, but with other types of neutron poison plates contained with the array stacks. All of these experiments were also fully reflected with Plexiglas. ${ }^{24}$ The poison plate materials included Type 304 stainless steel, steel with $1.1 \mathrm{wt} \%$ boron, steel with $1.6 \mathrm{wt} \%$ boron, boral, lead, depleted uranium, cadmium, and aluminum. Thirty-one independent experiments were performed with the fuel with an H/X of 30.6. In the case of the fuel with an $\mathrm{H} / \mathrm{X}$ of 2.8 , the 19 configurations used some of the fuel with an $\mathrm{H} / \mathrm{X}$ of 30.6 as a driver. An $8 \times 8 \times 2$ array of the lower-moderated fuel was used above and below the neutron poison plate, and on top of this was placed at least two layers of the highermoderated fuel. The thickness of driver fuel was varied to achieve criticality with the various neutron poison plate materials and thicknesses. The reference states that the neutron flux in the region containing the poison plate was characteristic of the lower-moderated fuel, and that $<30 \%$ 
of the fissions occurred in the higher-moderated fuel. However, when using these experiments as critical benchmarks, the importance of the more moderated fuel is significant, and the overall flux is more thermal than the experiments using only the lower-moderated fuel. These experiments are labeled BNWL2129T $x$ - $x x$ in subsequent sections of this report.

\subsubsection{Mixed Plutonium and Uranium Metal System}

A set of four mixed plutonium and uranium metal systems was analyzed as a means of including homogeneous uranium/plutonium systems with a fast energy spectrum. These experiments are documented in MIX-MET-FAST-011, and are part of the ZPPR-21 series of experiments that also include PU-MET-FAST-033 and HEU-MET-FAST-061. As described previously, the ZPPR-21 series began with a fissile core containing only plutonium, and gradually substituted highly enriched uranium metal for some of the plutonium metal until the final configuration contained only uranium. (The last configuration is described in HEU-MET-FAST061, and was not included in this database since it did not pertain to any of the applications of interest.) The four experiments in MIX-MET-FAST-011 contain between 41.4 and 7.7 wt \% plutonium metal, which included between 6.16 and $11.6 \mathrm{wt} \%{ }^{240} \mathrm{Pu}$. The bulk of the neutron spectrum is in the $100-\mathrm{keV}$ to $4-\mathrm{MeV}$ energy range and the peak is at about $600 \mathrm{keV}$. Thus, the spectrum is in the fast range, although not as hard as the spectrum in many other fast metal assemblies.

\subsection{LOW-ENRICHED URANIUM OXIDE SYSTEMS}

In order to include experiments with low-enriched uranium oxide at low moderation levels, 18 experiments from LEU-COMP-THERM-049 were placed in the database. These models primarily assist in validating ${ }^{238} \mathrm{U}$ capture and fission cross sections in the higher-neutron energy region. The experiments were performed under the MARACAS program at the Valduc facility in France. The uranium dioxide was enriched to $5 \mathrm{wt} \%{ }^{235} \mathrm{U}$, and was moderated to an $\mathrm{H} / \mathrm{X}$ of between 2 and 3. Uranium dioxide powder was moistened and contained in metal boxes, which were placed in various sized arrays on a split table, and the overall configuration was reflected with polyethylene. The overall neutron spectrum is thermal but has a significant intermediate energy component. 


\section{RESULTS}

The objective of this study is to determine which of the 318 critical benchmarks identified in the previous section are applicable for the criticality code validation for AOAs 3 and 4 of the MFFF. To assess the applicability of benchmark experiments to each AOA, several design systems were analyzed that are representative of the compositions and masses expected in the design of the MFFF in each AOA. The applicability of each experiment was determined independently for each design system. Each design system represents a subset of each AOA. The measure of applicability was established in Sect. 2.4 of this report. This criterion is that the $c_{k}$ correlation coefficient, relating the particular design systems to an experiment, meets or exceeds a value of 0.8. Tabulated results of $E_{\text {sum }}$ and $c_{k}$ values for all applications in relation to all benchmarks identified in Sect. 5 are given in Appendix B.

To compute correlation coefficients, group-wise, nuclide-reaction-specific sensitivity data were required for each of the 318 critical benchmarks and each of the design applications. Each of the critical experiments was modeled explicitly in 3-D using the SEN3 sensitivity analysis sequence of SCALE. Each of the spherical applications was modeled in 1-D using the SEN1 sensitivity analysis sequence of SCALE. Both SEN1 and SEN3 were executed within a prerelease version of SCALE-5 using the 238-group ENDF/B-V data library. The cross-section data were resonance shielded using the BONAMIST and NITAWLST modules.

Subsequent to the generation of the sensitivity data, the CANDE code was used to generate the correlation coefficients relating each application to each of the benchmark experiments. These correlation coefficients are shown in subsequent tables in order of descending values such that the experiments with the highest correlation to the design system are shown first in the tables.

\subsection{AOA 3 - $\mathrm{PUO}_{2}$ POWDERS}

The S/U analysis of the three applications submitted by DCS as representative of AOA 3 has determined that numerous benchmarks exceeded the 0.8 criterion for $c_{k}$ for each application. Some important calculated parameters for each application are shown in Table 5. A more detailed description of each application was previously presented in Sect. 4 of this document.

Table 5. Calculated characteristics of design systems from AOA 3

\begin{tabular}{cccl}
\hline Application & $\mathrm{H} / \mathrm{Pu}$ & EALF $(\mathrm{eV})$ & $k_{\text {eff }}$ \\
\hline AOA 3-1 & 1.58 & 1019 & 0.9984 \\
AOA 3-2 & 5.99 & 94.37 & 1.001 \\
AOA 3-3 & 3.04 & 884.3 & 1.006 \\
\hline
\end{tabular}


Of the 318 benchmark experiments, 91 were determined to satisfy the criteria of $c_{k} \geq 0.8$ for at least one of the analyzed design application systems from AOA 3. For the first application in AOA 3, 30 systems exhibit a $c_{k}$ value of 0.8 or greater. All of the experiments with a $c_{k}$ value in excess of 0.8 contain plutonium fuel. The majority of the systems are of metal composition with a fast energy spectrum. The experiment designator and $c_{k}$ values are shown in Table 6 along with other important parameters for each of the systems. For the second application in AOA 3, 61 systems exhibit a $c_{k}$ value of 0.8 or greater. Of these 61 systems, 23 are plutonium-only systems and 38 are MOX systems. Data regarding these systems are shown in Table 7. For the third application in AOA 3, 61 systems exhibit a $c_{k}$ value of 0.8 or greater. Of these 61 systems, 41 are plutonium fueled and 20 contain MOX fuel. Data regarding these systems is shown in Table 8. Note that numerous MOX benchmarks exceed the applicability criterion for these plutonium applications.

The S/U methods identified the majority of the benchmarks chosen by DCS as meeting the 0.8 criterion for $c_{k}$. Of the 46 experimental configurations identified by DCS, 38 were confirmed by the S/U methods as applicable to at least one of the design systems representing a subset of AOA 3. Of the 46 experiments, S/U methods identified 18 as meeting the applicability criterion for AOA 3-1, 21 for AOA 3-2, and 36 for AOA 3-3. These experiments are noted in Tables 6-8. 
Table 6. Experimental configurations with $c_{k}$ coefficients $\geq 0.8$ for AOA 3-1

\begin{tabular}{|c|c|c|c|c|c|c|}
\hline Experiment & $c_{k}$ & $\mathrm{H} /(\mathrm{Pu}+\mathrm{U})$ & $\mathrm{Wt} \%{ }^{240} \mathrm{Pu}$ & $\operatorname{EALF}(\mathrm{eV})$ & $k_{e f f}$ & $\sigma$ \\
\hline PMF016-05* & 0.8715 & 0 & 5.97 & $7.93 \mathrm{E}+03$ & 0.9965 & 0.0006 \\
\hline PMF016-01* & 0.8668 & 0 & 5.97 & $1.17 \mathrm{E}+04$ & 1.0118 & 0.0006 \\
\hline PMF037-16 & 0.8625 & 0 & 5.97 & $2.84 \mathrm{E}+04$ & 0.9996 & 0.0006 \\
\hline PMF037-15 & 0.8623 & 0 & 5.97 & $1.82 \mathrm{E}+04$ & 0.9985 & 0.0005 \\
\hline PMF003-02 & 0.8621 & 0 & 5.97 & $6.90 \mathrm{E}+05$ & 0.9935 & 0.0007 \\
\hline PMF003-01 & 0.8617 & 0 & 5.97 & $1.24 \mathrm{E}+06$ & 0.9937 & 0.0006 \\
\hline PMF037-07* & 0.8614 & 0 & 5.97 & $3.30 \mathrm{E}+04$ & 0.9984 & 0.0006 \\
\hline PMF003-03 & 0.8612 & 0 & 5.97 & $1.24 \mathrm{E}+06$ & 0.9879 & 0.0006 \\
\hline PMF001-01 & 0.8602 & 0 & 4.7 & $1.24 \mathrm{E}+06$ & 0.9949 & 0.0007 \\
\hline PMF016-03* & 0.8597 & 0 & 5.97 & $8.34 \mathrm{E}+03$ & 0.9995 & 0.0007 \\
\hline PMF037-12* & 0.8597 & 0 & 5.97 & $2.35 \mathrm{E}+04$ & 1.0009 & 0.0006 \\
\hline PMF003-04 & 0.8596 & 0 & 5.97 & $6.24 \mathrm{E}+05$ & 0.9926 & 0.0006 \\
\hline PMF016-04* & 0.8589 & 0 & 5.97 & $8.01 \mathrm{E}+03$ & 0.9982 & 0.0007 \\
\hline PMF017-01 & 0.8588 & 0 & 5.97 & $7.82 \mathrm{E}+05$ & 0.9901 & 0.0007 \\
\hline PMF037-01* & 0.8584 & 0 & 5.97 & $1.48 \mathrm{E}+05$ & 0.9973 & 0.0006 \\
\hline PMF003-05 & 0.8578 & 0 & 5.97 & $1.24 \mathrm{E}+06$ & 0.9908 & 0.0007 \\
\hline PMF037-10* & 0.8577 & 0 & 5.97 & $2.61 \mathrm{E}+04$ & 0.9993 & 0.0006 \\
\hline PMF016-02* & 0.8553 & 0 & 5.97 & $8.61 \mathrm{E}+03$ & 1.0003 & 0.0006 \\
\hline PMF017-02* & 0.855 & 0 & 5.97 & $4.05 \mathrm{E}+05$ & 0.9932 & 0.0007 \\
\hline PMF017-03* & 0.8541 & 0 & 5.97 & $2.30 \mathrm{E}+05$ & 0.994 & 0.0008 \\
\hline PMF017-04 & 0.8507 & 0 & 5.97 & $4.58 \mathrm{E}+05$ & 0.991 & 0.0006 \\
\hline PMF037-05* & 0.8497 & 0 & 5.97 & $5.12 \mathrm{E}+04$ & 0.9977 & 0.0006 \\
\hline PMF002-01 & 0.8488 & 0 & 20.1 & $1.26 \mathrm{E}+06$ & 0.9964 & 0.0005 \\
\hline PMF016-06* & 0.8425 & 0 & 5.97 & $7.78 \mathrm{E}+03$ & 1.0003 & 0.0007 \\
\hline PMF017-05* & 0.8405 & 0 & 5.97 & $9.39 \mathrm{E}+04$ & 1.002 & 0.0006 \\
\hline PCM002-02* & 0.8343 & 0.04 & 18.35 & $4.21 \mathrm{E}+03$ & 1.0308 & 0.0006 \\
\hline PMF033-01 & 0.8288 & 0 & 5.83 & $4.02 \mathrm{E}+05$ & 1.0066 & 0.0005 \\
\hline PCM002-01* & 0.8177 & 0.04 & 18.35 & $4.92 \mathrm{E}+03$ & 1.0322 & 0.0007 \\
\hline PCM002-03* & 0.8083 & 0.04 & 18.35 & $3.51 \mathrm{E}+03$ & 1.0262 & 0.0006 \\
\hline PCM002-04* & 0.8077 & 0.04 & 18.35 & $2.57 \mathrm{E}+03$ & 1.0197 & 0.0006 \\
\hline
\end{tabular}

*Benchmark experiment identified by DCS as applicable to AOA 3. 
Table 7. Experimental configurations with $c_{k}$ coefficients $\geq 0.8$ for AOA 3-2

\begin{tabular}{|c|c|c|c|c|c|c|}
\hline Experiment & $c_{k}$ & $\mathrm{H} /(\mathrm{Pu}+\mathrm{U})$ & $\mathrm{Wt} \%{ }^{240} \mathrm{Pu}$ & EALF $(e V)$ & $k_{e f f}$ & $\sigma$ \\
\hline PCM002-06* & 0.9893 & 5 & 11.46 & $9.25 \mathrm{E}+01$ & 1.0234 & 0.0006 \\
\hline PCM002-07* & 0.9880 & 5 & 11.46 & $8.49 \mathrm{E}+01$ & 1.022 & 0.0006 \\
\hline PCM002-08* & 0.9875 & 5 & 11.46 & $6.80 \mathrm{E}+01$ & 1.0212 & 0.0006 \\
\hline PCM002-09* & 0.9779 & 5 & 11.46 & $5.68 \mathrm{E}+01$ & 1.0218 & 0.0005 \\
\hline PCM001-02* & 0.9773 & 5 & 11.46 & $1.73 \mathrm{E}+03$ & 1.0198 & 0.0007 \\
\hline PCM001-04 & 0.9707 & 15 & 8.06 & $3.95 \mathrm{E}+01$ & 0.9878 & 0.0007 \\
\hline PCM001-03* & 0.9670 & 15 & 2.2 & $3.26 \mathrm{E}+01$ & 1.0168 & 0.0008 \\
\hline PCM002-21* & 0.9541 & 15 & 2.2 & $6.64 \mathrm{E}+00$ & 1.0101 & 0.0006 \\
\hline PCM002-22* & 0.9511 & 15 & 2.2 & $6.45 \mathrm{E}+00$ & 1.0143 & 0.0007 \\
\hline PCM002-20* & 0.9505 & 15 & 2.2 & $6.65 \mathrm{E}+00$ & 1.0087 & 0.0005 \\
\hline PCM002-19* & 0.9497 & 15 & 2.2 & $6.47 \mathrm{E}+00$ & 1.0088 & 0.0006 \\
\hline PCM002-18* & 0.9491 & 15 & 2.2 & $6.19 \mathrm{E}+00$ & 1.0102 & 0.0006 \\
\hline NSE55T5-07 & 0.9457 & 2.8 & 11.5 & $4.39 \mathrm{E}+01$ & 1.0042 & 0.0005 \\
\hline PCM002-14* & 0.9457 & 15 & 2.2 & $5.60 \mathrm{E}+00$ & 1.0295 & 0.0006 \\
\hline PU-29-1 & 0.9456 & 2.77 & 11.5 & $4.14 \mathrm{E}+01$ & 0.9941 & 0.0003 \\
\hline NSE55T5-01 & 0.9453 & 2.8 & 11.5 & $3.97 \mathrm{E}+01$ & 1.0058 & 0.0005 \\
\hline PU-29-4 & 0.9453 & 2.77 & 11.5 & $3.78 \mathrm{E}+01$ & 0.9932 & 0.0004 \\
\hline NSE55T5-10 & 0.9451 & 2.8 & 11.5 & $3.85 \mathrm{E}+01$ & 1.0036 & 0.0004 \\
\hline PU-29-3 & 0.9451 & 2.77 & 11.5 & $4.07 \mathrm{E}+01$ & 1.0022 & 0.0005 \\
\hline PU-29-2 & 0.9450 & 2.77 & 11.5 & $4.03 \mathrm{E}+01$ & 0.9931 & 0.0005 \\
\hline PU-29-7 & 0.9448 & 2.77 & 11.5 & $3.48 \mathrm{E}+01$ & 0.9944 & 0.0005 \\
\hline PCM002-15* & 0.9446 & 15 & 2.2 & $5.56 \mathrm{E}+00$ & 1.0283 & 0.0006 \\
\hline NSE55T5-08 & 0.9445 & 2.8 & 11.5 & $3.93 \mathrm{E}+01$ & 1.0026 & 0.0006 \\
\hline PCM002-16* & 0.9444 & 15 & 2.2 & $5.15 \mathrm{E}+00$ & 1.0235 & 0.0007 \\
\hline PU-29-5 & 0.9443 & 2.77 & 11.5 & $3.77 \mathrm{E}+01$ & 0.9937 & 0.0003 \\
\hline NSE55T5-05 & 0.9438 & 2.8 & 11.5 & $4.03 \mathrm{E}+01$ & 1.002 & 0.0005 \\
\hline NSE55T5-02 & 0.9437 & 2.8 & 11.5 & $3.97 \mathrm{E}+01$ & 1.0028 & 0.0005 \\
\hline PU-29-8 & 0.9437 & 2.77 & 11.5 & $3.44 \mathrm{E}+01$ & 0.9951 & 0.0005 \\
\hline PU-29-6 & 0.9432 & 2.77 & 11.5 & $3.67 \mathrm{E}+01$ & 0.9931 & 0.0003 \\
\hline PU-29-9 & 0.9431 & 2.77 & 11.5 & $3.46 \mathrm{E}+01$ & 0.9987 & 0.0005 \\
\hline PCM002-17* & 0.9426 & 15 & 2.2 & $4.93 \mathrm{E}+00$ & 1.0073 & 0.0007 \\
\hline
\end{tabular}


Table 7 (continued)

\begin{tabular}{|c|c|c|c|c|c|c|}
\hline Experiment & $c_{k}$ & $\mathrm{H} /(\mathrm{Pu}+\mathrm{U})$ & $\mathrm{Wt} \%{ }^{240} \mathrm{Pu}$ & EALF $(\mathrm{eV})$ & $k_{e f f}$ & $\sigma$ \\
\hline NSE55T5-03 & 0.9424 & 2.8 & 11.5 & $4.00 \mathrm{E}+01$ & 1.0049 & 0.0005 \\
\hline NSE55T5-04 & 0.9422 & 2.8 & 11.5 & 4.10E+01 & 1.0048 & 0.0005 \\
\hline NSE55T5-06 & 0.9422 & 2.8 & 11.5 & $4.14 \mathrm{E}+01$ & 1.0045 & 0.0005 \\
\hline PCM002-12* & 0.9419 & 15 & 2.2 & $5.13 \mathrm{E}+00$ & 1.0273 & 0.0006 \\
\hline PCM002-11* & 0.9390 & 15 & 2.2 & $4.55 \mathrm{E}+00$ & 1.028 & 0.0006 \\
\hline PCM002-10* & 0.9384 & 15 & 2.2 & $4.14 \mathrm{E}+00$ & 1.0306 & 0.0006 \\
\hline NSE55T5-09 & 0.937 & 2.8 & 11.5 & $3.88 \mathrm{E}+01$ & 1.0023 & 0.0005 \\
\hline BNWL2129T4-01 & 0.9005 & 7.13 & 10.95 & $6.13 \mathrm{E}+00$ & 1.0184 & 0.0006 \\
\hline BNWL2129T4-02 & 0.8909 & 7.64 & 10.89 & $4.51 \mathrm{E}+00$ & 1.0178 & 0.0006 \\
\hline BNWL2129T4-04 & 0.8888 & 7.51 & 10.9 & $5.08 \mathrm{E}+00$ & 1.0182 & 0.0005 \\
\hline BNWL2129T4-16 & 0.8885 & 7.37 & 10.92 & $5.24 \mathrm{E}+00$ & 1.0178 & 0.0006 \\
\hline BNWL2129T4-15 & 0.8867 & 7.51 & 10.9 & $5.08 \mathrm{E}+00$ & 1.0161 & 0.0005 \\
\hline BNWL2129T4-07 & 0.8856 & 7.57 & 10.89 & $4.91 \mathrm{E}+00$ & 1.0165 & 0.0005 \\
\hline BNWL2129T4-09 & 0.8855 & 7.39 & 10.92 & $5.78 \mathrm{E}+00$ & 1.0187 & 0.0006 \\
\hline BNWL2129T4-17 & 0.8844 & 7.68 & 10.88 & $4.28 \mathrm{E}+00$ & 1.0172 & 0.0005 \\
\hline PU-15-1 & 0.8787 & 2.86 & 11.5 & $1.51 \mathrm{E}+01$ & 0.9811 & 0.0003 \\
\hline PCM002-13* & 0.8774 & 15 & 2.2 & $5.46 \mathrm{E}+00$ & 1.0256 & 0.0006 \\
\hline BNWL2129T4-19 & 0.8724 & 7.79 & 10.87 & $4.05 \mathrm{E}+00$ & 1.0181 & 0.0006 \\
\hline BNWL2129T4-12 & 0.8699 & 8.09 & 10.83 & $3.84 \mathrm{E}+00$ & 1.02 & 0.0005 \\
\hline BNWL2129T4-10 & 0.8617 & 7.72 & 10.88 & $5.24 \mathrm{E}+00$ & 1.0159 & 0.0006 \\
\hline BNWL2129T4-03 & 0.8602 & 8.08 & 10.83 & $3.44 \mathrm{E}+00$ & 1.018 & 0.0007 \\
\hline BNWL2129T4-18 & 0.8581 & 7.91 & 10.85 & $3.58 \mathrm{E}+00$ & 1.0171 & 0.0005 \\
\hline BNWL2129T4-05 & 0.8476 & 8.29 & 10.8 & $3.22 \mathrm{E}+00$ & 1.0183 & 0.0006 \\
\hline BNWL2129T4-08 & 0.8292 & 8.71 & 10.75 & $2.40 \mathrm{E}+00$ & 1.0186 & 0.0005 \\
\hline BNWL2129T4-11 & 0.8204 & 8.52 & 10.77 & $3.48 \mathrm{E}+00$ & 1.0166 & 0.0005 \\
\hline BNWL2129T4-13 & 0.8192 & 8.79 & 10.74 & $2.47 \mathrm{E}+00$ & 1.0214 & 0.0007 \\
\hline PCM001-05* & 0.8181 & 49.6 & 18.35 & $1.54 \mathrm{E}+00$ & 1.0087 & 0.0007 \\
\hline PCM002-05* & 0.8178 & 0.04 & 18.35 & $1.87 \mathrm{E}+03$ & 1.0171 & 0.0006 \\
\hline PCI001-01 & 0.8158 & 0.37 & 5.3 & $3.08 \mathrm{E}+02$ & 0.9988 & 0.0001 \\
\hline BNWL2129T4-06 & 0.8074 & 8.81 & 10.74 & $2.24 \mathrm{E}+00$ & 1.018 & 0.0005 \\
\hline
\end{tabular}

*Benchmark experiment identified by DCS as applicable to AOA 3. 
Table 8. Experimental configurations with $c_{k}$ coefficients $\geq 0.8$ for AOA 3-3

\begin{tabular}{|c|c|c|c|c|c|c|}
\hline Experiment & $c_{k}$ & $\mathrm{H} /(\mathrm{Pu}+\mathrm{U})$ & $\mathrm{Wt} \%{ }^{240} \mathrm{Pu}$ & EALF $(\mathrm{eV})$ & $k_{\text {eff }}$ & $\sigma$ \\
\hline PCM001-02* & 0.9647 & 5 & 11.46 & $1.73 \mathrm{E}+03$ & 1.0198 & 0.0007 \\
\hline PCM002-06* & 0.9537 & 5 & 11.46 & $9.25 \mathrm{E}+01$ & 1.0234 & 0.0006 \\
\hline PCM002-09* & 0.9486 & 5 & 11.46 & $5.68 \mathrm{E}+01$ & 1.0218 & 0.0005 \\
\hline PCM002-08* & 0.9483 & 5 & 11.46 & $6.80 \mathrm{E}+01$ & 1.0212 & 0.0006 \\
\hline PCM002-07* & 0.9339 & 5 & 11.46 & $8.49 \mathrm{E}+01$ & 1.022 & 0.0006 \\
\hline PCM002-05* & 0.9263 & 0.04 & 18.35 & $1.87 \mathrm{E}+03$ & 1.0171 & 0.0006 \\
\hline PCM002-03* & 0.9152 & 0.04 & 18.35 & $3.51 \mathrm{E}+03$ & 1.0262 & 0.0006 \\
\hline PCM002-04* & 0.9123 & 0.04 & 18.35 & $2.57 \mathrm{E}+03$ & 1.0197 & 0.0006 \\
\hline PCM002-01* & 0.908 & 0.04 & 18.35 & $4.92 \mathrm{E}+03$ & 1.0322 & 0.0007 \\
\hline PCM002-02* & 0.8954 & 0.04 & 18.35 & $4.21 \mathrm{E}+03$ & 1.0308 & 0.0006 \\
\hline PMF016-06* & 0.885 & 0 & 5.97 & $7.78 \mathrm{E}+03$ & 1.0003 & 0.0007 \\
\hline РCM001-04 & 0.881 & 15 & 8.06 & $3.95 \mathrm{E}+01$ & 0.9878 & 0.0007 \\
\hline PMF016-01* & 0.8772 & 0 & 5.97 & $1.17 \mathrm{E}+04$ & 1.0118 & 0.0006 \\
\hline PMF016-02* & 0.8764 & 0 & 5.97 & $8.61 \mathrm{E}+03$ & 1.0003 & 0.0006 \\
\hline PMF016-04* & 0.8761 & 0 & 5.97 & $8.01 \mathrm{E}+03$ & 0.9982 & 0.0007 \\
\hline PU-29-1 & 0.8755 & 2.77 & 11.5 & $4.14 \mathrm{E}+01$ & 0.9941 & 0.0003 \\
\hline PU-29-2 & 0.8752 & 2.77 & 11.5 & $4.03 \mathrm{E}+01$ & 0.9931 & 0.0005 \\
\hline PU-29-3 & 0.8748 & 2.77 & 11.5 & $4.07 \mathrm{E}+01$ & 1.0022 & 0.0005 \\
\hline NSE55T5-01 & 0.8744 & 2.8 & 11.5 & $3.97 \mathrm{E}+01$ & 1.0058 & 0.0005 \\
\hline PU-29-4 & 0.8744 & 2.77 & 11.5 & $3.78 \mathrm{E}+01$ & 0.9932 & 0.0004 \\
\hline PU-29-5 & 0.874 & 2.77 & 11.5 & $3.77 \mathrm{E}+01$ & 0.9937 & 0.0003 \\
\hline NSE55T5-05 & 0.8737 & 2.8 & 11.5 & $4.03 \mathrm{E}+01$ & 1.002 & 0.0005 \\
\hline NSE55T5-07 & 0.8737 & 2.8 & 11.5 & $4.39 \mathrm{E}+01$ & 1.0042 & 0.0005 \\
\hline NSE55T5-08 & 0.8736 & 2.8 & 11.5 & $3.93 \mathrm{E}+01$ & 1.0026 & 0.0006 \\
\hline PCM001-03 & 0.8736 & 15 & 2.2 & $3.26 \mathrm{E}+01$ & 1.0168 & 0.0008 \\
\hline PMF037-15 & 0.8729 & 0 & 5.97 & $1.82 \mathrm{E}+04$ & 0.9985 & 0.0005 \\
\hline NSE55T5-02 & 0.8728 & 2.8 & 11.5 & $3.97 \mathrm{E}+01$ & 1.0028 & 0.0005 \\
\hline NSE55T5-10 & 0.8728 & 2.8 & 11.5 & $3.85 \mathrm{E}+01$ & 1.0036 & 0.0004 \\
\hline PU-29-8 & 0.8728 & 2.77 & 11.5 & $3.44 \mathrm{E}+01$ & 0.9951 & 0.0005 \\
\hline PU-29-7 & 0.8727 & 2.77 & 11.5 & $3.48 \mathrm{E}+01$ & 0.9944 & 0.0005 \\
\hline NSE55T5-06 & 0.8726 & 2.8 & 11.5 & 4.14E+01 & 1.0045 & 0.0005 \\
\hline
\end{tabular}


Table 8 (continued)

\begin{tabular}{|c|c|c|c|c|c|c|}
\hline Experiment & $c_{k}$ & $\mathrm{H} /(\mathrm{Pu}+\mathrm{U})$ & $\mathrm{Wt} \%{ }^{240} \mathrm{Pu}$ & $\operatorname{EALF}(\mathrm{eV})$ & $k_{e f f}$ & $\sigma$ \\
\hline PU-29-6 & 0.8723 & 2.77 & 11.5 & $3.67 \mathrm{E}+01$ & 0.9931 & 0.0003 \\
\hline NSE55T5-04 & 0.872 & 2.8 & 11.5 & $4.10 \mathrm{E}+01$ & 1.0048 & 0.0005 \\
\hline NSE55T5-03 & 0.8717 & 2.8 & 11.5 & $4.00 \mathrm{E}+01$ & 1.0049 & 0.0005 \\
\hline PU-29-9 & 0.8716 & 2.77 & 11.5 & $3.46 \mathrm{E}+01$ & 0.9987 & 0.0005 \\
\hline PMF016-05* & 0.871 & 0 & 5.97 & $7.93 \mathrm{E}+03$ & 0.9965 & 0.0006 \\
\hline NSE55T5-09 & 0.8696 & 2.8 & 11.5 & $3.88 \mathrm{E}+01$ & 1.0023 & 0.0005 \\
\hline PMF037-07* & 0.8685 & 0 & 5.97 & $3.30 \mathrm{E}+04$ & 0.9984 & 0.0006 \\
\hline PMF037-12* & 0.8685 & 0 & 5.97 & $2.35 \mathrm{E}+04$ & 1.0009 & 0.0006 \\
\hline PMF016-03* & 0.8665 & 0 & 5.97 & $8.34 \mathrm{E}+03$ & 0.9995 & 0.0007 \\
\hline PMF037-05* & 0.8664 & 0 & 5.97 & $5.12 \mathrm{E}+04$ & 0.9977 & 0.0006 \\
\hline PMF017-05* & 0.8639 & 0 & 5.97 & $9.39 \mathrm{E}+04$ & 1.002 & 0.0006 \\
\hline PMF037-16 & 0.8622 & 0 & 5.97 & $2.84 \mathrm{E}+04$ & 0.9996 & 0.0006 \\
\hline PMF037-10* & 0.8596 & 0 & 5.97 & $2.61 \mathrm{E}+04$ & 0.9993 & 0.0006 \\
\hline PCM002-21* & 0.8495 & 15 & 2.2 & $6.64 \mathrm{E}+00$ & 1.0101 & 0.0006 \\
\hline PCM002-20* & 0.8489 & 15 & 2.2 & $6.65 \mathrm{E}+00$ & 1.0087 & 0.0005 \\
\hline PCM002-22* & 0.8483 & 15 & 2.2 & $6.45 \mathrm{E}+00$ & 1.0143 & 0.0007 \\
\hline PCM002-18* & 0.8471 & 15 & 2.2 & $6.19 \mathrm{E}+00$ & 1.0102 & 0.0006 \\
\hline PCM002-19* & 0.8464 & 15 & 2.2 & $6.47 \mathrm{E}+00$ & 1.0088 & 0.0006 \\
\hline PCM002-17* & 0.8393 & 15 & 2.2 & $4.93 \mathrm{E}+00$ & 1.0073 & 0.0007 \\
\hline PMF037-01* & 0.8379 & 0 & 5.97 & $1.48 \mathrm{E}+05$ & 0.9973 & 0.0006 \\
\hline PCM002-14* & 0.8378 & 15 & 2.2 & $5.60 \mathrm{E}+00$ & 1.0295 & 0.0006 \\
\hline PCM002-15* & 0.8375 & 15 & 2.2 & $5.56 \mathrm{E}+00$ & 1.0283 & 0.0006 \\
\hline PCM002-16* & 0.8358 & 15 & 2.2 & $5.15 \mathrm{E}+00$ & 1.0235 & 0.0007 \\
\hline PCM002-12* & 0.8331 & 15 & 2.2 & $5.13 \mathrm{E}+00$ & 1.0273 & 0.0006 \\
\hline PMF017-03* & 0.8328 & 0 & 5.97 & $2.30 \mathrm{E}+05$ & 0.994 & 0.0008 \\
\hline PCM002-11* & 0.8293 & 15 & 2.2 & $4.55 \mathrm{E}+00$ & 1.028 & 0.0006 \\
\hline PCM002-10* & 0.829 & 15 & 2.2 & $4.14 \mathrm{E}+00$ & 1.0306 & 0.0006 \\
\hline PMF017-04 & 0.8244 & 0 & 5.97 & $4.58 \mathrm{E}+05$ & 0.991 & 0.0006 \\
\hline PMF017-02* & 0.821 & 0 & 5.97 & $4.05 \mathrm{E}+05$ & 0.9932 & 0.0007 \\
\hline BNWL2129T4-01 & 0.8073 & 7.13 & 10.95 & $6.13 \mathrm{E}+00$ & 1.0184 & 0.0006 \\
\hline
\end{tabular}

*Benchmark experiment identified by DCS as applicable to AOA 3. 


\subsection{AOA 4 - MOX POWDERS}

The S/U analysis of the applications submitted by DCS as representative of AOA 4 has revealed that numerous experimental benchmarks exceed the 0.8 criterion for $c_{k}$ for three of the four critical design systems. For the fourth application, several benchmarks exhibit a $c_{k}$ value that approaches this criterion for the critical configuration. For reduced mass cases using the same materials as the fourth design system, numerous benchmarks exceed the $c_{k}$ criterion. Some calculated characteristics of these design systems are presented in Table 9.

Table 9. Calculated characteristics of design systems from AOA 4

\begin{tabular}{cccl}
\hline Application & $\mathrm{H} /(\mathrm{U}+\mathrm{Pu})$ & $\mathrm{EALF}(\mathrm{eV})$ & $k_{\text {eff }}$ \\
\hline AOA 4-1 & 1.58 & 127.0 & 1.002 \\
AOA 4-2 & 1.58 & 3751 & 0.9989 \\
AOA 4-3 & 1.58 & 27.75 & 1.000 \\
AOA 4-4 & 0.3031 & 2355 & 0.9993 \\
AOA 4-4-P163 & 0.3031 & 1214 & 0.935 \\
AOA 4-4-P40 & 0.3031 & 367.8 & 0.812 \\
AOA 4-4-P8 & 0.3031 & 86.36 & 0.643 \\
\hline
\end{tabular}

Of the 318 benchmark experiments examined in this evaluation, 67 were found to exceed the $c_{k}$ criterion for at least one of the design systems analyzed. For application AOA 4-1, 60 experimental benchmarks exceed the 0.8 criterion for $c_{k}$. Of these, 48 exceed a $c_{k}$ value of 0.9 , with 17 even exceeding 0.98 , exhibiting a very strong correlation to the design system. Of the 60 experiments with a $c_{k}$ of 0.8 or greater, 39 benchmarks were MOX and 21 were plutonium fueled. These results are shown in Table 10.

For application AOA 4-2, 54 benchmarks exceed the 0.8 criterion for $c_{k}$. Of these, 20 values exceed 0.9 . Of the 54 experiments with $c_{k}$ values exceeding $0.8,34$ are MOX and the remaining 20 are plutonium fueled. These results are shown in Table 11. Note that the matching systems exhibited EALF values of approximately $40 \mathrm{eV}$, where the EALF of this application is nearly $4000 \mathrm{eV}$. Thus, the S/U methods have identified applicable experiments where traditional techniques might not. A nuclide-reaction-specific analysis is presented in Sect. 6.2.1 to provide further information as to why the $\mathrm{S} / \mathrm{U}$ analysis identifies these experiments as applicable to AOA 4-2.

For application AOA 4-3, 45 MOX benchmarks exhibit $c_{k}$ values in excess of 0.8. One of these values exceeds 0.9 , and no plutonium experiments have values exceeding 0.8 . These results are shown in Table 12.

For application AOA 4-4, no benchmarks exceed the $c_{k}$ criterion of 0.8 . However, the values for 20 systems exceed 0.73 , with two of these values exceeding 0.74 . These results are 
shown in Table 13. Each of these 20 benchmarks is a MOX system. It is noteworthy that this application system exhibits an EALF of $2355 \mathrm{eV}$, and no existing MOX benchmark presented here exhibits an EALF of this magnitude. However, AOA 4-2 exhibited an EALF even greater than that for AOA 4-4 and numerous experiments met the 0.8 criterion for AOA 4.2. This seemingly contradictory issue is further explored in Sect. 6.2.2.

For the reduced mass configurations of the material from AOA 4-4, the results are improved with decreasing mass. For the $163 \mathrm{~kg}$ Pu case, AOA 4-4-P163, no benchmarks exceed the 0.8 criterion for $c_{k}$. However, 28 exhibit a $c_{k}$ of 0.7 or higher, with 20 of these exceeding 0.76 . Of these experiments, 22 are MOX and the remaining six are plutonium fueled. These results are shown in Table 14. For the $40 \mathrm{~kg}$ Pu case, AOA 4-4-P40, 20 benchmarks exceed the 0.8 criterion for $c_{k}$. All of these benchmarks consist of MOX fuel. These results are shown in Table 15. For the $8 \mathrm{~kg} \mathrm{Pu}$ case, AOA 4-4-P8, 46 benchmarks exceed the 0.8 criterion for $c_{k}$. Of these experiments, 38 are MOX and the remaining eight are plutonium fueled. These results are shown in Table 16. A nuclide-reaction-specific analysis is presented in Sect. 6.2.2 to provide further details on these systems.

Of the 14 benchmarks identified by DCS for the validation of AOA 4, the S/U methods have identified 10 for AOA 4-1, 10 for AOA 4-2, 14 for AOA 4-3 and none for AOA 4-4. However, of the 20 benchmarks exceeding 0.73 for the critical configuration of AOA 4-4, 10 were identified by DCS. These same 10 experiments exceeded the 0.8 criterion for two of the reduced mass cases of AOA 4-4. The experiments identified by DCS are noted in Tables 10-16. 
Table 10. Experimental configurations with $c_{k}$ coefficients $\geq 0.8$ for AOA 4-1

\begin{tabular}{ccccccc}
\hline Experiment & $c_{k}$ & $\mathrm{H} /(\mathrm{Pu}+\mathrm{U})$ & $\mathrm{Wt} \%{ }^{240} \mathrm{Pu}$ & $\mathrm{EALF}(\mathrm{eV})$ & $k_{\text {eff }}$ & $\sigma$ \\
\hline PU-29-2* & 0.9837 & 2.77 & 11.5 & $4.03 \mathrm{E}+01$ & 0.9931 & 0.0005 \\
PU-29-1* & 0.9836 & 2.77 & 11.5 & $4.14 \mathrm{E}+01$ & 0.9941 & 0.0003 \\
NSE55T5-07 & 0.9833 & 2.8 & 11.5 & $4.39 \mathrm{E}+01$ & 1.0042 & 0.0005 \\
PU-29-3* & 0.9829 & 2.77 & 11.5 & $4.07 \mathrm{E}+01$ & 1.0022 & 0.0005 \\
PU-29-4* & 0.9824 & 2.77 & 11.5 & $3.78 \mathrm{E}+01$ & 0.9932 & 0.0004 \\
NSE55T5-10 & 0.9822 & 2.8 & 11.5 & $3.85 \mathrm{E}+01$ & 1.0036 & 0.0004 \\
PU-29-5* & 0.9822 & 2.77 & 11.5 & $3.77 \mathrm{E}+01$ & 0.9937 & 0.0003 \\
NSE55T5-06 & 0.9821 & 2.8 & 11.5 & $4.14 \mathrm{E}+01$ & 1.0045 & 0.0005 \\
NSE55T5-01 & 0.9819 & 2.8 & 11.5 & $3.97 \mathrm{E}+01$ & 1.0058 & 0.0005 \\
NSE55T5-05 & 0.9817 & 2.8 & 11.5 & $4.03 \mathrm{E}+01$ & 1.002 & 0.0005 \\
NSE55T5-02 & 0.9811 & 2.8 & 11.5 & $3.97 \mathrm{E}+01$ & 1.0028 & 0.0005 \\
NSE55T5-08 & 0.9809 & 2.8 & 11.5 & $3.93 \mathrm{E}+01$ & 1.0026 & 0.0006 \\
PU-29-7* & 0.9808 & 2.77 & 11.5 & $3.48 \mathrm{E}+01$ & 0.9944 & 0.0005 \\
NSE55T5-04 & 0.9806 & 2.8 & 11.5 & $4.10 \mathrm{E}+01$ & 1.0048 & 0.0005 \\
PU-29-8* & 0.9805 & 2.77 & 11.5 & $3.44 \mathrm{E}+01$ & 0.9951 & 0.0005 \\
NSE55T5-03 & 0.9803 & 2.8 & 11.5 & $4.00 \mathrm{E}+01$ & 1.0049 & 0.0005 \\
PU-29-6* & 0.9803 & 2.77 & 11.5 & $3.67 \mathrm{E}+01$ & 0.9931 & 0.0003 \\
PU-29-9* & 0.9796 & 2.77 & 11.5 & $3.46 \mathrm{E}+01$ & 0.9987 & 0.0005 \\
NSE55T5-09 & 0.9783 & 2.8 & 11.5 & $3.88 \mathrm{E}+01$ & 1.0023 & 0.0005 \\
PU-15-1* & 0.9493 & 2.86 & 11.5 & $1.51 \mathrm{E}+01$ & 0.9811 & 0.0003 \\
PCM002-06 & 0.9484 & 5 & 11.46 & $9.25 \mathrm{E}+01$ & 1.0234 & 0.0006 \\
PCM002-07 & 0.9470 & 5 & 11.46 & $8.49 \mathrm{E}+01$ & 1.022 & 0.0006 \\
PCM002-09 & 0.9451 & 5 & 11.46 & $5.68 \mathrm{E}+01$ & 1.0218 & 0.0005 \\
PCM002-08 & 0.9447 & 5 & 11.46 & $6.80 \mathrm{E}+01$ & 1.0212 & 0.0006 \\
BNWL2129T4-01 & 0.9367 & 7.13 & 10.95 & $6.13 \mathrm{E}+00$ & 1.0184 & 0.0006 \\
PCM001-04 & 0.9359 & 15 & 8.06 & $3.95 \mathrm{E}+01$ & 0.9878 & 0.0007 \\
PCM001-02 & 0.9329 & 5 & 11.46 & $1.73 \mathrm{E}+03$ & 1.0198 & 0.0007 \\
BNWL2129T4-02 & 0.9268 & 7.64 & 10.89 & $4.51 \mathrm{E}+00$ & 1.0178 & 0.0006 \\
BNWL2129T4-09 & 0.9261 & 7.39 & 10.92 & $5.78 \mathrm{E}+00$ & 1.0187 & 0.0006 \\
BNWL2129T4-04 & 0.9258 & 7.51 & 10.9 & $5.08 \mathrm{E}+00$ & 1.0182 & 0.0005 \\
PCM001-03 & 0.9241 & 15 & 2.2 & $3.26 \mathrm{E}+01$ & 1.0168 & 0.0008 \\
BNWL2129T4-16 & 0.9237 & 7.37 & 10.92 & $5.24 \mathrm{E}+00$ & 1.0178 & 0.0006
\end{tabular}


Table 10 (continued)

\begin{tabular}{ccccccc}
\hline Experiment & $c_{k}$ & $\mathrm{H} /(\mathrm{Pu}+\mathrm{U})$ & $\mathrm{Wt} \%{ }^{240} \mathrm{Pu}$ & $\mathrm{EALF}(\mathrm{eV})$ & $k_{\text {eff }}$ & $\sigma$ \\
\hline BNWL2129T4-07 & 0.9230 & 7.57 & 10.89 & $4.91 \mathrm{E}+00$ & 1.0165 & 0.0005 \\
BNWL2129T4-15 & 0.9224 & 7.51 & 10.9 & $5.08 \mathrm{E}+00$ & 1.0161 & 0.0005 \\
PCM002-21 & 0.9198 & 15 & 2.2 & $6.64 \mathrm{E}+00$ & 1.0101 & 0.0006 \\
BNWL2129T4-17 & 0.9193 & 7.68 & 10.88 & $4.28 \mathrm{E}+00$ & 1.0172 & 0.0005 \\
PCM002-22 & 0.9182 & 15 & 2.2 & $6.45 \mathrm{E}+00$ & 1.0143 & 0.0007 \\
PCM002-20 & 0.9176 & 15 & 2.2 & $6.65 \mathrm{E}+00$ & 1.0087 & 0.0005 \\
PCM002-18 & 0.9164 & 15 & 2.2 & $6.19 \mathrm{E}+00$ & 1.0102 & 0.0006 \\
PCM002-19 & 0.9149 & 15 & 2.2 & $6.47 \mathrm{E}+00$ & 1.0088 & 0.0006 \\
PCM002-17 & 0.9108 & 15 & 2.2 & $4.93 \mathrm{E}+00$ & 1.0073 & 0.0007 \\
BNWL2129T4-19 & 0.9068 & 7.79 & 10.87 & $4.05 \mathrm{E}+00$ & 1.0181 & 0.0006 \\
BNWL2129T4-12 & 0.9054 & 8.09 & 10.83 & $3.84 \mathrm{E}+00$ & 1.02 & 0.0005 \\
PCM002-15 & 0.9053 & 15 & 2.2 & $5.56 \mathrm{E}+00$ & 1.0283 & 0.0006 \\
PCM002-14 & 0.9045 & 15 & 2.2 & $5.60 \mathrm{E}+00$ & 1.0295 & 0.0006 \\
BNWL2129T4-10 & 0.9043 & 7.72 & 10.88 & $5.24 \mathrm{E}+00$ & 1.0159 & 0.0006 \\
PCM002-16 & 0.9023 & 15 & 2.2 & $5.15 \mathrm{E}+00$ & 1.0235 & 0.0007 \\
PCM002-12 & 0.9005 & 15 & 2.2 & $5.13 \mathrm{E}+00$ & 1.0273 & 0.0006 \\
PCM002-10 & 0.8984 & 15 & 2.2 & $4.14 \mathrm{E}+00$ & 1.0306 & 0.0006 \\
PCM002-11 & 0.8977 & 15 & 2.2 & $4.55 \mathrm{E}+00$ & 1.028 & 0.0006 \\
BNWL2129T4-03 & 0.8947 & 8.08 & 10.83 & $3.44 \mathrm{E}+00$ & 1.018 & 0.0007 \\
BNWL2129T4-18 & 0.8921 & 7.91 & 10.85 & $3.58 \mathrm{E}+00$ & 1.0171 & 0.0005 \\
BNWL2129T4-05 & 0.8824 & 8.29 & 10.8 & $3.22 \mathrm{E}+00$ & 1.0183 & 0.0006 \\
BNWL2129T4-11 & 0.8648 & 8.52 & 10.77 & $3.48 \mathrm{E}+00$ & 1.0166 & 0.0005 \\
BNWL2129T4-08 & 0.8640 & 8.71 & 10.75 & $2.40 \mathrm{E}+00$ & 1.0186 & 0.0005 \\
BNWL2129T4-13 & 0.8549 & 8.79 & 10.74 & $2.47 \mathrm{E}+00$ & 1.0214 & 0.0007 \\
PCI001-01 & 0.8493 & 0.37 & 5.3 & $3.08 \mathrm{E}+02$ & 0.9988 & 0.0001 \\
PCM002-13 & 0.8454 & 15 & 2.2 & $5.46 \mathrm{E}+00$ & 1.0256 & 0.0006 \\
BNWL2129T4-06 & 0.8410 & 8.81 & 10.74 & $2.24 \mathrm{E}+00$ & 1.018 & 0.0005 \\
MCT001-01 & 0.8112 & 3.3346 & 11.5414 & $1.61 \mathrm{E}-03$ & 1.0022 & 0.0005 \\
\hline Bench & & & &
\end{tabular}

*Benchmark experiment identified by DCS as applicable to AOA 4. 
Table 11. Experimental configurations with $c_{k}$ coefficients $\geq 0.8$ for AOA 4-2

\begin{tabular}{|c|c|c|c|c|c|c|}
\hline Experiment & $c_{k}$ & $\mathrm{H} /(\mathrm{Pu}+\mathrm{U})$ & $\mathrm{Wt} \%{ }^{240} \mathrm{Pu}$ & EALF $(\mathrm{eV})$ & $k_{e f f}$ & $\sigma$ \\
\hline NSE55T5-07 & 0.9371 & 2.8 & 11.5 & $4.39 \mathrm{E}+01$ & 1.0042 & 0.0005 \\
\hline NSE55T5-04 & 0.9356 & 2.8 & 11.5 & $4.10 \mathrm{E}+01$ & 1.0048 & 0.0005 \\
\hline NSE55T5-06 & 0.9354 & 2.8 & 11.5 & $4.14 \mathrm{E}+01$ & 1.0045 & 0.0005 \\
\hline NSE55T5-05 & 0.9350 & 2.8 & 11.5 & $4.03 \mathrm{E}+01$ & 1.002 & 0.0005 \\
\hline NSE55T5-01 & 0.9345 & 2.8 & 11.5 & $3.97 \mathrm{E}+01$ & 1.0058 & 0.0005 \\
\hline PU-29-3* & 0.9342 & 2.77 & 11.5 & $4.07 \mathrm{E}+01$ & 1.0022 & 0.0005 \\
\hline NSE55T5-03 & 0.9341 & 2.8 & 11.5 & $4.00 \mathrm{E}+01$ & 1.0049 & 0.0005 \\
\hline PU-29-1* & 0.9340 & 2.77 & 11.5 & $4.14 \mathrm{E}+01$ & 0.9941 & 0.0003 \\
\hline PU-29-2* & 0.9339 & 2.77 & 11.5 & $4.03 \mathrm{E}+01$ & 0.9931 & 0.0005 \\
\hline NSE55T5-10 & 0.9336 & 2.8 & 11.5 & $3.85 \mathrm{E}+01$ & 1.0036 & 0.0004 \\
\hline NSE55T5-02 & 0.9334 & 2.8 & 11.5 & $3.97 \mathrm{E}+01$ & 1.0028 & 0.0005 \\
\hline NSE55T5-08 & 0.9334 & 2.8 & 11.5 & $3.93 \mathrm{E}+01$ & 1.0026 & 0.0006 \\
\hline PU-29-4* & 0.9324 & 2.77 & 11.5 & $3.78 \mathrm{E}+01$ & 0.9932 & 0.0004 \\
\hline PU-29-5* & 0.9322 & 2.77 & 11.5 & $3.77 \mathrm{E}+01$ & 0.9937 & 0.0003 \\
\hline PU-29-8* & 0.9311 & 2.77 & 11.5 & $3.44 \mathrm{E}+01$ & 0.9951 & 0.0005 \\
\hline NSE55T5-09 & 0.9305 & 2.8 & 11.5 & $3.88 \mathrm{E}+01$ & 1.0023 & 0.0005 \\
\hline PU-29-7* & 0.9303 & 2.77 & 11.5 & $3.48 \mathrm{E}+01$ & 0.9944 & 0.0005 \\
\hline PU-29-6* & 0.9299 & 2.77 & 11.5 & $3.67 \mathrm{E}+01$ & 0.9931 & 0.0003 \\
\hline PU-29-9* & 0.9298 & 2.77 & 11.5 & $3.46 \mathrm{E}+01$ & 0.9987 & 0.0005 \\
\hline PU-15-1* & 0.9086 & 2.86 & 11.5 & $1.51 \mathrm{E}+01$ & 0.9811 & 0.0003 \\
\hline PCM001-02 & 0.8974 & 5 & 11.46 & $1.73 \mathrm{E}+03$ & 1.0198 & 0.0007 \\
\hline PCM002-07 & 0.8955 & 5 & 11.46 & $8.49 \mathrm{E}+01$ & 1.022 & 0.0006 \\
\hline PCM002-06 & 0.8898 & 5 & 11.46 & $9.25 \mathrm{E}+01$ & 1.0234 & 0.0006 \\
\hline PCM002-09 & 0.8841 & 5 & 11.46 & $5.68 \mathrm{E}+01$ & 1.0218 & 0.0005 \\
\hline PCM002-08 & 0.8828 & 5 & 11.46 & $6.80 \mathrm{E}+01$ & 1.0212 & 0.0006 \\
\hline PCM001-04 & 0.8784 & 15 & 8.06 & $3.95 \mathrm{E}+01$ & 0.9878 & 0.0007 \\
\hline BNWL2129T4-01 & 0.8651 & 7.13 & 10.95 & $6.13 \mathrm{E}+00$ & 1.0184 & 0.0006 \\
\hline PCM001-03 & 0.8615 & 15 & 2.2 & $3.26 \mathrm{E}+01$ & 1.0168 & 0.0008 \\
\hline BNWL2129T4-02 & 0.8557 & 7.64 & 10.89 & $4.51 \mathrm{E}+00$ & 1.0178 & 0.0006 \\
\hline BNWL2129T4-09 & 0.8543 & 7.39 & 10.92 & $5.78 \mathrm{E}+00$ & 1.0187 & 0.0006 \\
\hline BNWL2129T4-04 & 0.8532 & 7.51 & 10.9 & $5.08 \mathrm{E}+00$ & 1.0182 & 0.0005 \\
\hline
\end{tabular}


Table 11 (continued)

\begin{tabular}{ccccccc}
\hline Experiment & $c_{k}$ & $\mathrm{H} /(\mathrm{Pu}+\mathrm{U})$ & $\mathrm{Wt} \%{ }^{240} \mathrm{Pu}$ & $\mathrm{EALF}(\mathrm{eV})$ & $k_{\text {eff }}$ & $\sigma$ \\
\hline BNWL2129T4-07 & 0.8509 & 7.57 & 10.89 & $4.91 \mathrm{E}+00$ & 1.0165 & 0.0005 \\
BNWL2129T4-16 & 0.8508 & 7.37 & 10.92 & $5.24 \mathrm{E}+00$ & 1.0178 & 0.0006 \\
BNWL2129T4-15 & 0.8505 & 7.51 & 10.9 & $5.08 \mathrm{E}+00$ & 1.0161 & 0.0005 \\
BNWL2129T4-17 & 0.8452 & 7.68 & 10.88 & $4.28 \mathrm{E}+00$ & 1.0172 & 0.0005 \\
PCM002-21 & 0.8452 & 15 & 2.2 & $6.64 \mathrm{E}+00$ & 1.0101 & 0.0006 \\
PCM002-22 & 0.8415 & 15 & 2.2 & $6.45 \mathrm{E}+00$ & 1.0143 & 0.0007 \\
PCM002-20 & 0.8403 & 15 & 2.2 & $6.65 \mathrm{E}+00$ & 1.0087 & 0.0005 \\
PCI001-01 & 0.8388 & 0.37 & 5.3 & $3.08 \mathrm{E}+02$ & 0.9988 & 0.0001 \\
PCM002-18 & 0.8387 & 15 & 2.2 & $6.19 \mathrm{E}+00$ & 1.0102 & 0.0006 \\
PCM002-19 & 0.8375 & 15 & 2.2 & $6.47 \mathrm{E}+00$ & 1.0088 & 0.0006 \\
BNWL2129T4-10 & 0.8353 & 7.72 & 10.88 & $5.24 \mathrm{E}+00$ & 1.0159 & 0.0006 \\
PCM002-17 & 0.8315 & 15 & 2.2 & $4.93 \mathrm{E}+00$ & 1.0073 & 0.0007 \\
BNWL2129T4-19 & 0.8287 & 7.79 & 10.87 & $4.05 \mathrm{E}+00$ & 1.0181 & 0.0006 \\
BNWL2129T4-12 & 0.8282 & 8.09 & 10.83 & $3.84 \mathrm{E}+00$ & 1.02 & 0.0005 \\
PCM002-14 & 0.8251 & 15 & 2.2 & $5.60 \mathrm{E}+00$ & 1.0295 & 0.0006 \\
PCM002-15 & 0.8250 & 15 & 2.2 & $5.56 \mathrm{E}+00$ & 1.0283 & 0.0006 \\
PCM002-16 & 0.8221 & 15 & 2.2 & $5.15 \mathrm{E}+00$ & 1.0235 & 0.0007 \\
PCM002-12 & 0.8203 & 15 & 2.2 & $5.13 \mathrm{E}+00$ & 1.0273 & 0.0006 \\
BNWL2129T4-03 & 0.8173 & 8.08 & 10.83 & $3.44 \mathrm{E}+00$ & 1.018 & 0.0007 \\
PCM002-10 & 0.8173 & 15 & 2.2 & $4.14 \mathrm{E}+00$ & 1.0306 & 0.0006 \\
PCM002-11 & 0.8165 & 15 & 2.2 & $4.55 \mathrm{E}+00$ & 1.028 & 0.0006 \\
BNWL2129T4-18 & 0.8131 & 7.91 & 10.85 & $3.58 \mathrm{E}+00$ & 1.0171 & 0.0005 \\
\hline BNWL2129T4-05 & 0.8016 & 8.29 & 10.8 & $3.22 \mathrm{E}+00$ & 1.0183 & 0.0006 \\
\hline
\end{tabular}

*Benchmark experiment identified by DCS as applicable to AOA 4. 
Table 12. Experimental configurations with $c_{k}$ coefficients $\geq 0.8$ for AOA 4-3

\begin{tabular}{|c|c|c|c|c|c|c|}
\hline Experiment & $c_{k}$ & $\mathrm{H} /(\mathrm{Pu}+\mathrm{U})$ & $\mathrm{Wt} \%{ }^{240} \mathrm{Pu}$ & EALF $(\mathrm{eV})$ & $k_{e f f}$ & $\sigma$ \\
\hline PU-15-1* & 0.9036 & 2.86 & 11.5 & $1.51 \mathrm{E}+01$ & 0.9811 & 0.0003 \\
\hline BNWL2129T4-10 & 0.8482 & 7.72 & 10.88 & $5.24 \mathrm{E}+00$ & 1.0159 & 0.0006 \\
\hline BNWL2129T4-09 & 0.8468 & 7.39 & 10.92 & $5.78 \mathrm{E}+00$ & 1.0187 & 0.0006 \\
\hline NSE55T5-07 & 0.8442 & 2.8 & 11.5 & $4.39 \mathrm{E}+01$ & 1.0042 & 0.0005 \\
\hline BNWL2129T4-01 & 0.8441 & 7.13 & 10.95 & $6.13 \mathrm{E}+00$ & 1.0184 & 0.0006 \\
\hline NSE55T5-10 & 0.8432 & 2.8 & 11.5 & $3.85 \mathrm{E}+01$ & 1.0036 & 0.0004 \\
\hline PU-29-7* & 0.8425 & 2.77 & 11.5 & $3.48 \mathrm{E}+01$ & 0.9944 & 0.0005 \\
\hline NSE55T5-01 & 0.8423 & 2.8 & 11.5 & $3.97 \mathrm{E}+01$ & 1.0058 & 0.0005 \\
\hline NSE55T5-02 & 0.8422 & 2.8 & 11.5 & $3.97 \mathrm{E}+01$ & 1.0028 & 0.0005 \\
\hline NSE55T5-04 & 0.8419 & 2.8 & 11.5 & $4.10 \mathrm{E}+01$ & 1.0048 & 0.0005 \\
\hline NSE55T5-05 & 0.8417 & 2.8 & 11.5 & $4.03 \mathrm{E}+01$ & 1.002 & 0.0005 \\
\hline NSE55T5-03 & 0.8416 & 2.8 & 11.5 & $4.00 \mathrm{E}+01$ & 1.0049 & 0.0005 \\
\hline PU-29-3* & 0.8416 & 2.77 & 11.5 & $4.07 \mathrm{E}+01$ & 1.0022 & 0.0005 \\
\hline PU-29-4* & 0.8416 & 2.77 & 11.5 & $3.78 \mathrm{E}+01$ & 0.9932 & 0.0004 \\
\hline BNWL2129T4-02 & 0.8414 & 7.64 & 10.89 & $4.51 \mathrm{E}+00$ & 1.0178 & 0.0006 \\
\hline PU-29-8* & 0.8414 & 2.77 & 11.5 & $3.44 \mathrm{E}+01$ & 0.9951 & 0.0005 \\
\hline PU-29-9* & 0.8413 & 2.77 & 11.5 & $3.46 \mathrm{E}+01$ & 0.9987 & 0.0005 \\
\hline PU-29-1* & 0.8408 & 2.77 & 11.5 & $4.14 \mathrm{E}+01$ & 0.9941 & 0.0003 \\
\hline BNWL2129T4-11 & 0.8407 & 8.52 & 10.77 & $3.48 \mathrm{E}+00$ & 1.0166 & 0.0005 \\
\hline BNWL2129T4-16 & 0.8405 & 7.37 & 10.92 & $5.24 \mathrm{E}+00$ & 1.0178 & 0.0006 \\
\hline NSE55T5-06 & 0.8405 & 2.8 & 11.5 & $4.14 \mathrm{E}+01$ & 1.0045 & 0.0005 \\
\hline PU-29-5* & 0.8405 & 2.77 & 11.5 & $3.77 \mathrm{E}+01$ & 0.9937 & 0.0003 \\
\hline PU-29-6* & 0.8405 & 2.77 & 11.5 & $3.67 \mathrm{E}+01$ & 0.9931 & 0.0003 \\
\hline PU-29-2* & 0.8404 & 2.77 & 11.5 & $4.03 \mathrm{E}+01$ & 0.9931 & 0.0005 \\
\hline BNWL2129T4-04 & 0.8402 & 7.51 & 10.9 & $5.08 \mathrm{E}+00$ & 1.0182 & 0.0005 \\
\hline BNWL2129T4-15 & 0.8402 & 7.51 & 10.9 & $5.08 \mathrm{E}+00$ & 1.0161 & 0.0005 \\
\hline NSE55T5-08 & 0.8399 & 2.8 & 11.5 & $3.93 \mathrm{E}+01$ & 1.0026 & 0.0006 \\
\hline BNWL2129T4-07 & 0.8391 & 7.57 & 10.89 & $4.91 \mathrm{E}+00$ & 1.0165 & 0.0005 \\
\hline BNWL2129T4-17 & 0.8377 & 7.68 & 10.88 & $4.28 \mathrm{E}+00$ & 1.0172 & 0.0005 \\
\hline NSE55T5-09 & 0.8359 & 2.8 & 11.5 & $3.88 \mathrm{E}+01$ & 1.0023 & 0.0005 \\
\hline BNWL2129T4-19 & 0.8347 & 7.79 & 10.87 & $4.05 \mathrm{E}+00$ & 1.0181 & 0.0006 \\
\hline
\end{tabular}


Table 12 (continued)

\begin{tabular}{ccccccc}
\hline Experiment & $c_{k}$ & $\mathrm{H} /(\mathrm{Pu}+\mathrm{U})$ & $\mathrm{Wt} \%{ }^{240} \mathrm{Pu}$ & $\mathrm{EALF}(\mathrm{eV})$ & \multicolumn{1}{c}{$k_{\text {eff }}$} & $\sigma$ \\
\hline BNWL2129T4-12 & 0.8340 & 8.09 & 10.83 & $3.84 \mathrm{E}+00$ & 1.02 & 0.0005 \\
BNWL2129T4-03 & 0.8313 & 8.08 & 10.83 & $3.44 \mathrm{E}+00$ & 1.018 & 0.0007 \\
BNWL2129T4-18 & 0.8283 & 7.91 & 10.85 & $3.58 \mathrm{E}+00$ & 1.0171 & 0.0005 \\
BNWL2129T4-05 & 0.8244 & 8.29 & 10.8 & $3.22 \mathrm{E}+00$ & 1.0183 & 0.0006 \\
MCT002-02 & 0.8233 & 1.1946 & 7.7593 & $7.73 \mathrm{E}-01$ & 0.9958 & 0.0006 \\
MCT009-01 & 0.8189 & 1.4103 & 7.8651 & $5.52 \mathrm{E}-01$ & 0.9945 & 0.0005 \\
BNWL2129T4-08 & 0.8181 & 8.71 & 10.75 & $2.40 \mathrm{E}+00$ & 1.0186 & 0.0005 \\
PU-8-3* & 0.8180 & 7.33 & 11.5 & $6.38 \mathrm{E}-01$ & 1.0059 & 0.0006 \\
PU-8-4* & 0.8180 & 7.33 & 11.5 & $6.30 \mathrm{E}-01$ & 1.0053 & 0.0006 \\
PU-8-2* & 0.8179 & 7.33 & 11.5 & $6.41 \mathrm{E}-01$ & 1.0036 & 0.0005 \\
PU-8-1* & 0.8178 & 7.33 & 11.5 & $6.45 \mathrm{E}-01$ & 1.005 & 0.0006 \\
BNWL2129T4-13 & 0.8104 & 8.79 & 10.74 & $2.47 \mathrm{E}+00$ & 1.0214 & 0.0007 \\
BNWL2129T4-06 & 0.8055 & 8.81 & 10.74 & $2.24 \mathrm{E}+00$ & 1.018 & 0.0005 \\
MCT002-01 & 0.8032 & 1.1946 & 7.7593 & $5.79 \mathrm{E}-01$ & 0.9934 & 0.0006 \\
\hline
\end{tabular}

*Benchmark experiment identified by DCS as applicable to AOA 4 
Table 13. Experimental configurations with $c_{k}$ coefficients $\geq 0.7$ for AOA 4-4

\begin{tabular}{|c|c|c|c|c|c|c|}
\hline Experiment & $c_{k}$ & $\mathrm{H} /(\mathrm{Pu}+\mathrm{U})$ & $\mathrm{Wt} \%{ }^{240} \mathrm{Pu}$ & EALF $(\mathrm{eV})$ & $k_{e f f}$ & $\sigma$ \\
\hline NSE55T5-04 & 0.7420 & 2.8 & 11.5 & $4.10 \mathrm{E}+01$ & 1.0048 & 0.0005 \\
\hline PU-15-1* & 0.7420 & 2.86 & 11.5 & $1.51 \mathrm{E}+01$ & 0.9811 & 0.0003 \\
\hline NSE55T5-03 & 0.7388 & 2.8 & 11.5 & $4.00 \mathrm{E}+01$ & 1.0049 & 0.0005 \\
\hline NSE55T5-05 & 0.7372 & 2.8 & 11.5 & $4.03 \mathrm{E}+01$ & 1.002 & 0.0005 \\
\hline NSE55T5-07 & 0.7363 & 2.8 & 11.5 & $4.39 \mathrm{E}+01$ & 1.0042 & 0.0005 \\
\hline NSE55T5-01 & 0.7358 & 2.8 & 11.5 & $3.97 \mathrm{E}+01$ & 1.0058 & 0.0005 \\
\hline NSE55T5-08 & 0.7357 & 2.8 & 11.5 & $3.93 \mathrm{E}+01$ & 1.0026 & 0.0006 \\
\hline NSE55T5-06 & 0.7354 & 2.8 & 11.5 & 4.14E+01 & 1.0045 & 0.0005 \\
\hline NSE55T5-02 & 0.7349 & 2.8 & 11.5 & $3.97 \mathrm{E}+01$ & 1.0028 & 0.0005 \\
\hline NSE55T5-09 & 0.7332 & 2.8 & 11.5 & $3.88 \mathrm{E}+01$ & 1.0023 & 0.0005 \\
\hline PU-29-3* & 0.7330 & 2.77 & 11.5 & $4.07 \mathrm{E}+01$ & 1.0022 & 0.0005 \\
\hline PU-29-8* & 0.7330 & 2.77 & 11.5 & $3.44 \mathrm{E}+01$ & 0.9951 & 0.0005 \\
\hline PU-29-9* & 0.7325 & 2.77 & 11.5 & $3.46 \mathrm{E}+01$ & 0.9987 & 0.0005 \\
\hline NSE55T5-10 & 0.7316 & 2.8 & 11.5 & $3.85 \mathrm{E}+01$ & 1.0036 & 0.0004 \\
\hline PU-29-6* & 0.7311 & 2.77 & 11.5 & $3.67 \mathrm{E}+01$ & 0.9931 & 0.0003 \\
\hline PU-29-4* & 0.7306 & 2.77 & 11.5 & $3.78 \mathrm{E}+01$ & 0.9932 & 0.0004 \\
\hline PU-29-5* & 0.7306 & 2.77 & 11.5 & $3.77 \mathrm{E}+01$ & 0.9937 & 0.0003 \\
\hline PU-29-7* & 0.7305 & 2.77 & 11.5 & $3.48 \mathrm{E}+01$ & 0.9944 & 0.0005 \\
\hline PU-29-1* & 0.7303 & 2.77 & 11.5 & $4.14 \mathrm{E}+01$ & 0.9941 & 0.0003 \\
\hline PU-29-2* & 0.7293 & 2.77 & 11.5 & $4.03 \mathrm{E}+01$ & 0.9931 & 0.0005 \\
\hline
\end{tabular}

*Benchmark experiment identified by DCS as applicable to AOA 4. 
Table 14. Experimental configurations with $c_{k}$ coefficients $\geq 0.7$ for AOA 4-4-P163

\begin{tabular}{|c|c|c|c|c|c|c|}
\hline Experiment & $c_{k}$ & $\mathrm{H} /(\mathrm{Pu}+\mathrm{U})$ & $\mathrm{Wt} \%{ }^{240} \mathrm{Pu}$ & EALF $(\mathrm{eV})$ & $k_{\text {eff }}$ & $\sigma$ \\
\hline NSE55T5-04 & 0.7718 & 2.8 & 11.5 & $4.10 \mathrm{E}+01$ & 1.0048 & 0.0005 \\
\hline PU-15-1* & 0.7714 & 2.86 & 11.5 & $1.51 \mathrm{E}+01$ & 0.9811 & 0.0003 \\
\hline NSE55T5-03 & 0.7689 & 2.8 & 11.5 & $4.00 \mathrm{E}+01$ & 1.0049 & 0.0005 \\
\hline NSE55T5-05 & 0.7676 & 2.8 & 11.5 & $4.03 \mathrm{E}+01$ & 1.002 & 0.0005 \\
\hline NSE55T5-07 & 0.7663 & 2.8 & 11.5 & $4.39 \mathrm{E}+01$ & 1.0042 & 0.0005 \\
\hline NSE55T5-01 & 0.7662 & 2.8 & 11.5 & $3.97 \mathrm{E}+01$ & 1.0058 & 0.0005 \\
\hline NSE55T5-08 & 0.7661 & 2.8 & 11.5 & $3.93 \mathrm{E}+01$ & 1.0026 & 0.0006 \\
\hline NSE55T5-06 & 0.7659 & 2.8 & 11.5 & $4.14 \mathrm{E}+01$ & 1.0045 & 0.0005 \\
\hline NSE55T5-02 & 0.7654 & 2.8 & 11.5 & $3.97 \mathrm{E}+01$ & 1.0028 & 0.0005 \\
\hline NSE55T5-09 & 0.7643 & 2.8 & 11.5 & $3.88 \mathrm{E}+01$ & 1.0023 & 0.0005 \\
\hline PU-29-3* & 0.7639 & 2.77 & 11.5 & $4.07 \mathrm{E}+01$ & 1.0022 & 0.0005 \\
\hline PU-29-8* & 0.7638 & 2.77 & 11.5 & $3.44 \mathrm{E}+01$ & 0.9951 & 0.0005 \\
\hline PU-29-9* & 0.7633 & 2.77 & 11.5 & $3.46 \mathrm{E}+01$ & 0.9987 & 0.0005 \\
\hline NSE55T5-10 & 0.7622 & 2.8 & 11.5 & $3.85 \mathrm{E}+01$ & 1.0036 & 0.0004 \\
\hline PU-29-6* & 0.7622 & 2.77 & 11.5 & $3.67 \mathrm{E}+01$ & 0.9931 & 0.0003 \\
\hline PU-29-5* & 0.7617 & 2.77 & 11.5 & $3.77 \mathrm{E}+01$ & 0.9937 & 0.0003 \\
\hline PU-29-4* & 0.7616 & 2.77 & 11.5 & $3.78 \mathrm{E}+01$ & 0.9932 & 0.0004 \\
\hline PU-29-1* & 0.7615 & 2.77 & 11.5 & $4.14 \mathrm{E}+01$ & 0.9941 & 0.0003 \\
\hline PU-29-7* & 0.7615 & 2.77 & 11.5 & $3.48 \mathrm{E}+01$ & 0.9944 & 0.0005 \\
\hline PU-29-2* & 0.7605 & 2.77 & 11.5 & $4.03 \mathrm{E}+01$ & 0.9931 & 0.0005 \\
\hline PCM002-09 & 0.7132 & 5 & 11.46 & $5.68 \mathrm{E}+01$ & 1.0218 & 0.0005 \\
\hline PCM001-02 & 0.7114 & 5 & 11.46 & $1.73 \mathrm{E}+03$ & 1.0198 & 0.0007 \\
\hline PCM002-06 & 0.7082 & 5 & 11.46 & $9.25 \mathrm{E}+01$ & 1.0234 & 0.0006 \\
\hline BNWL2129T4-01 & 0.7017 & 7.13 & 10.95 & $6.13 \mathrm{E}+00$ & 1.0184 & 0.0006 \\
\hline PCM002-07 & 0.7016 & 5 & 11.46 & $8.49 \mathrm{E}+01$ & 1.022 & 0.0006 \\
\hline РСM002-08 & 0.7008 & 5 & 11.46 & $6.80 \mathrm{E}+01$ & 1.0212 & 0.0006 \\
\hline BNWL2129T4-02 & 0.7006 & 7.64 & 10.89 & $4.51 \mathrm{E}+00$ & 1.0178 & 0.0006 \\
\hline PCI001-01 & 0.7001 & 0.37 & 5.3 & $3.08 \mathrm{E}+02$ & 0.9988 & 0.0001 \\
\hline
\end{tabular}

*Benchmark experiment identified by DCS as applicable to AOA 4. 
Table 15. Experimental configurations with $c_{k}$ coefficients $\geq 0.8$ for AOA 4-4-P40

\begin{tabular}{ccccccc}
\hline Experiment & $c_{k}$ & $\mathrm{H} /(\mathrm{Pu}+\mathrm{U})$ & $\mathrm{Wt} \%{ }^{240} \mathrm{Pu}$ & $\mathrm{EALF}(\mathrm{eV})$ & $k_{\text {eff }}$ & $\sigma$ \\
\hline PU-15-1* & 0.8323 & 2.86 & 11.5 & $1.51 \mathrm{E}+01$ & 0.9811 & 0.0003 \\
NSE55T5-04 & 0.8320 & 2.8 & 11.5 & $4.10 \mathrm{E}+01$ & 1.0048 & 0.0005 \\
NSE55T5-03 & 0.8300 & 2.8 & 11.5 & $4.00 \mathrm{E}+01$ & 1.0049 & 0.0005 \\
NSE55T5-05 & 0.8291 & 2.8 & 11.5 & $4.03 \mathrm{E}+01$ & 1.002 & 0.0005 \\
NSE55T5-01 & 0.8278 & 2.8 & 11.5 & $3.97 \mathrm{E}+01$ & 1.0058 & 0.0005 \\
NSE55T5-08 & 0.8278 & 2.8 & 11.5 & $3.93 \mathrm{E}+01$ & 1.0026 & 0.0006 \\
NSE55T5-02 & 0.8276 & 2.8 & 11.5 & $3.97 \mathrm{E}+01$ & 1.0028 & 0.0005 \\
NSE55T5-09 & 0.8275 & 2.8 & 11.5 & $3.88 \mathrm{E}+01$ & 1.0023 & 0.0005 \\
NSE55T5-06 & 0.8274 & 2.8 & 11.5 & $4.14 \mathrm{E}+01$ & 1.0045 & 0.0005 \\
PU-29-8* & 0.8270 & 2.77 & 11.5 & $3.44 \mathrm{E}+01$ & 0.9951 & 0.0005 \\
NSE55T5-07 & 0.8265 & 2.8 & 11.5 & $4.39 \mathrm{E}+01$ & 1.0042 & 0.0005 \\
PU-29-3* & 0.8265 & 2.77 & 11.5 & $4.07 \mathrm{E}+01$ & 1.0022 & 0.0005 \\
PU-29-9* & 0.8265 & 2.77 & 11.5 & $3.46 \mathrm{E}+01$ & 0.9987 & 0.0005 \\
PU-29-6* & 0.8261 & 2.77 & 11.5 & $3.67 \mathrm{E}+01$ & 0.9931 & 0.0003 \\
PU-29-5* & 0.8253 & 2.77 & 11.5 & $3.77 \mathrm{E}+01$ & 0.9937 & 0.0003 \\
PU-29-4* & 0.8250 & 2.77 & 11.5 & $3.78 \mathrm{E}+01$ & 0.9932 & 0.0004 \\
PU-29-7* & 0.8250 & 2.77 & 11.5 & $3.48 \mathrm{E}+01$ & 0.9944 & 0.0005 \\
PU-29-1* & 0.8249 & 2.77 & 11.5 & $4.14 \mathrm{E}+01$ & 0.9941 & 0.0003 \\
NSE55T5-10 & 0.8244 & 2.8 & 11.5 & $3.85 \mathrm{E}+01$ & 1.0036 & 0.0004 \\
PU-29-2* & 0.8242 & 2.77 & 11.5 & $4.03 \mathrm{E}+01$ & 0.9931 & 0.0005 \\
\hline
\end{tabular}

*Benchmark experiment identified by DCS as applicable to AOA 4. 
Table 16. Experimental configurations with $c_{k}$ coefficients $\geq 0.8$ for AOA 4-4-P8

\begin{tabular}{|c|c|c|c|c|c|c|}
\hline Experiment & $c_{k}$ & $\mathrm{H} /(\mathrm{Pu}+\mathrm{U})$ & $\mathrm{Wt} \%{ }^{240} \mathrm{Pu}$ & EALF $(e V)$ & $k_{e f f}$ & $\sigma$ \\
\hline PU-15-1* & 0.8915 & 2.86 & 11.5 & $1.51 \mathrm{E}+01$ & 0.9811 & 0.0003 \\
\hline PU-29-6* & 0.8883 & 2.77 & 11.5 & $3.67 \mathrm{E}+01$ & 0.9931 & 0.0003 \\
\hline PU-29-8* & 0.8878 & 2.77 & 11.5 & $3.44 \mathrm{E}+01$ & 0.9951 & 0.0005 \\
\hline PU-29-9* & 0.8877 & 2.77 & 11.5 & $3.46 \mathrm{E}+01$ & 0.9987 & 0.0005 \\
\hline NSE55T5-09 & 0.8876 & 2.8 & 11.5 & $3.88 \mathrm{E}+01$ & 1.0023 & 0.0005 \\
\hline PU-29-5* & 0.8867 & 2.77 & 11.5 & $3.77 \mathrm{E}+01$ & 0.9937 & 0.0003 \\
\hline PU-29-7* & 0.8867 & 2.77 & 11.5 & $3.48 \mathrm{E}+01$ & 0.9944 & 0.0005 \\
\hline NSE55T5-04 & 0.8863 & 2.8 & 11.5 & $4.10 \mathrm{E}+01$ & 1.0048 & 0.0005 \\
\hline NSE55T5-03 & 0.8862 & 2.8 & 11.5 & $4.00 \mathrm{E}+01$ & 1.0049 & 0.0005 \\
\hline NSE55T5-02 & 0.8861 & 2.8 & 11.5 & $3.97 \mathrm{E}+01$ & 1.0028 & 0.0005 \\
\hline NSE55T5-05 & 0.8861 & 2.8 & 11.5 & $4.03 \mathrm{E}+01$ & 1.002 & 0.0005 \\
\hline PU-29-4* & 0.8860 & 2.77 & 11.5 & $3.78 \mathrm{E}+01$ & 0.9932 & 0.0004 \\
\hline PU-29-3* & 0.8858 & 2.77 & 11.5 & $4.07 \mathrm{E}+01$ & 1.0022 & 0.0005 \\
\hline PU-29-1* & 0.8856 & 2.77 & 11.5 & $4.14 \mathrm{E}+01$ & 0.9941 & 0.0003 \\
\hline NSE55T5-08 & 0.8855 & 2.8 & 11.5 & $3.93 \mathrm{E}+01$ & 1.0026 & 0.0006 \\
\hline PU-29-2* & 0.8852 & 2.77 & 11.5 & $4.03 \mathrm{E}+01$ & 0.9931 & 0.0005 \\
\hline NSE55T5-01 & 0.8851 & 2.8 & 11.5 & $3.97 \mathrm{E}+01$ & 1.0058 & 0.0005 \\
\hline NSE55T5-06 & 0.8841 & 2.8 & 11.5 & $4.14 \mathrm{E}+01$ & 1.0045 & 0.0005 \\
\hline NSE55T5-10 & 0.8831 & 2.8 & 11.5 & $3.85 \mathrm{E}+01$ & 1.0036 & 0.0004 \\
\hline NSE55T5-07 & 0.8810 & 2.8 & 11.5 & $4.39 \mathrm{E}+01$ & 1.0042 & 0.0005 \\
\hline BNWL2129T4-10 & 0.8763 & 7.72 & 10.88 & $5.24 \mathrm{E}+00$ & 1.0159 & 0.0006 \\
\hline BNWL2129T4-09 & 0.8760 & 7.39 & 10.92 & $5.78 \mathrm{E}+00$ & 1.0187 & 0.0006 \\
\hline BNWL2129T4-01 & 0.8752 & 7.13 & 10.95 & $6.13 \mathrm{E}+00$ & 1.0184 & 0.0006 \\
\hline BNWL2129T4-07 & 0.8748 & 7.57 & 10.89 & $4.91 \mathrm{E}+00$ & 1.0165 & 0.0005 \\
\hline BNWL2129T4-15 & 0.8742 & 7.51 & 10.9 & $5.08 \mathrm{E}+00$ & 1.0161 & 0.0005 \\
\hline BNWL2129T4-02 & 0.8740 & 7.64 & 10.89 & $4.51 \mathrm{E}+00$ & 1.0178 & 0.0006 \\
\hline BNWL2129T4-04 & 0.8738 & 7.51 & 10.9 & $5.08 \mathrm{E}+00$ & 1.0182 & 0.0005 \\
\hline BNWL2129T4-16 & 0.8724 & 7.37 & 10.92 & $5.24 \mathrm{E}+00$ & 1.0178 & 0.0006 \\
\hline BNWL2129T4-17 & 0.8706 & 7.68 & 10.88 & $4.28 \mathrm{E}+00$ & 1.0172 & 0.0005 \\
\hline BNWL2129T4-12 & 0.8639 & 8.09 & 10.83 & $3.84 \mathrm{E}+00$ & 1.02 & 0.0005 \\
\hline BNWL2129T4-11 & 0.8612 & 8.52 & 10.77 & $3.48 \mathrm{E}+00$ & 1.0166 & 0.0005 \\
\hline
\end{tabular}


Table 16 (continued)

\begin{tabular}{ccccccc}
\hline Experiment & $c_{k}$ & $\mathrm{H} /(\mathrm{Pu}+\mathrm{U})$ & $\mathrm{Wt} \%{ }^{240} \mathrm{Pu}$ & $\mathrm{EALF}(\mathrm{eV})$ & $k_{\text {eff }}$ & $\sigma$ \\
\hline BNWL2129T4-19 & 0.8612 & 7.79 & 10.87 & $4.05 \mathrm{E}+00$ & 1.0181 & 0.0006 \\
BNWL2129T4-03 & 0.8582 & 8.08 & 10.83 & $3.44 \mathrm{E}+00$ & 1.018 & 0.0007 \\
BNWL2129T4-18 & 0.8578 & 7.91 & 10.85 & $3.58 \mathrm{E}+00$ & 1.0171 & 0.0005 \\
BNWL2129T4-05 & 0.8528 & 8.29 & 10.8 & $3.22 \mathrm{E}+00$ & 1.0183 & 0.0006 \\
BNWL2129T4-08 & 0.8450 & 8.71 & 10.75 & $2.40 \mathrm{E}+00$ & 1.0186 & 0.0005 \\
BNWL2129T4-13 & 0.8413 & 8.79 & 10.74 & $2.47 \mathrm{E}+00$ & 1.0214 & 0.0007 \\
PCM002-09 & 0.8406 & 5 & 11.46 & $5.68 \mathrm{E}+01$ & 1.0218 & 0.0005 \\
BNWL2129T4-06 & 0.8281 & 8.81 & 10.74 & $2.24 \mathrm{E}+00$ & 1.018 & 0.0005 \\
PCM002-06 & 0.8217 & 5 & 11.46 & $9.25 \mathrm{E}+01$ & 1.0234 & 0.0006 \\
PCM002-08 & 0.8209 & 5 & 11.46 & $6.80 \mathrm{E}+01$ & 1.0212 & 0.0006 \\
PCM002-13 & 0.8029 & 15 & 2.2 & $5.46 \mathrm{E}+00$ & 1.0256 & 0.0006 \\
PCM002-20 & 0.8026 & 15 & 2.2 & $6.65 \mathrm{E}+00$ & 1.0087 & 0.0005 \\
PCM002-18 & 0.8025 & 15 & 2.2 & $6.19 \mathrm{E}+00$ & 1.0102 & 0.0006 \\
PCM002-17 & 0.8022 & 15 & 2.2 & $4.93 \mathrm{E}+00$ & 1.0073 & 0.0007 \\
PCM002-22 & 0.8010 & 15 & 2.2 & $6.45 \mathrm{E}+00$ & 1.0143 & 0.0007 \\
\hline
\end{tabular}

*Benchmark experiment identified by DCS as applicable to AOA 4. 


\subsubsection{Nuclide-Reaction-Specific Analysis of AOA 4-2}

To gain more understanding of the physics that lead to the high-valued correlation coefficients for design system AOA 4-2 where traditional trending methods might indicate less applicability, a nuclide-reaction-specific sensitivity analysis was performed for two selected benchmark experiments. The two selected experiments are NSE55T4-01 and NSE55T5-04, which exhibit $c_{k}$ values with AOA 4-2 of 0.5273 and 0.9256 , respectively. Pertinent data for each of these systems is shown in Table 17. Note that the EALF values indicate that the average fission distribution is quite different between the design application and the two benchmarks. However, the $\mathrm{H} /(\mathrm{Pu}+\mathrm{U})$ and $\mathrm{Pu} /(\mathrm{Pu}+\mathrm{U})$ ratios are comparable, especially for NSE55T5-04.

Table 17. Properties of systems considered for nuclide-reaction-specific analysis of AOA 4-2

\begin{tabular}{cccc}
\hline & AOA 4-2 & NSE55T4-01 & NSE55T5-04 \\
\hline$c_{k}$ value with AOA 4-2 & 1.0 & 0.5273 & 0.9356 \\
$\mathrm{H} /(\mathrm{Pu}+\mathrm{U})$ & 1.58 & 30.6 & 2.8 \\
$\mathrm{Pu} /(\mathrm{Pu}+\mathrm{U})$ & 0.219 & 0.146 & 0.303 \\
$\mathrm{Wt} \%{ }^{240} \mathrm{Pu}$ & 4 & 7.97 & 11.5 \\
$\mathrm{EALF}(\mathrm{eV})$ & 3751 & 0.143 & 41.0 \\
\hline
\end{tabular}

The $T\left(c_{k}\right)$ values were computed for important reactions for each of these experiments in relation to AOA 4-2. Recall that a $T\left(c_{k}\right)$ value of 1.0 indicates that for the particular nuclidereaction pair considered, the benchmark exhibits the same amount of shared variance as the application. Previous studies have used a criterion of 0.95 for $T$ values to indicate coverage of an application by a benchmark ${ }_{5}^{5}$ The contribution of each reaction to the $c_{k}$ value for the system is related to the magnitude of the sensitivity coefficient for the application. Thus, a system with several high-sensitivity reactions that also have high $T\left(c_{k}\right)$ values would produce a high $c_{k}$ value. The sensitivity coefficients and $T\left(c_{k}\right)$ values for AOA 4-2 are presented in Table 18. 
Table 18. Nuclide-reaction-specific sensitivity data for AOA 4-2 with $T\left(c_{k}\right)$ values for benchmarks NSE55T4-01 and NSE55T5-04

\begin{tabular}{cccc}
\hline & \multirow{2}{*}{$\begin{array}{c}\text { Sensitivity } \\
\text { coefficient }\end{array}$} & \multicolumn{2}{c}{$T\left(c_{k}\right)$} \\
\cline { 3 - 4 } & 0.1463 & NSE55T4-01 & NSE55T5-04 \\
\hline${ }^{1} \mathrm{H}$ scatter & 0.4690 & 0.1640 & 0.9246 \\
${ }^{239} \mathrm{Pu}$ fission & -0.1722 & 0.3105 & 0.9525 \\
${ }^{239} \mathrm{Pu}$ capture & 0.09601 & 0.0794 & 0.9671 \\
${ }^{238} \mathrm{U}$ fission & -0.1834 & 0.3465 & 0.3550 \\
${ }^{238} \mathrm{U}$ capture & 0.09838 & 0.0678 & 0.4850 \\
${ }^{238} \mathrm{U}$ scatter & &
\end{tabular}

Examination of the data in Table 18 provides insight as to why NSE55T5-04 exhibits a high correlation with AOA 4-2, even though the EALF values might indicate otherwise. For the reaction for which AOA 4-2 exhibits the most sensitivity, ${ }^{239} \mathrm{Pu}$ fission, NSE55T5-04 provides adequate coverage, with a $T\left(c_{k}\right)$ value 0.9525 . Two other important reactions, ${ }^{1} \mathrm{H}$ scatter and ${ }^{239} \mathrm{Pu}$ capture are also well covered. Although the ${ }^{238} \mathrm{U}$ reactions are not covered as well, the overall coverage for important nuclides and reactions is adequate to produce a high $c_{k}$ value. In contrast, the $T\left(c_{k}\right)$ values for NSE55T4-01 show that it only provides adequate coverage for ${ }^{1} \mathrm{H}$ scatter. The coverage for ${ }^{239} \mathrm{Pu}$ fission is quite poor, and thus, the $c_{k}$ value produced for this benchmark is much lower.

The properties of NSE55T5-04 that are most likely responsible for the high correlation coefficient with AOA 4-2, even though the EALF values of the systems differ by two orders of magnitude, are the high $\mathrm{Pu} /(\mathrm{Pu}+\mathrm{U})$ ratio and the low $\mathrm{H} /(\mathrm{Pu}+\mathrm{U})$ ratio. Even though the EALF values indicate that the average fission distributions of the two systems are quite different, the benchmark is fueled with enough ${ }^{239} \mathrm{Pu}$ that the sensitivity of $k_{\text {eff }}$ to ${ }^{239} \mathrm{Pu}$ fission has a large enough magnitude at fast energies to provide a high correlation with the design application. The energy-dependent ${ }^{239} \mathrm{Pu}$ fission sensitivity profiles are presented in Fig. 1, which illustrates that, although the sensitivity of NSE55T5-04 is more pronounced in the thermal region, it is still comparable to that of AOA 4-2 though intermediate and fast energies. The highly correlated NSE55T5-04 is contrasted by the poorly correlated NSE55T4-01, whose ${ }^{239} \mathrm{Pu}$ fission sensitivity profile demonstrates the dominance of thermal fission in this system. 


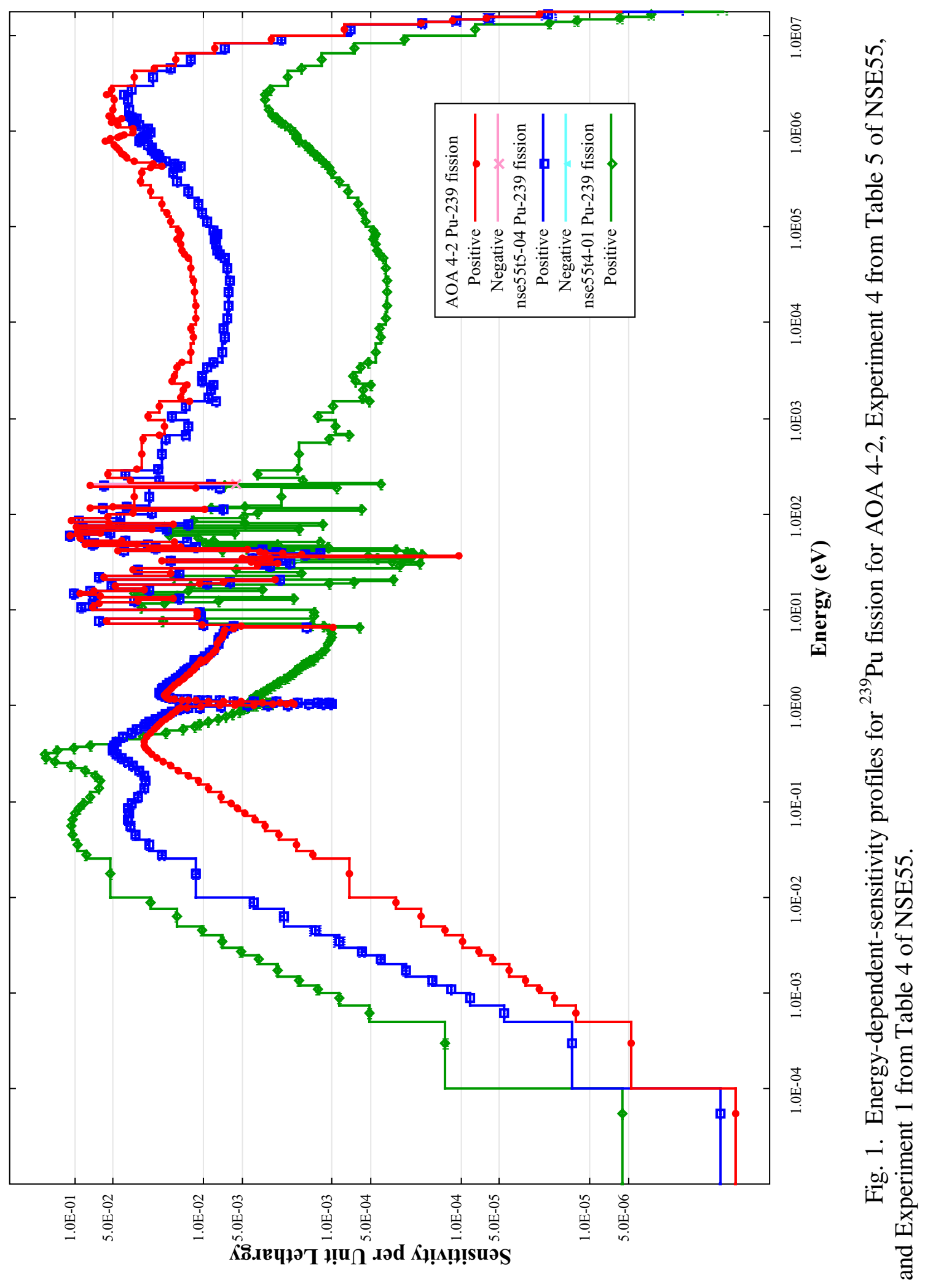




\subsubsection{Analysis of Mass Variations for AOA 4-4}

The variation in the correlation coefficient with system mass for the four cases of AOA 4-4 was further investigated using the nuclide-reaction-specific S/U tools. As noted in Sect. 6.2, the S/U methods found that no benchmark experiments met the 0.8 criterion for $c_{k}$ for the critical configuration, but the correlation coefficients are improved as the mass of the system is reduced. Although the previous section explained how a system with an EALF of nearly $4000 \mathrm{eV}$ could be highly correlated to systems with much lower average spectra, this argument does not apply to the critical configuration of AOA 4-4. The EALF for this system is $2355 \mathrm{eV}$, but the energy-dependent profiles exhibit a higher sensitivity in the fast range for AOA 4-4 than is observed for AOA 4-2. This is shown in Fig. 2. This difference in the profiles, when coupled with the cross-section-covariance data, for all nuclides in the system results in a significantly different correlation coefficient.

Table 19 presents the sensitivity coefficients for important reactions for each system with the corresponding $T\left(c_{k}\right)$ values generated with MOX polystyrene compact benchmark experiment PU-29-1. To further illustrate the differences among these systems, the energy-dependentsensitivity profiles for each of these design systems and benchmark-experiment PU-29-1 are presented below. This data is presented in Fig. 3 for ${ }^{239} \mathrm{Pu}$ fission and in Fig. 4 for ${ }^{238} \mathrm{U}$ capture. Recall that PU-29-1 exhibited $c_{k}$ values of $0.7303,0.7615,0.8249$ and 0.8856 for AOA 4-4, AOA 4-4-P163, AOA 4-4-P40 and AOA 4-4-P8, respectively. An examination of the effects due to the reduction of system mass for each nuclide-reaction pair will be presented here. For ${ }^{1} \mathrm{H}$ scatter, which will mostly occur in the water reflector of this dry system, reducing the mass of fuel in the system places a higher percentage of the fuel in proximity of the reflector, and thus increases the sensitivity of the system to hydrogen in the reflector region. With its increased importance, which is greater than that observed in the benchmark experiment, the coverage of this nuclide is diminished. However, because the cross-section data for ${ }^{1} \mathrm{H}$ scatter is well known, the covariance data has a small magnitude, and its effect on the global $c_{k}$ correlation coefficient is minimized. For ${ }^{239} \mathrm{Pu}$ fission, although the magnitude of the sensitivity coefficient is decreased, the $T\left(c_{k}\right)$ value is somewhat improved for AOA 4-4-P8 and minimally reduced for the other reduced mass cases. Fig. 3 illustrates that ${ }^{239} \mathrm{Pu}$ fission will have a positive contribution to $c_{k}$, as the sensitivity profiles for the reduced mass cases approach that of the benchmark experiment, especially in the fast region. A similar effect is produced for ${ }^{239} \mathrm{Pu}$ capture, although the sensitivity profiles are not shown. For ${ }^{238} \mathrm{U}$ fission, the $T\left(c_{k}\right)$ values are reduced as the sensitivity coefficient increases, similar to the effect seen for ${ }^{1} \mathrm{H}$ scatter. For ${ }^{238} \mathrm{U}$ capture, as the spectrum of the system is shifted towards thermal with reduced mass, the sensitivity to ${ }^{238} \mathrm{U}$ capture is reduced. The $T\left(c_{k}\right)$ value is somewhat improved, but is still quite low. However, this slight improvement in $T\left(c_{k}\right)$, along with the reduction in the magnitude of the sensitivity coefficient, will produce a noticeable increase in $c_{k}$. The trend of the sensitivity profiles towards that of the benchmark experiment, especially in the fast region, is shown in Fig. 4. 


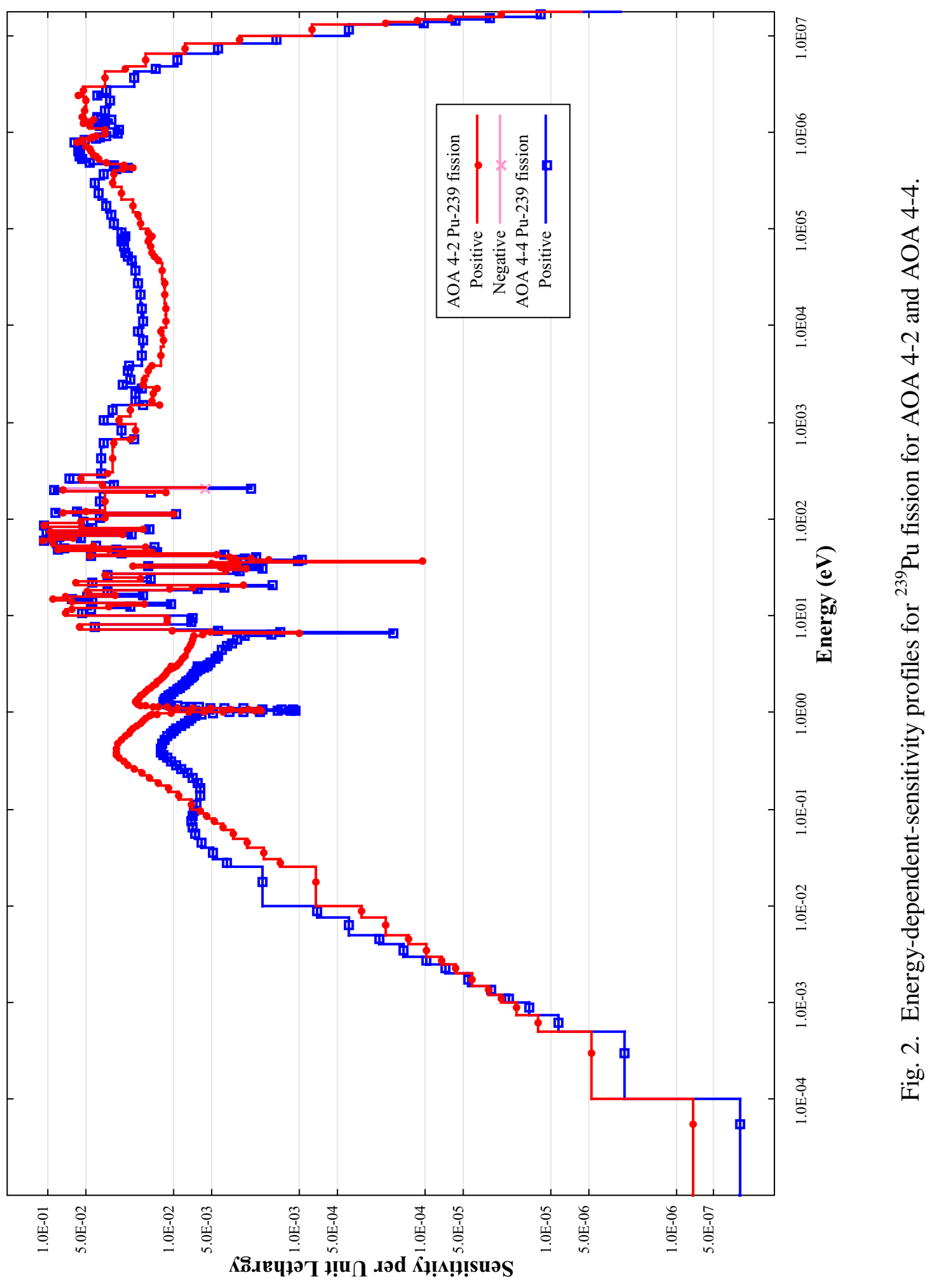




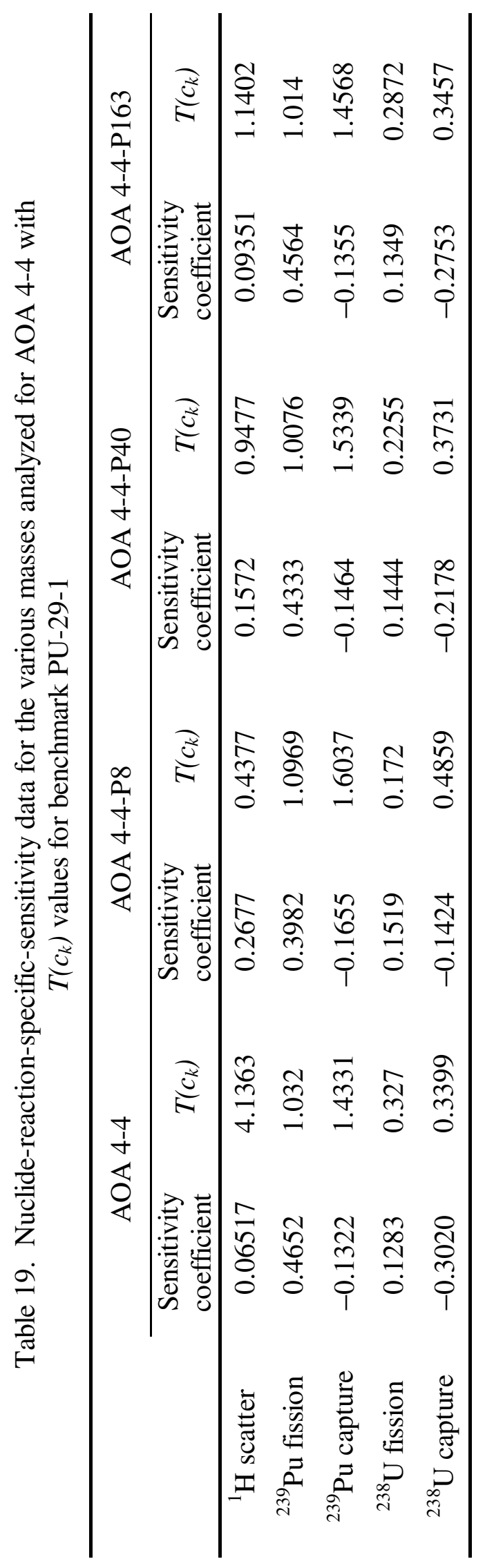




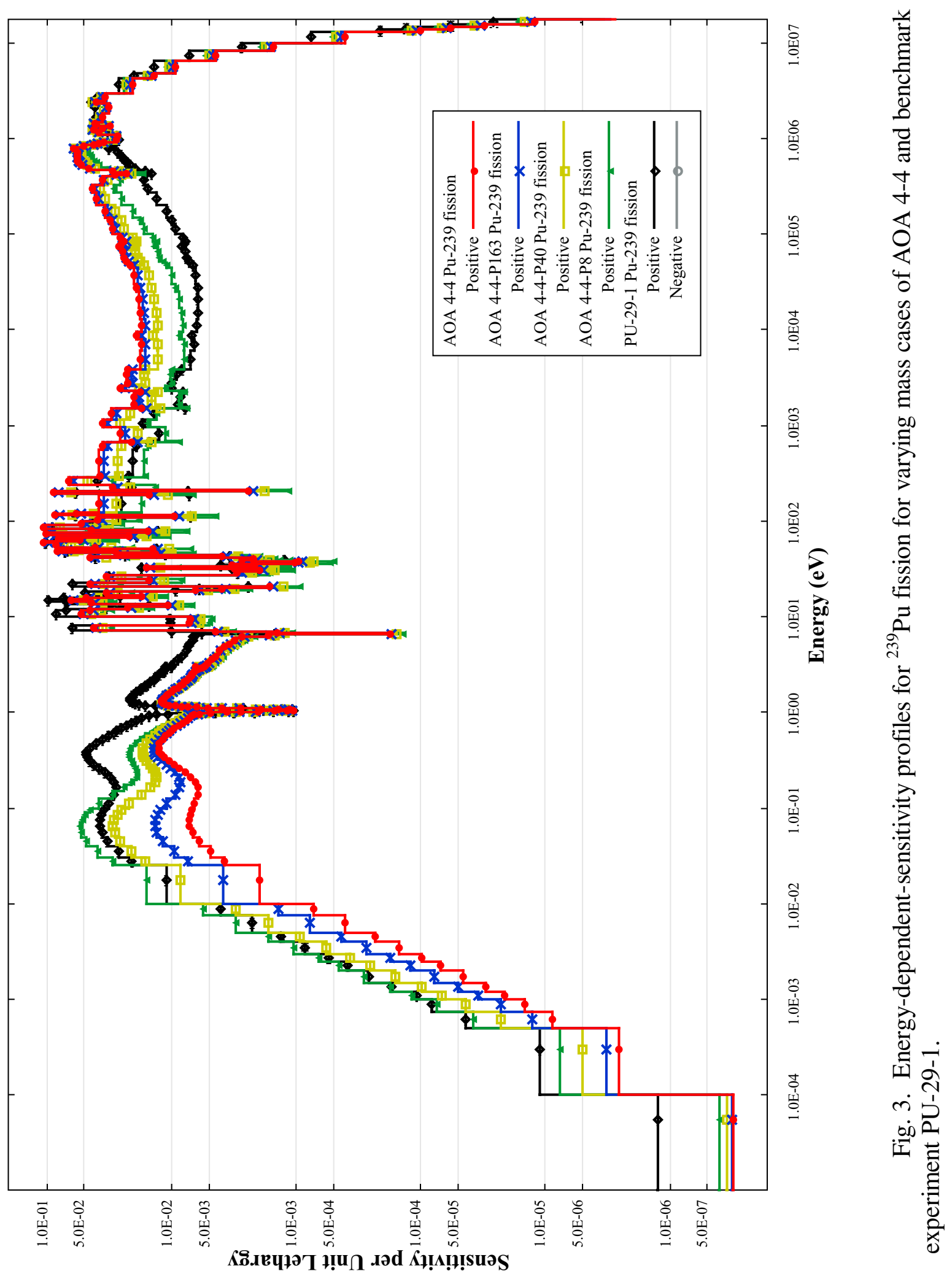




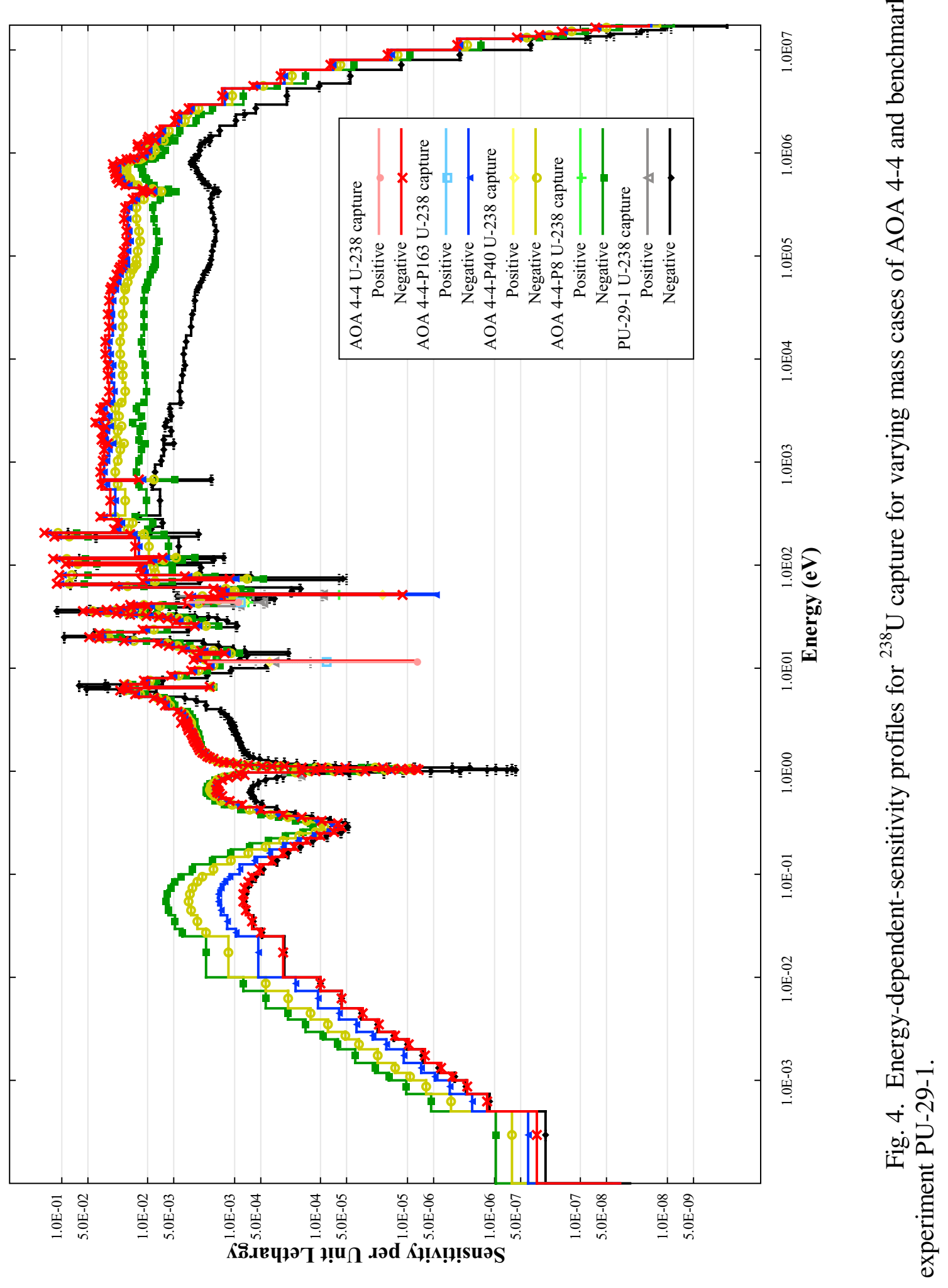


Thus, by reducing the mass of the system from a critical configuration to one that might be encountered by mass-control limits, several marked changes have been realized in the $S / U$ analysis. Most notable is that the resultant changes in the system energy spectrum have reduced the sensitivity of the smaller systems to cross-section data in the fast region. This has produced more similarity between the design applications and the benchmark experiments.

This exercise has demonstrated that the selection of design systems used for validation studies should be carefully considered. The selection of the proper materials for analysis is crucial, but the geometrical limitations should also be given proper consideration.

\subsubsection{Identification of Additional Benchmarks for ${ }^{238} \mathrm{U}$}

Although the large-mass, high-density critical configuration of AOA 4-4 is not likely a realistic system from a facility design perspective, it provides an instructive example for the detailed use of the S/U tools. Further investigations of this system were conducted to identify additional data that might be useful to provide full coverage for this system. It was noted in the previous section that ${ }^{238} \mathrm{U}$ capture and fission reactions do not appear to be well covered for the critical configuration of AOA 4-4. In a search for experiments with similar sensitivities to ${ }^{238} \mathrm{U}$, the dry uranium benchmarks, LEU-COMP-THERM-049, were identified. Although the $c_{k}$ values for AOA 4-4 with these experiments are only in the range of 0.25 , the $T\left(c_{k}\right)$ values for ${ }^{238} \mathrm{U}$ fission are $\sim 0.8$ for some experimental configurations and $T\left(c_{k}\right)$ values for ${ }^{238} \mathrm{U}$ capture are $\sim 1.0$ for all experimental configurations. For the subcritical configuration, AOA 4-4-P8, LEU-COMPTHERM-049 experiments again exhibit $c_{k}$ values of about 0.25 . The $T\left(c_{k}\right)$ values for ${ }^{238} \mathrm{U}$ fission are somewhat lower at about 0.4 , but the $T\left(c_{k}\right)$ values for ${ }^{238} \mathrm{U}$ capture are about 1.5 . Fig. 5 depicts the energy-dependent-sensitivity profiles for ${ }^{238} \mathrm{U}$ capture for AOA 4-4 and AOA 4-4-P8 along with those from experiments PU-29-1 and LEU-COMP-THERM-049-01. It can be observed from this figure that the profile from the uranium benchmark more closely matches that of the critical AOA 4-4 than does the MOX benchmark, PU-29-1, at fast energies. Also the uranium benchmark profile exceeds the other systems in the thermal region. At fast energies, the uranium benchmarks closely match the behavior of the subcritical design system AOA 4-4-P8.

If a technique, such as the generalized trending tool GLLSM, was applied to AOA 4-4 using a combination of MOX and LEU benchmarks, it is possible that full coverage of important reactions could be achieved. A scoping study was performed to determine the completeness parameter, and thus, the applicability of GLLSM using the selected benchmarks for this application. These results are shown in Appendix A. 


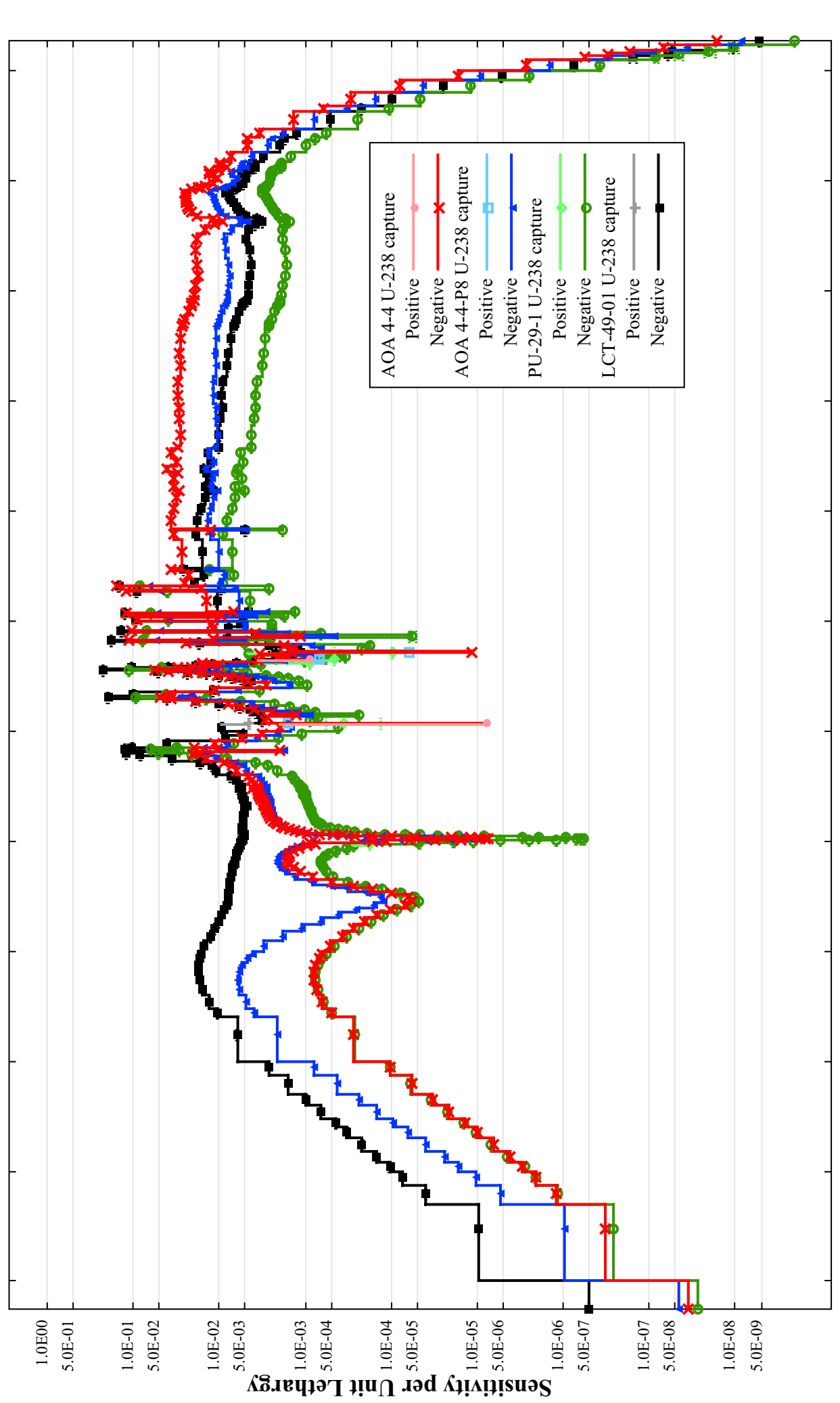

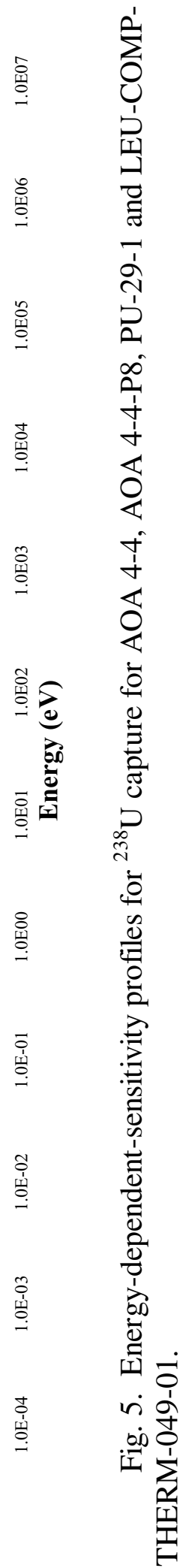




\section{CONCLUSIONS}

This S/U study has identified a number critical benchmark experiments that exceed the previously established criterion for applicability to the criticality code validation for $\mathrm{AOA} 3, \mathrm{PuO}_{2}$ powders, and $\mathrm{AOA} 4$, MOX powders, of the MFFF. This criterion is that the correlation coefficient, $c_{k}$, meets or exceeds a value of 0.8 .

In this study, SEN3 was used to generate sensitivity data for 318 benchmark experiments. Also, SEN1 was used to generate sensitivity data for seven design application compositions provided by DCS as typical of those encountered in the MFFF. Of the analyzed applications, three are from AOA 3 and four are from AOA 4. The CANDE code generated correlation coefficients relating the similarity of each benchmark to each application. This data was tabulated, and those experiments exceeding the criterion for the correlation coefficient were reported.

For $\mathrm{AOA} 3, \mathrm{PuO}_{2}$ powders, the $\mathrm{S} / \mathrm{U}$ methods demonstrate that the series of plutonium benchmarks identified by DCS as applicable to the criticality code validation exceed the S/U criteria for the three design systems evaluated. Of the 46 benchmarks identified by DCS, 38 were confirmed by the $\mathrm{S} / \mathrm{U}$ methods as applicable to the $\mathrm{PuO}_{2}$

powder systems. In addition to the experiments identified by DCS, additional plutonium and MOX benchmarks are available that exceed the S/U criterion for this AOA.

For AOA 4, MOX powders, the S/U methods demonstrate that the series of MOX benchmarks identified by DCS as applicable to the criticality code validation exceed the S/U criteria for critical configurations of three of the four compositions studied. These benchmarks meet the S/U criterion for subcritical configurations of the fourth composition. Additional MOX benchmarks included in this study also demonstrate high correlation coefficients with the design systems from this AOA. Additionally, several plutonium-fueled benchmarks exhibit high correlation coefficients with a subset of the MOX design systems studied. 


\section{REFERENCES}

1. SCALE: A Modular Code System for Performing Standardized Computer Analysis for Licensing and Evaluations, NUREG/CR-0200, Rev. 6 (ORNL/NUREG/CSD2R6), Vols. I, II, and III, May 2000. Available from Radiation Safety Information Computational Center at Oak Ridge National Laboratory as CCC-545.

2. B. T. Rearden and R. L. Childs, "Prototypical Sensitivity and Uncertainty Analysis Codes for Criticality Safety with the SCALE Code System," Trans. Am. Nucl. Soc. 83, 98-100 (2000).

3. B. L. Broadhead, C. M. Hopper, R. L. Childs, and C. V. Parks, Sensitivity and Uncertainty Analyses Applied to Criticality Safety Validation, NUREG/CR-6655, Vols. 1 and 2 (ORNL/TM-13692/V1 and V2), U.S. Nuclear Regulatory Commission, Oak Ridge National Laboratory, November 1999.

4. B. L. Broadhead, C. M. Hopper, K. R. Elam, B. T. Rearden, and R. L. Childs, "Criticality Safety Applications of S/U Validation Methods," Trans. Am. Nucl. Soc. 83, 107-113 (2000).

5. B. L. Broadhead and B. T. Rearden, "Foundations for Sensitivity-Based Criticality Validation Techniques," Trans. Am. Nucl. Soc. 83, 93-95 (2000).

6. B. L. Broadhead, "Uncertainty Analysis Methods for S/U Criticality Validation Techniques," Trans. Am. Nucl. Soc. 83, 95-98 (2000).

7. B. L. Broadhead, R. L. Childs and C. M. Hopper, "Illustrative Examples of Least Squares Methods for Criticality Safety," Trans. Am. Nucl. Soc. 83, 100-103 (2000).

8. B. T. Rearden, C. M. Hopper, K. R. Elam, B. L. Broadhead, and P. B. Fox, "Prototypic Applications of Sensitivity and Uncertainty Analysis for Experiment Needs," Trans. Am. Nucl. Soc. 83, 103-107 (2000).

9. M. E. Dunn and B. T. Rearden, "Application of Sensitivity and Uncertainty Analysis Methods to a Validation Study for Weapons-Grade Mixed-Oxide Fuel," 35666.pdf in Proc. of 2001 ANS Embedded Topical Meeting on Practical Implementation of Nuclear Criticality Safety, November 11-15, 2001, Reno, NV (2001). [ANS Order No.: 700284; ISBN: 0-89448-659-4]

10. American National Standard for Nuclear Criticality Safety in Operations with Fissionable Materials Outside Reactors, ANSI/ANS-8.1, American Nuclear Society, La Grange Park, IL (1983).

11. E. M. Oblow, "Sensitivity Theory from a Differential Viewpoint," Nucl. Sci. Eng. 59, 187 (1976). 
12. W. M. Stacey, Jr., "Variational Estimates and Generalized Perturbation Theory for the Ratios of Linear and Bilinear Functionals," J. Math. Phys., 13, 1119 (1972); see also W. M. Stacey, Jr., "Variational Estimates of Reactivity Worths and Reaction Rate Ratios in Critical Nuclear Reactors," Nucl. Sci. Eng. 48, 444 (1972).

13. L. N. Usachev, "Perturbation Theory for the Breeding Ratio and for Other Number Ratios Pertaining to Various Reactor Processes," J. Nucl. Energy Pts. A/B, 18, 571 (1964).

14. A. Gandini, "A Generalized Perturbation Method for Bilinear Functionals of the Real and Adjoint Neutron Fluxes," J. Nucl. Energy 21, 755 (1967).

15. C. R. Weisbin, J. H. Marable, J. L. Lucius, E. M. Oblow, F. R. Mynatt, R. W. Peelle, and F. G. Perey, Application of FORSS Sensitivity and Uncertainty Methodology to Fast Reactor Benchmark Analysis, ORNL/TM-5563, Union Carbide Corp., Oak Ridge National Laboratory, December 1976.

16. J. D. Smith, III and B. L. Broadhead, Multigroup Covariance Matrices for Fast Reactor Studies, ORNL/TM-7389, Martin Marietta Energy Systems, Oak Ridge National Laboratory, April 1981.

17. R. E. McFarlane, R. J. Barrett, D. W. Muir, and R. M. Boicourt, The NJOY Nuclear Data Processing System: User's Manual, LA-7584-M, Los Alamos National Laboratory, 1978.

18. R. L. Childs, SEN1: A One Dimensional Cross-Section Sensitivity and Uncertainty Module for Criticality Safety Analysis, NUREG/CR-5719 (ORNL/TM-13738), U.S. Nuclear Regulatory Commission, Oak Ridge National Laboratory, July 1999.

19. B. T. Rearden, "Development of SAMS: A Sensitivity Analysis Module for the SCALE Code System Using KENO V.a in the CSAS25 Sequence," Ph.D. Dissertation, Texas A\&M University (1999).

20. M. L. Williams, B. L. Broadhead, and C. V. Parks, "Eigenvalue Sensitivity Theory for Resonance-Shielded Cross Sections," Nuc. Sci. Eng. 138, 177-191 (2001).

21. International Handbook of Evaluated Criticality Safety Benchmark Experiments, Nuclear Energy Agency Nuclear Science Committee of the Organization for Economic Co-operation and Development, NEA/NSC/DOC(95)03, Paris (1999).

22. S. R. Bierman and E. D. Clayton, "Critical Experiments with Low-Moderated Homogeneous Mixtures of Plutonium and Uranium Oxides Containing 8, 15, and 30 wt \% Plutonium," Nucl. Sci. Eng. 61, 370-376 (1976).

23. S. R. Bierman, and E. D. Clayton, "Critical Experiments to Measure the Neutron Poisoning Effect of Copper and Copper-Cadmium Plates," Nucl. Sci. Eng., 55, 5866 (1974). 
24. S. R. Bierman, B. M. Durst, and E. D. Clayton, Critical Experiments Measuring the Reactivity Worths of Materials Commonly Encountered as Fixed Neutron Poisons, BNWL-2129, Battelle Pacific Northwest Laboratories, October 1976. 


\section{APPENDIX A}

COMPLETENESS PARAMETER 


\section{APPENDIX A \\ COMPLETENESS PARAMETER}

Previously developed guidelines relate the number of systems and the magnitude of $c_{k}$ parameters for which convergence of the GLLSM and hence convergences of trending studies with $c_{k}$ are expected. However, the GLLSM procedure is useful for general purpose trending when the values of $c_{k}$ are outside of the range of applicability. For these situations another parameter was developed to ensure that the set of benchmarks is "complete" in the sense that it completely tests all the important cross section elements in the particular application of interest. The availability of sensitivity coefficients provides a key element in the definition of this completeness parameter.

The completeness value, $\mathrm{R}$, is defined as follows:

$$
R=S_{a} / S_{t}
$$

where

$$
\begin{aligned}
& S_{t}=\sum_{i} \sum_{j} \sum_{x}\left|S_{x a i j}\right|, \\
& S_{a}=\sum_{i} \sum_{j} \sum_{x}\left|d S_{x a i j}\right|,
\end{aligned}
$$

and

$$
\begin{aligned}
& \qquad d=\left\{\begin{array}{l}
1, \text { if } N_{i x}^{j}>9 \\
0, \text { if } N_{i x}^{j} \leq 9
\end{array}\right. \\
& N_{i x}^{j} \quad=\text { number of systems for which } S_{\text {xeij }}>\left|0.9 \times S_{\text {xaij }}\right| \\
& \mathrm{e} \quad=\text { experiment } \\
& \mathrm{a} \quad=\text { application } \\
& \mathrm{S}_{\mathrm{xij}} \quad=\text { the sensitivity of } \mathrm{k}_{\mathrm{eff}} \text { to the cross sections of the constituent material nuclide } \mathrm{j} \\
& \mathrm{i}, \mathrm{x} \quad=\text { indices for reaction and energy group. }
\end{aligned}
$$

The completeness value is designed to give the effective fraction of the total sensitivity for each application system that is "covered" by the benchmark set. This coverage is defined by comparing the magnitude of each group-wise sensitivity coefficient for the application with respect to each of the corresponding sensitivities of the benchmark systems. The minimum 
coverage of these sensitivities for the benchmark systems is defined as $90 \%$ of the application sensitivity, hence the value of 0.9 in the definition of $N_{i x}^{j}$.

Work is planned but has not been completed to determine the magnitude of the $\mathrm{R}$ parameter, such that completeness is assured. Until then, the R-value is useful only in relative comparisons, i.e., the higher the number the better coverage for important reactions in the system. Note, the completeness parameter is a sensitivity-only parameter; the cross-section-covariance data is not included in its computation.

For this study, an evaluation of this completeness parameter was conducted to determine if the GLLSM methods would be useful for the determination of a computational bias for the critical configuration of AOA 4-4, where no benchmarks exceeded the 0.8 criterion for $c_{k}$. The results of this evaluation are given in Table A.1. These completeness parameters were computed in reference to the entire 318-experiment benchmark suite, including the LEU experiments that demonstrate a high $\mathrm{T}\left(\mathrm{c}_{\mathrm{k}}\right)$ value for ${ }^{238} \mathrm{U}$ capture for AOA 4-4. As can be seen from this table, AOA 4-4 exhibits a very low completeness parameter relative to the other applications studied. Thus, addition benchmarks would need to be identified before reliable GLLSM results could be produced.

Table A.1. Completeness parameter $(R)$ for each design system using the 318-benchmark-experiment set

\begin{tabular}{cc}
\hline Application & Completeness parameter \\
\hline AOA 3-1 & 0.6724 \\
AOA 3-2 & 0.7835 \\
AOA 3-3 & 0.7943 \\
AOA 4-1 & 0.8271 \\
AOA 4-2 & 0.5784 \\
AOA 4-3 & 0.6292 \\
AOA 4-4 & 0.4433 \\
AOA 4-4-P163 & 0.5055 \\
AOA 4-4-P40 & 0.6137 \\
AOA 4-4-P8 & 0.6816 \\
\hline
\end{tabular}




\section{APPENDIX B}

\section{INTEGRAL VALUES}




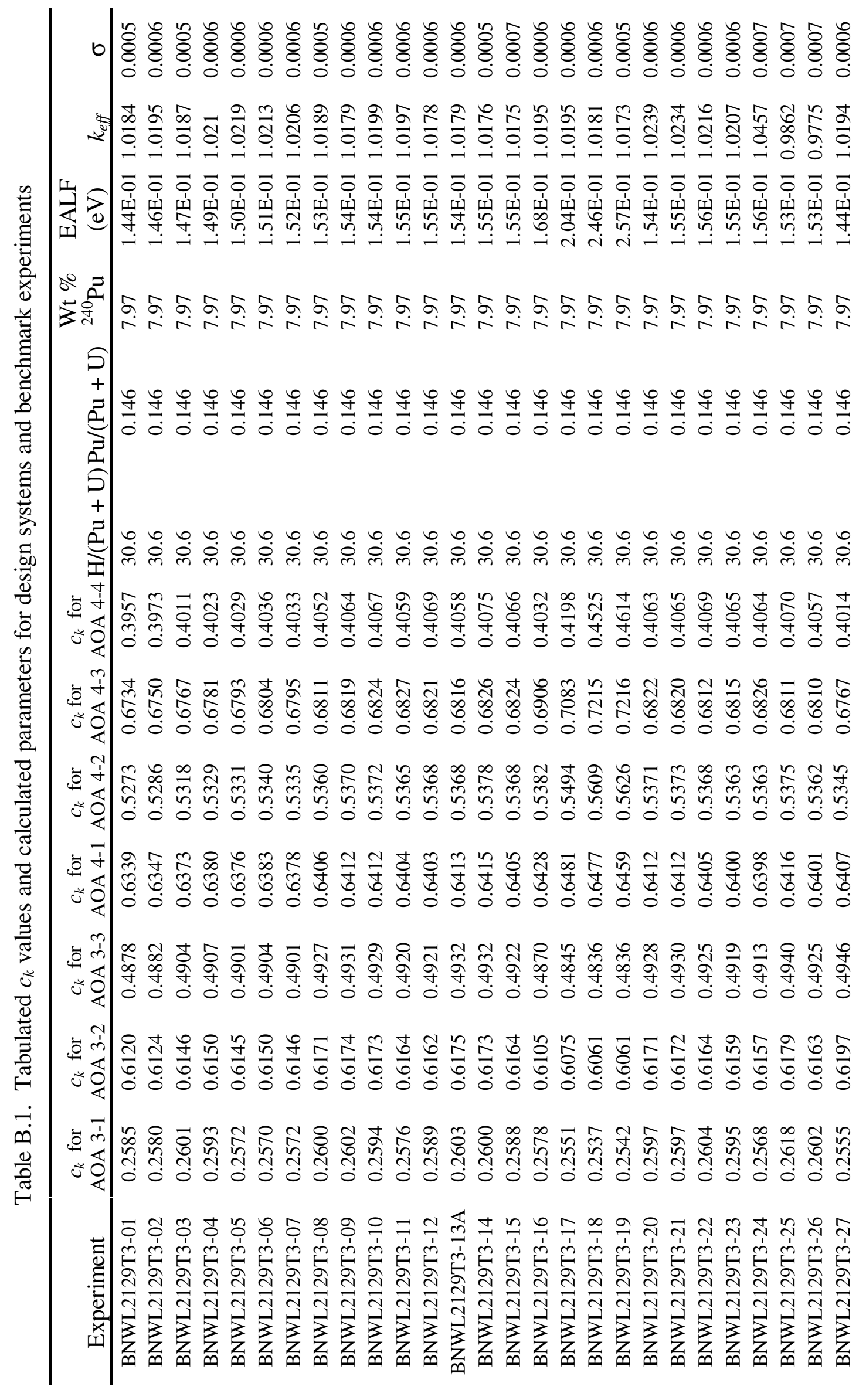




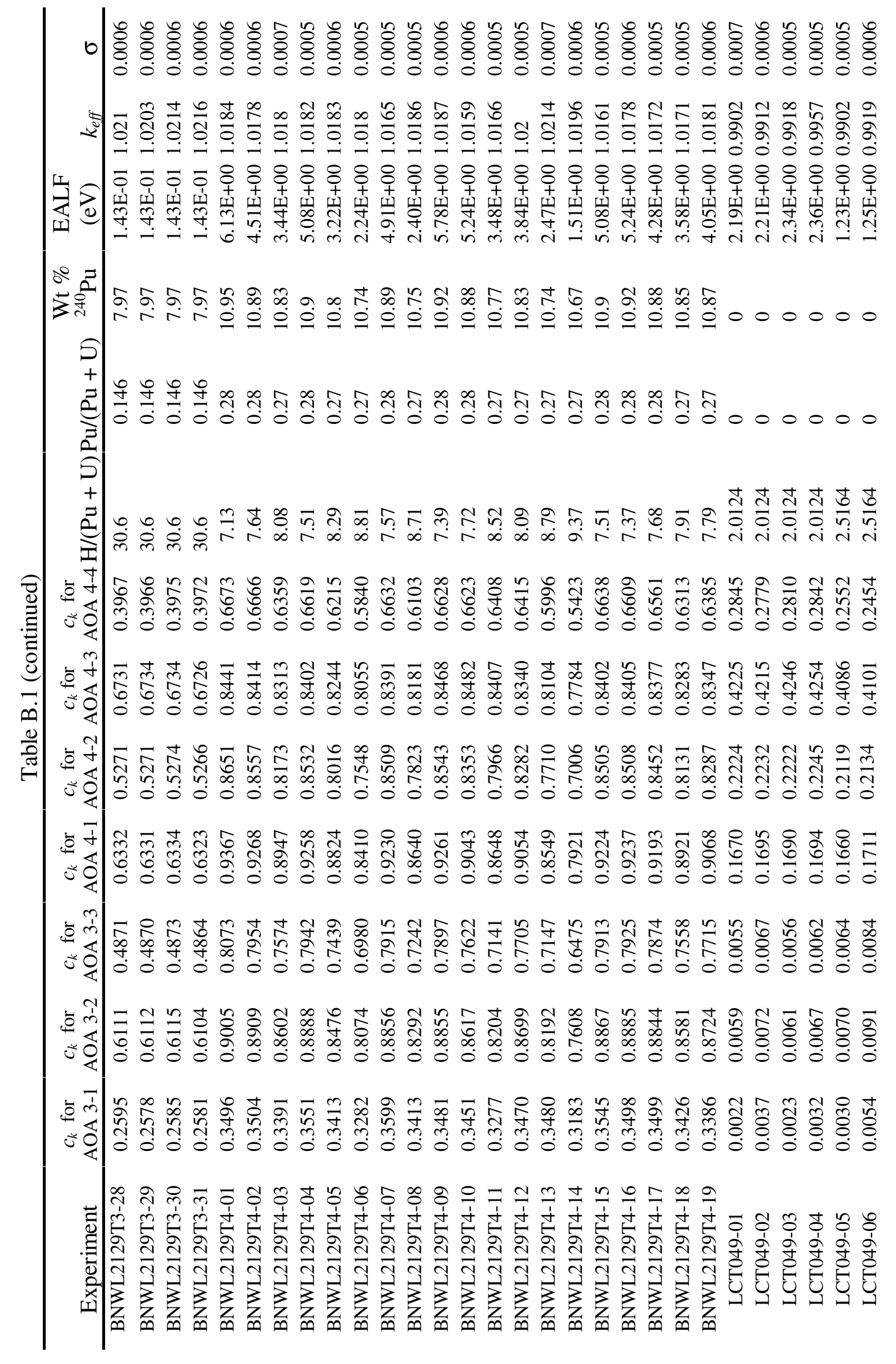




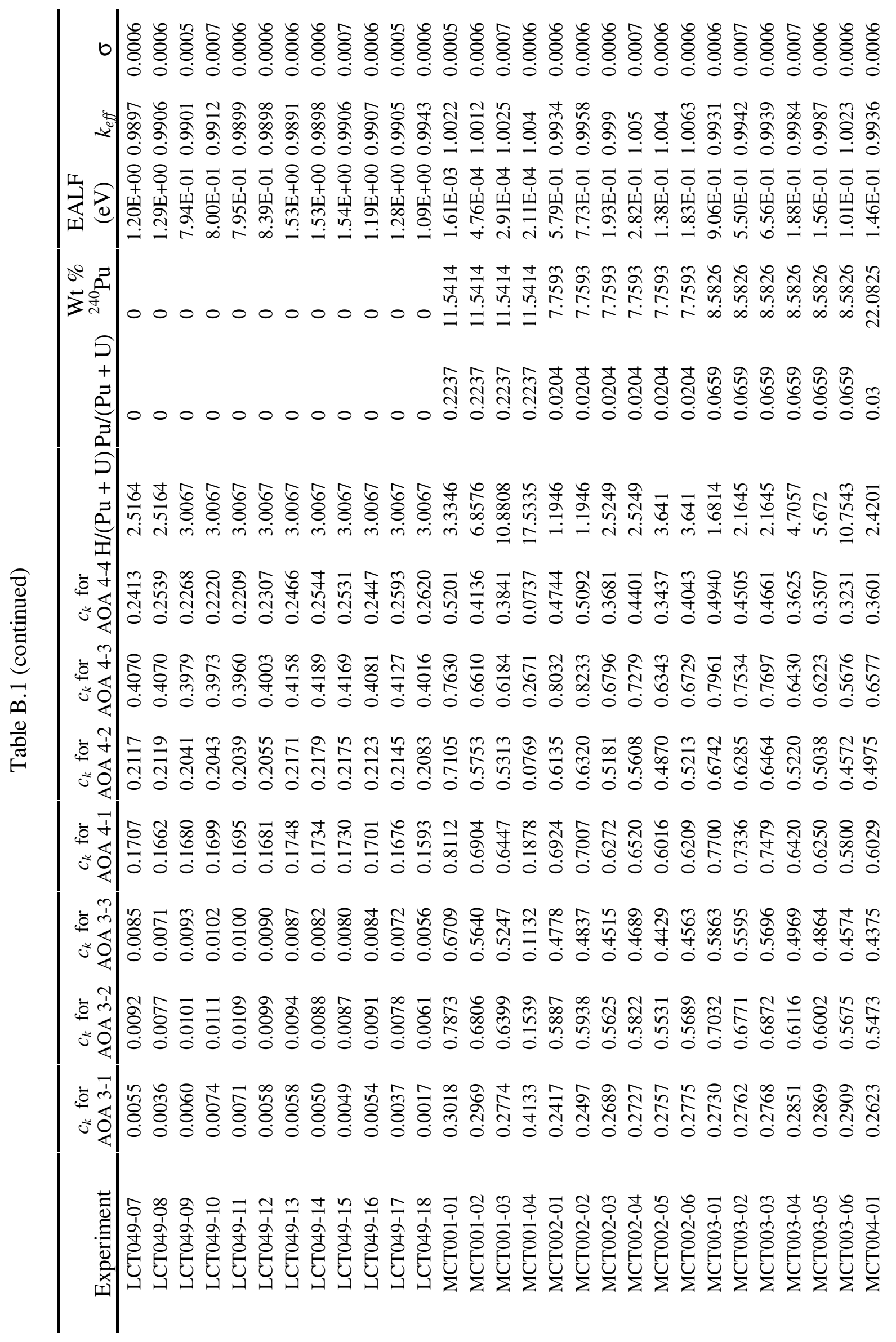




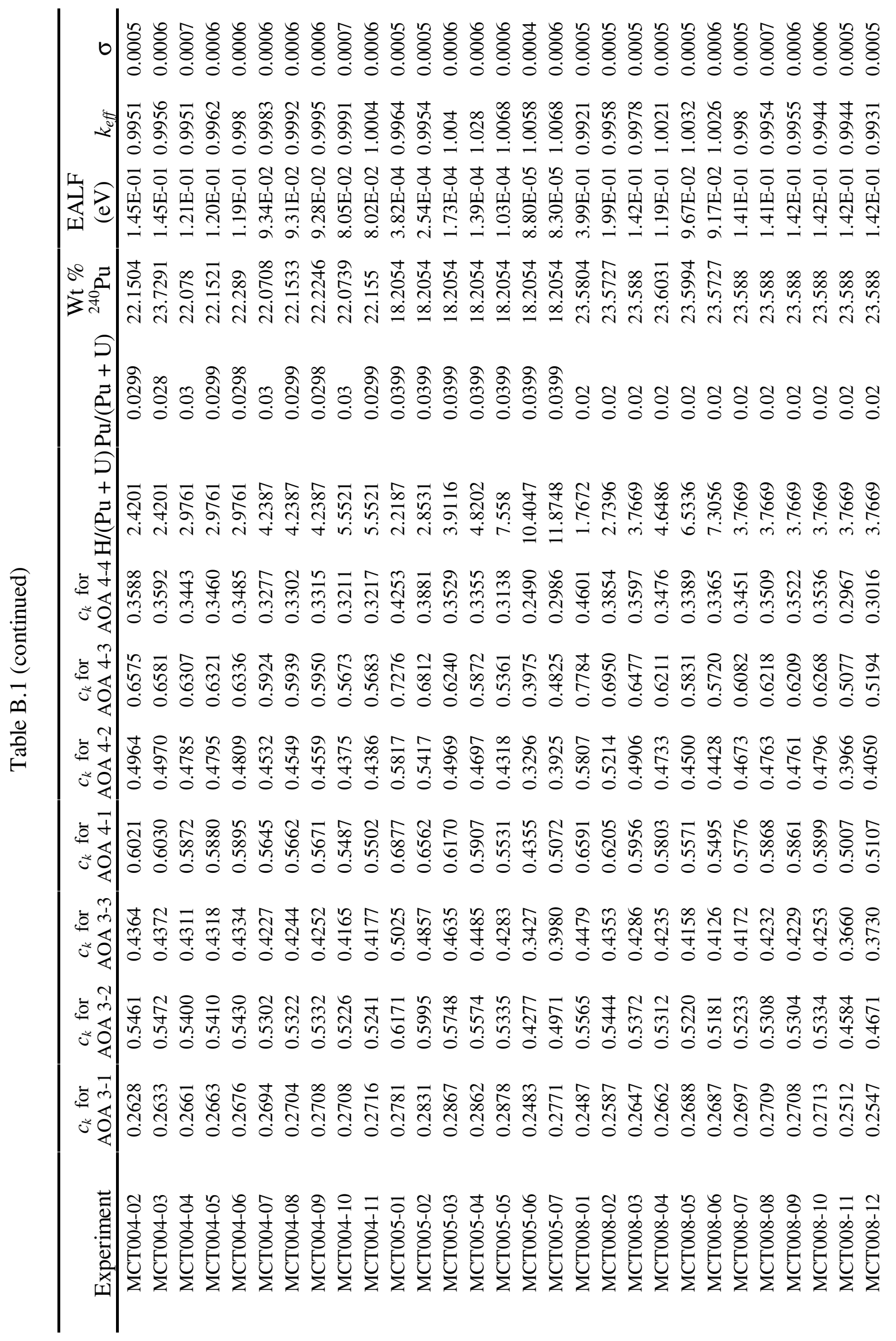




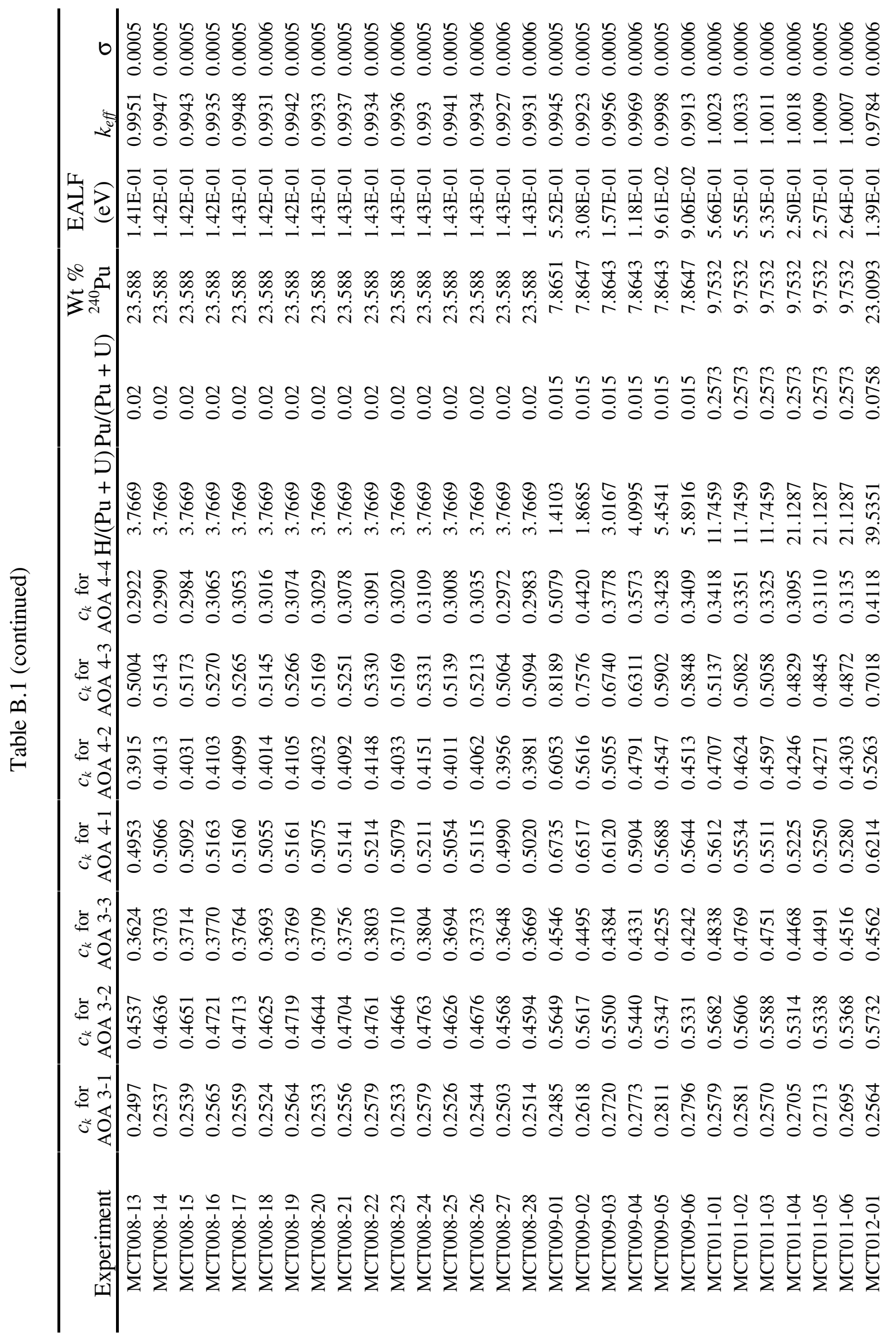




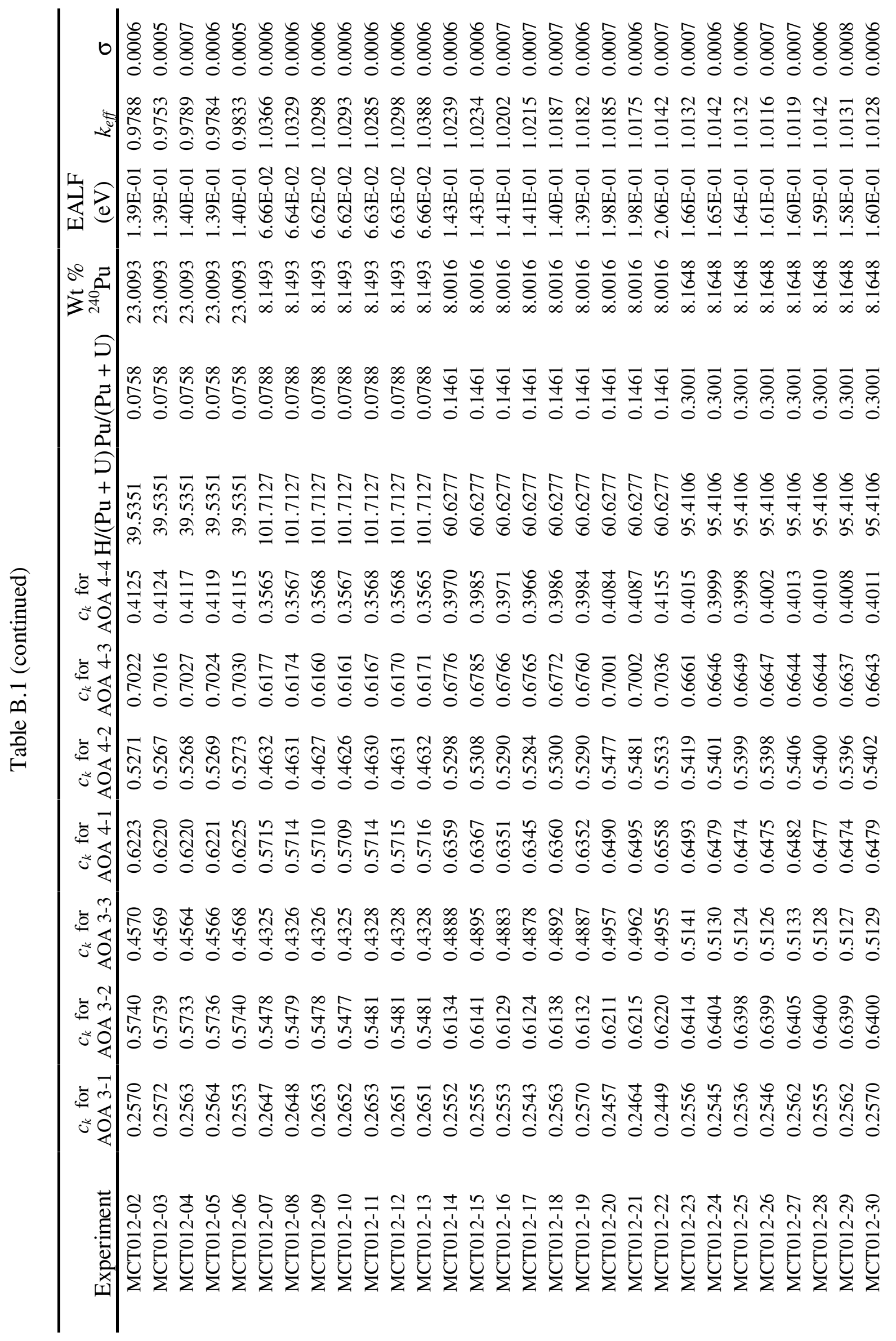




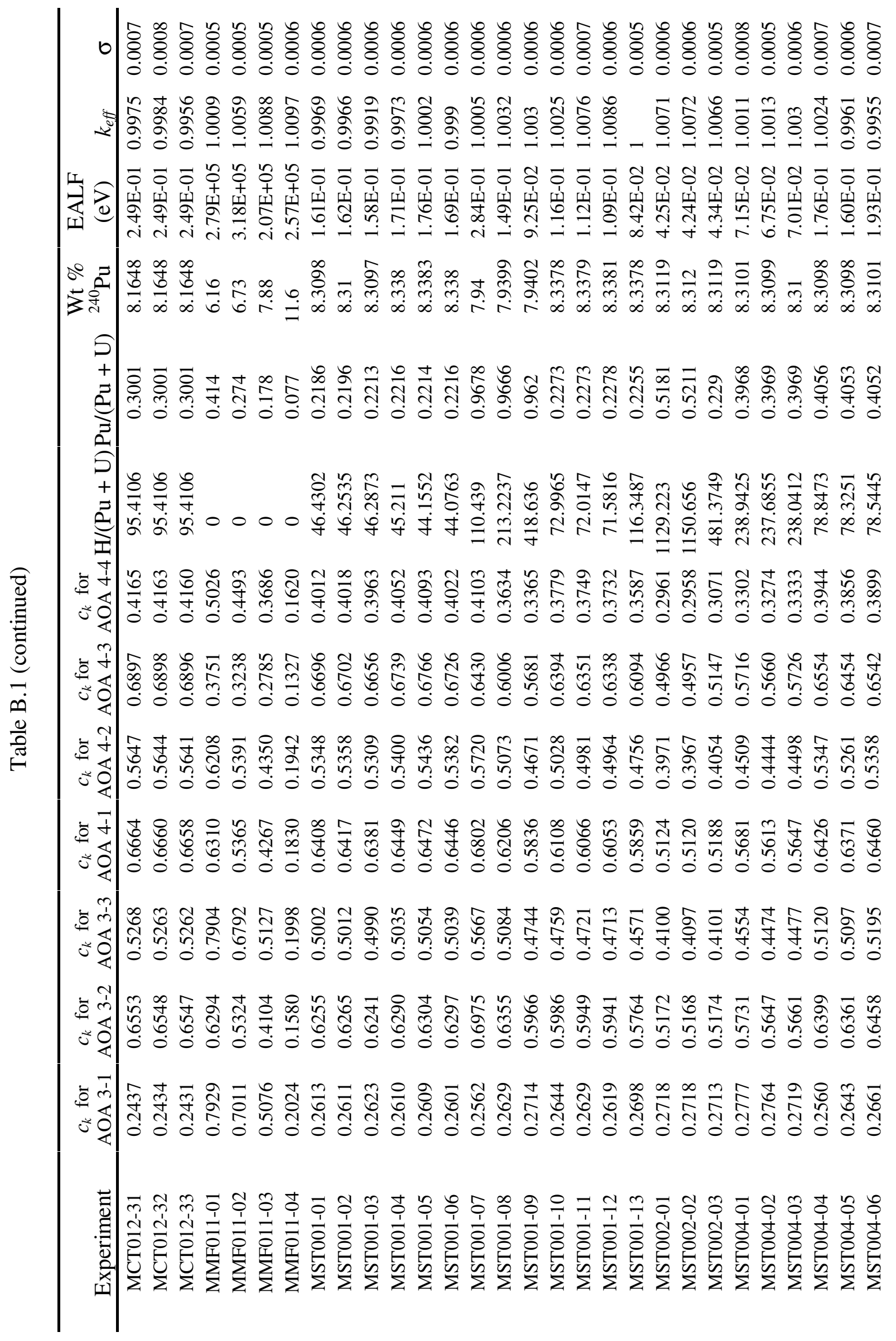




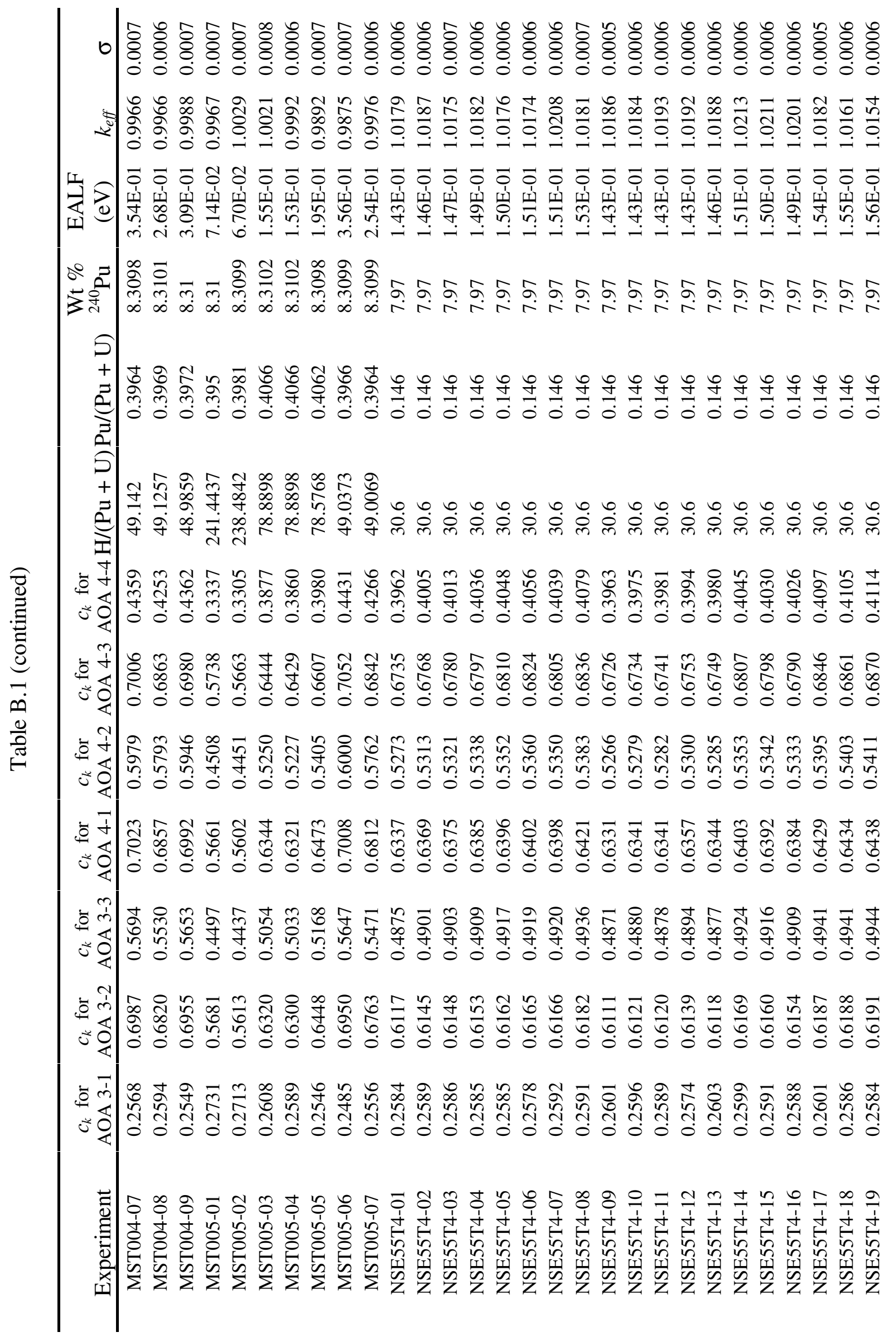




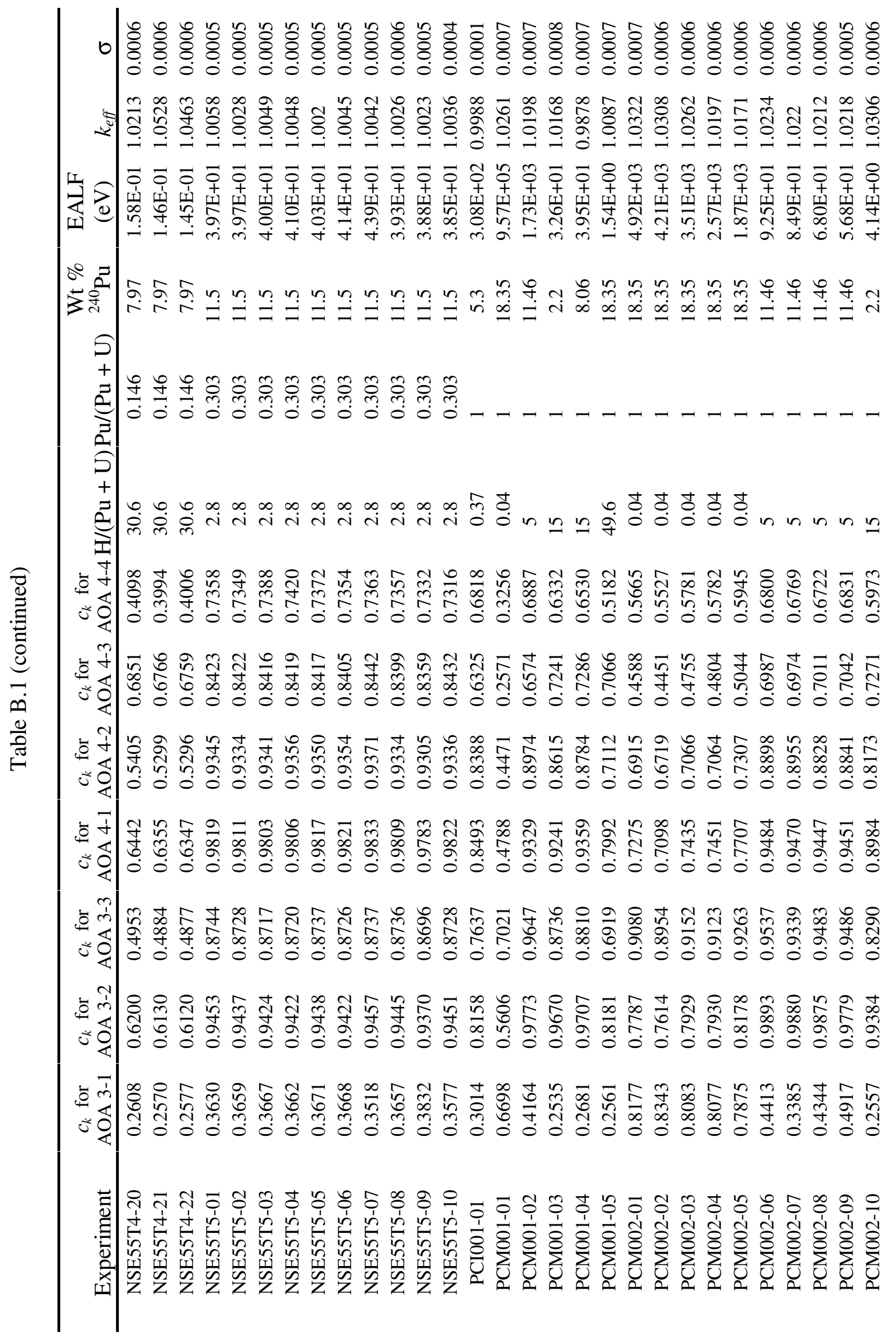




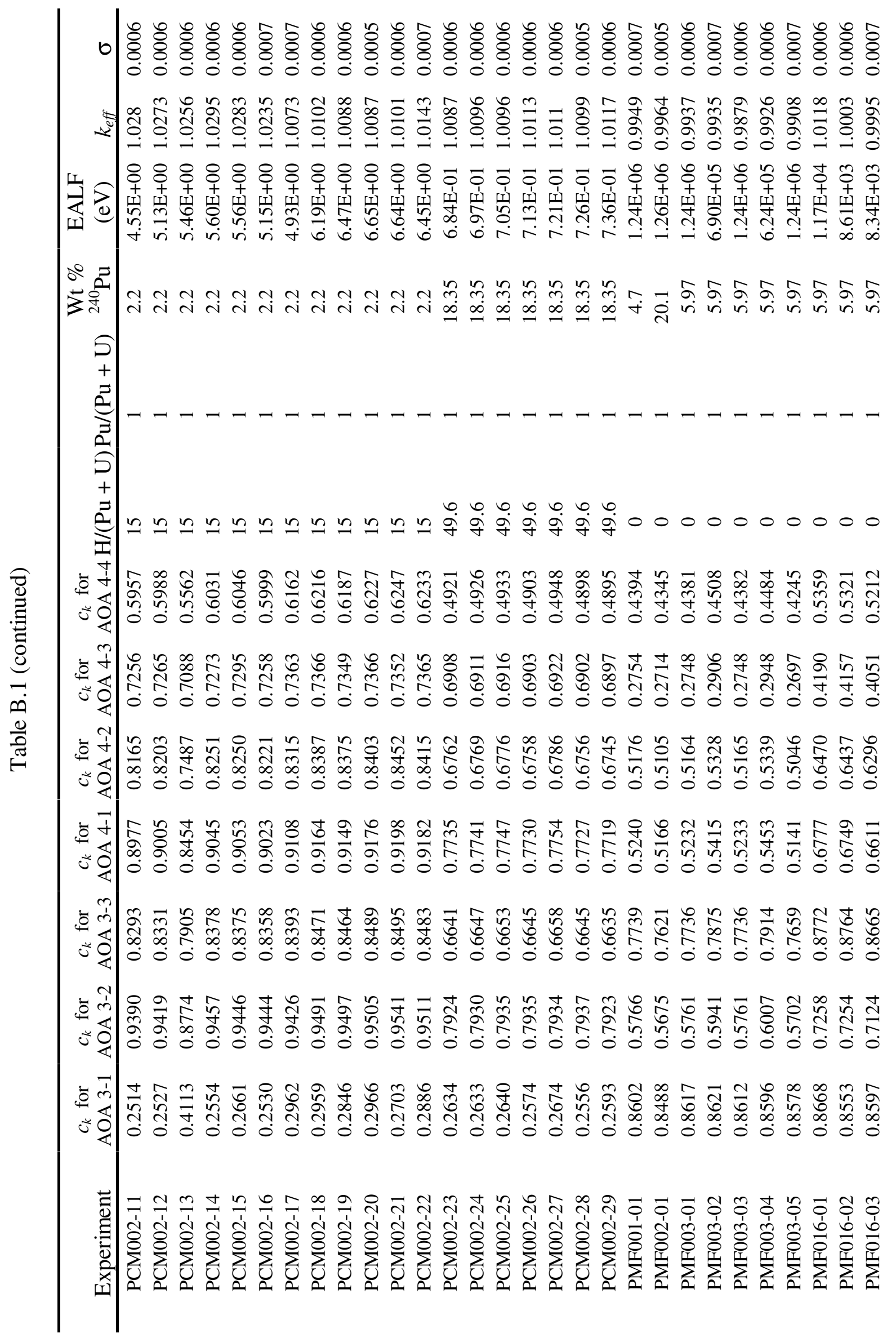




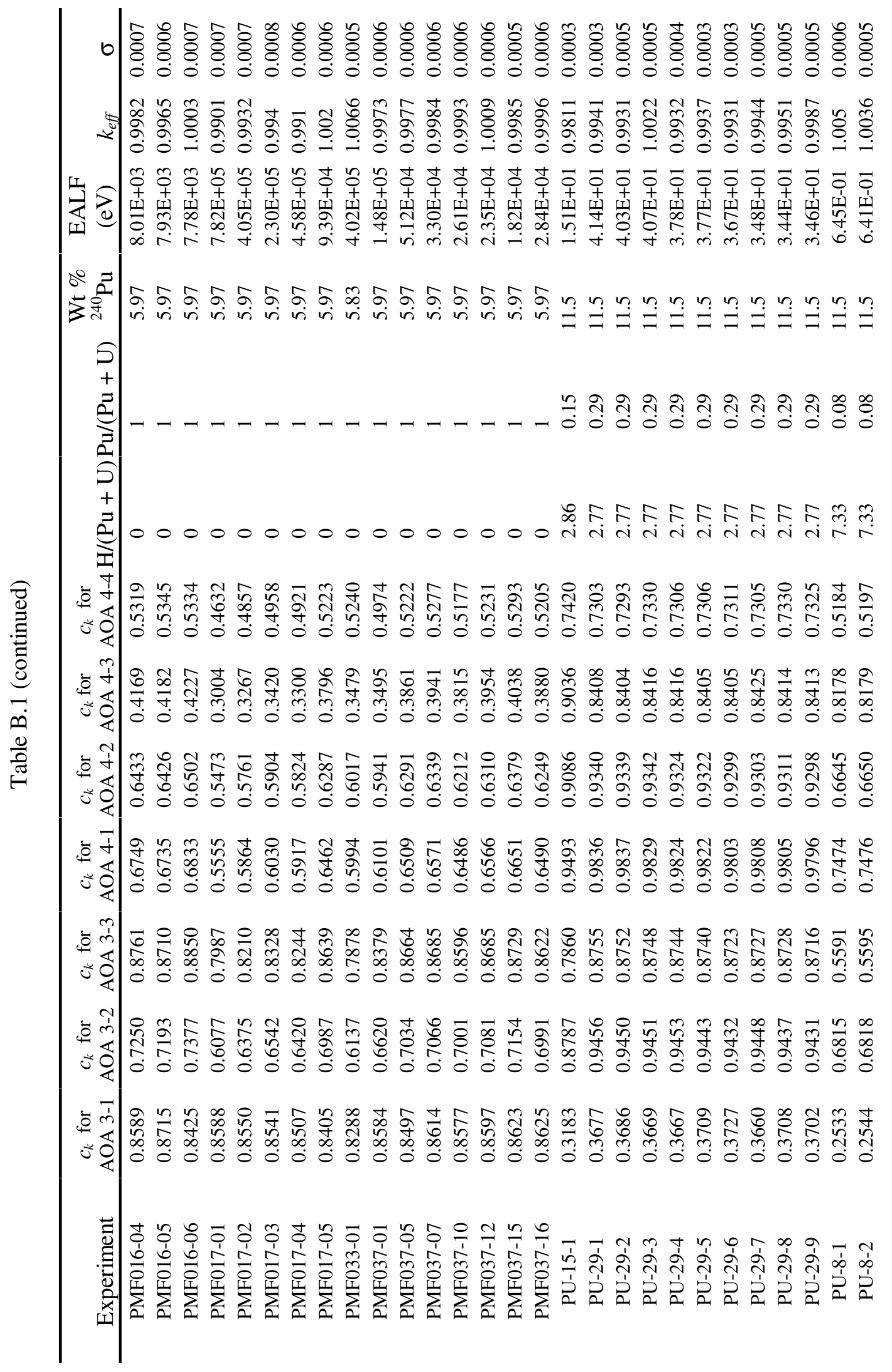




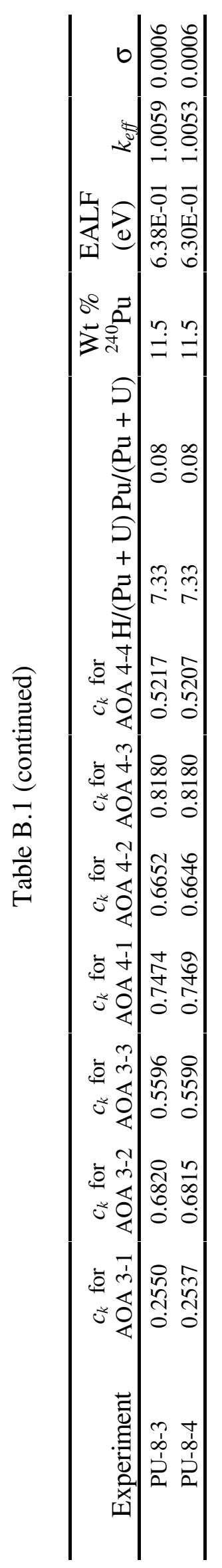




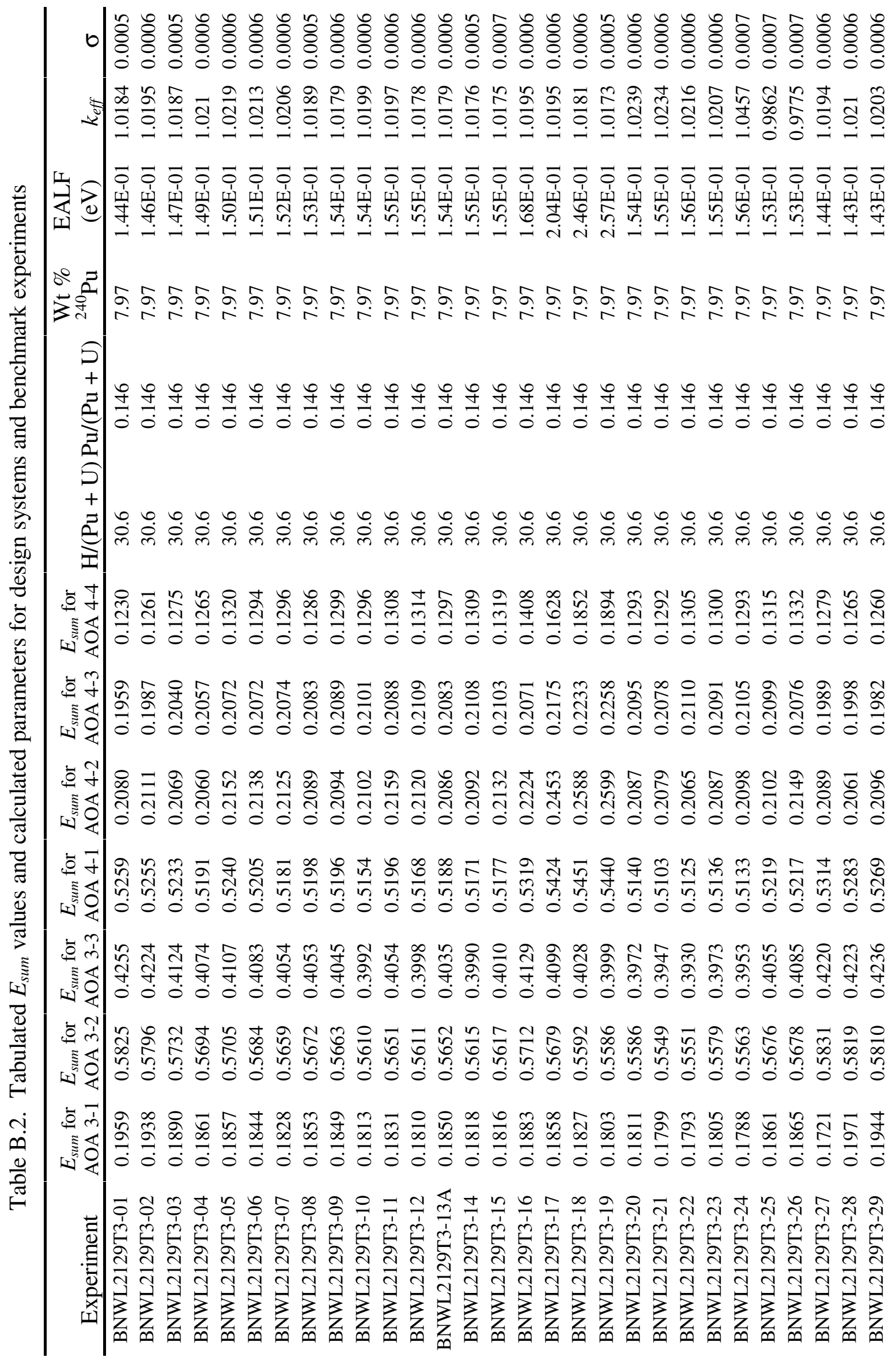




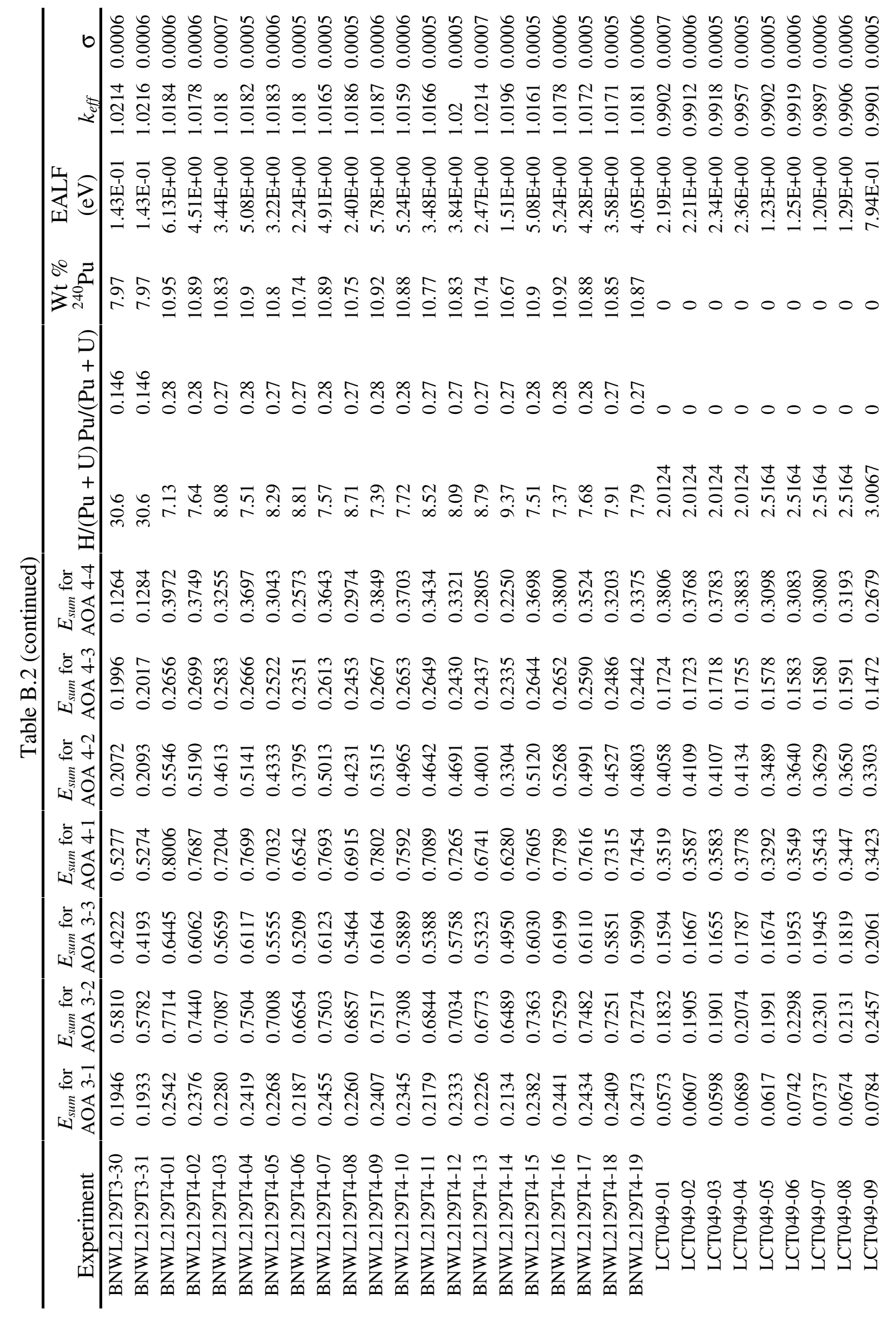




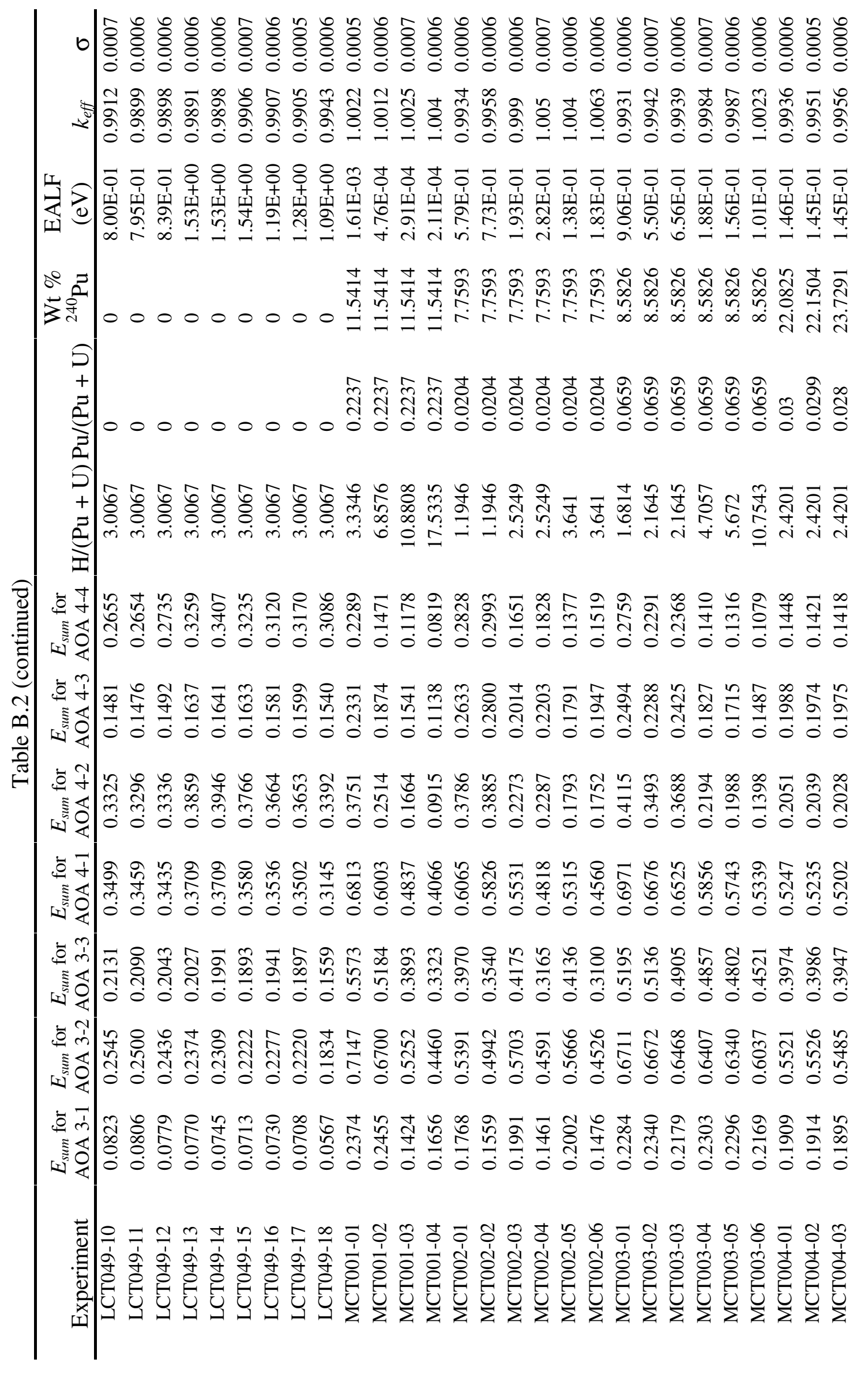




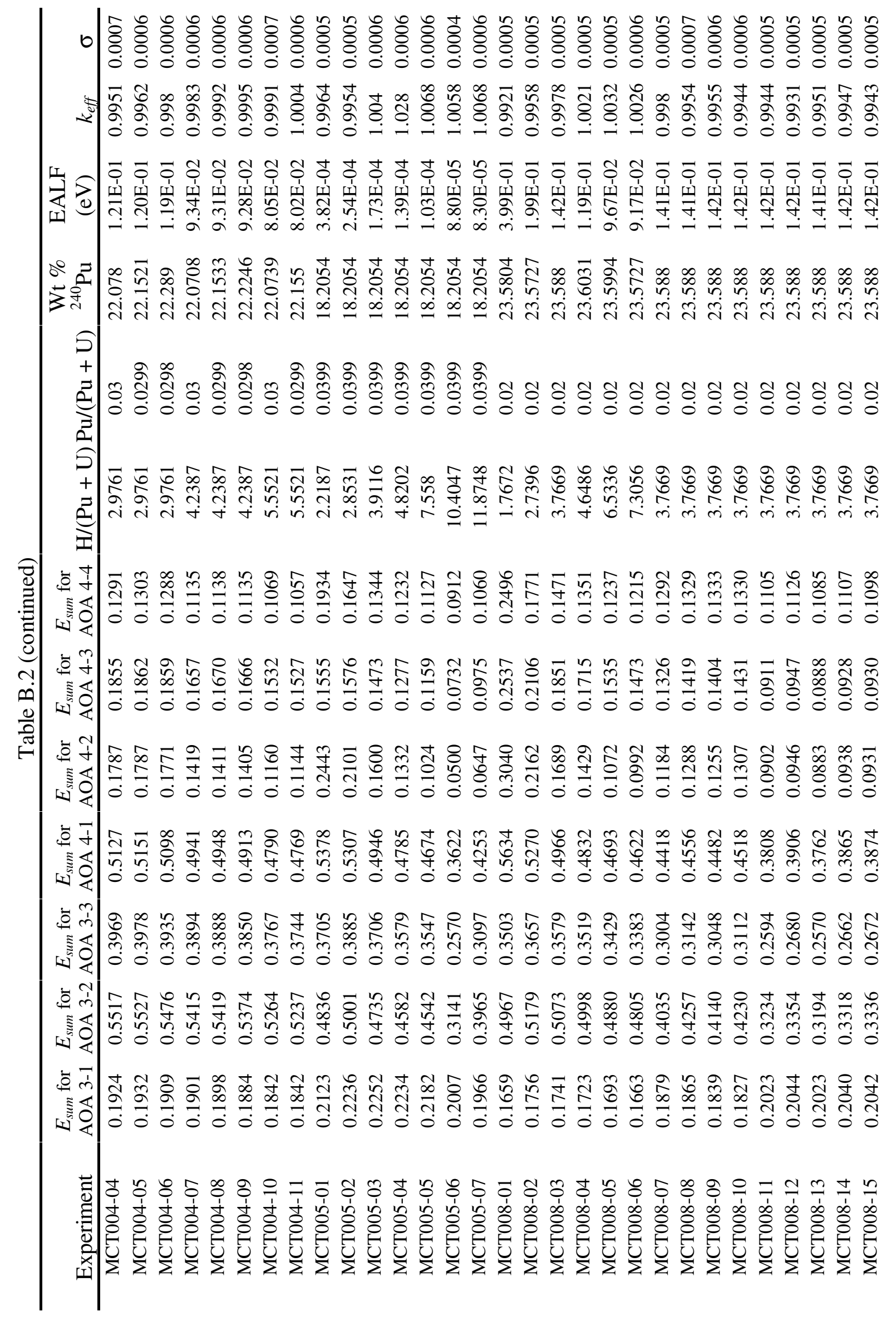




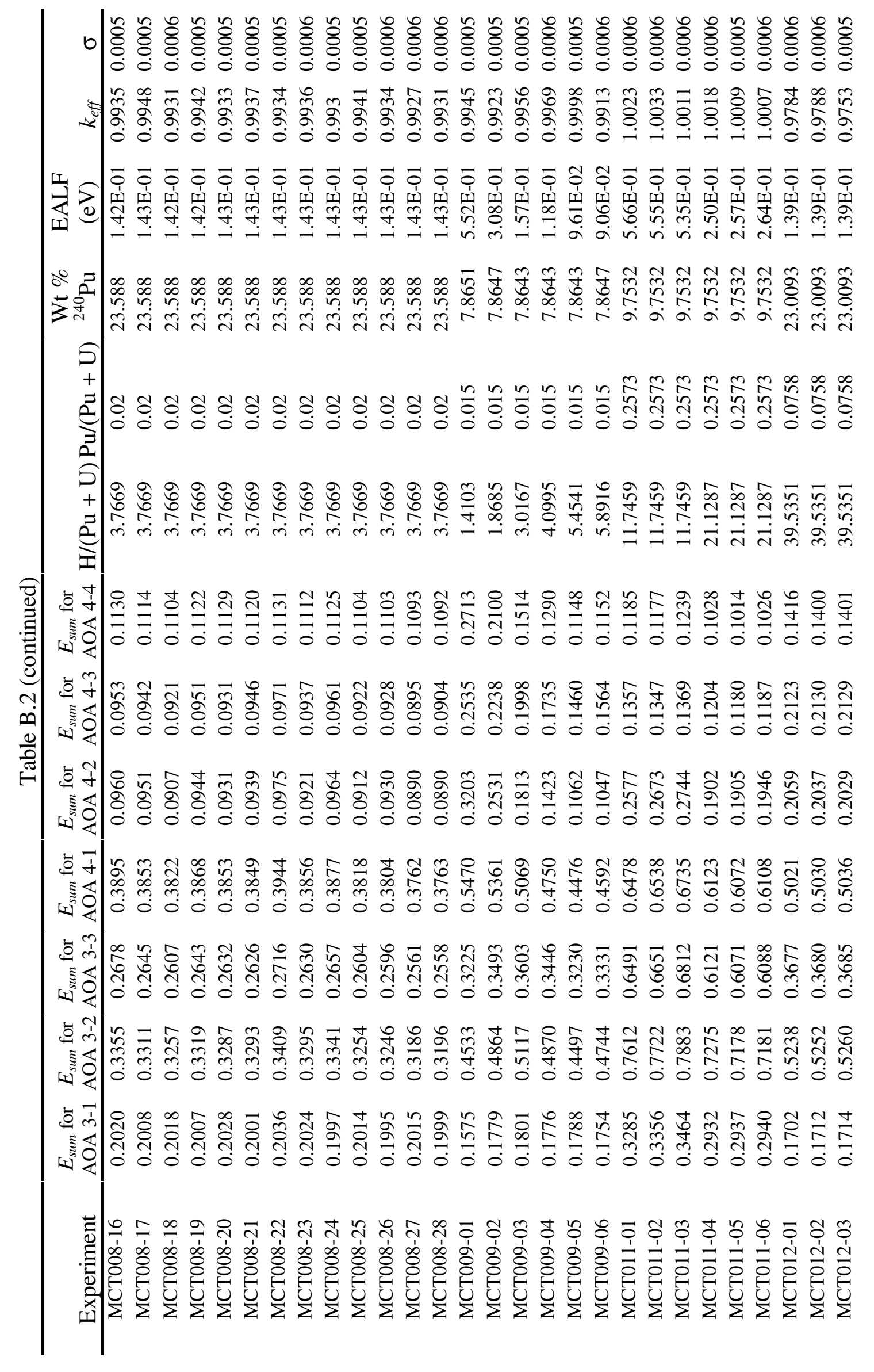




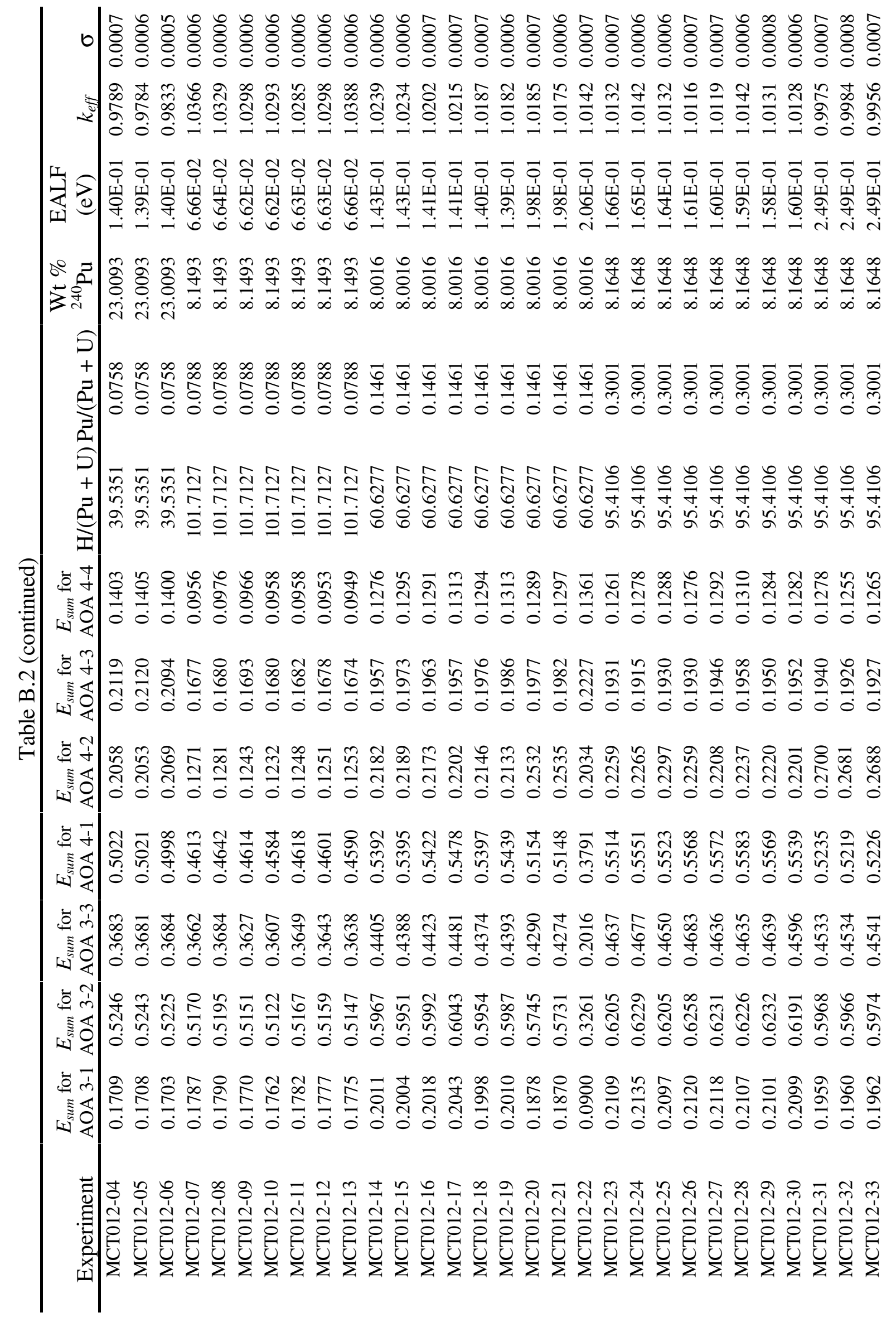




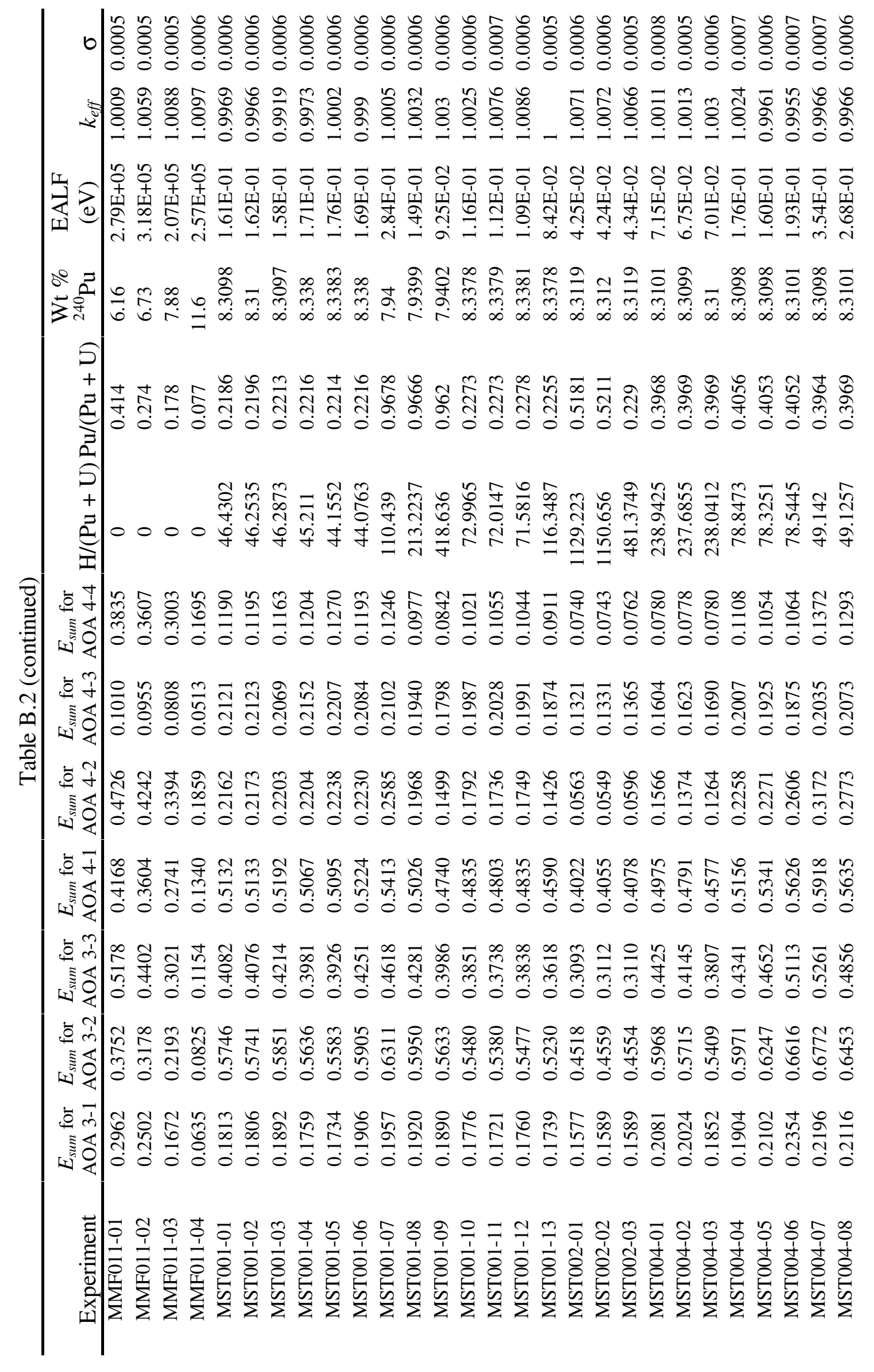




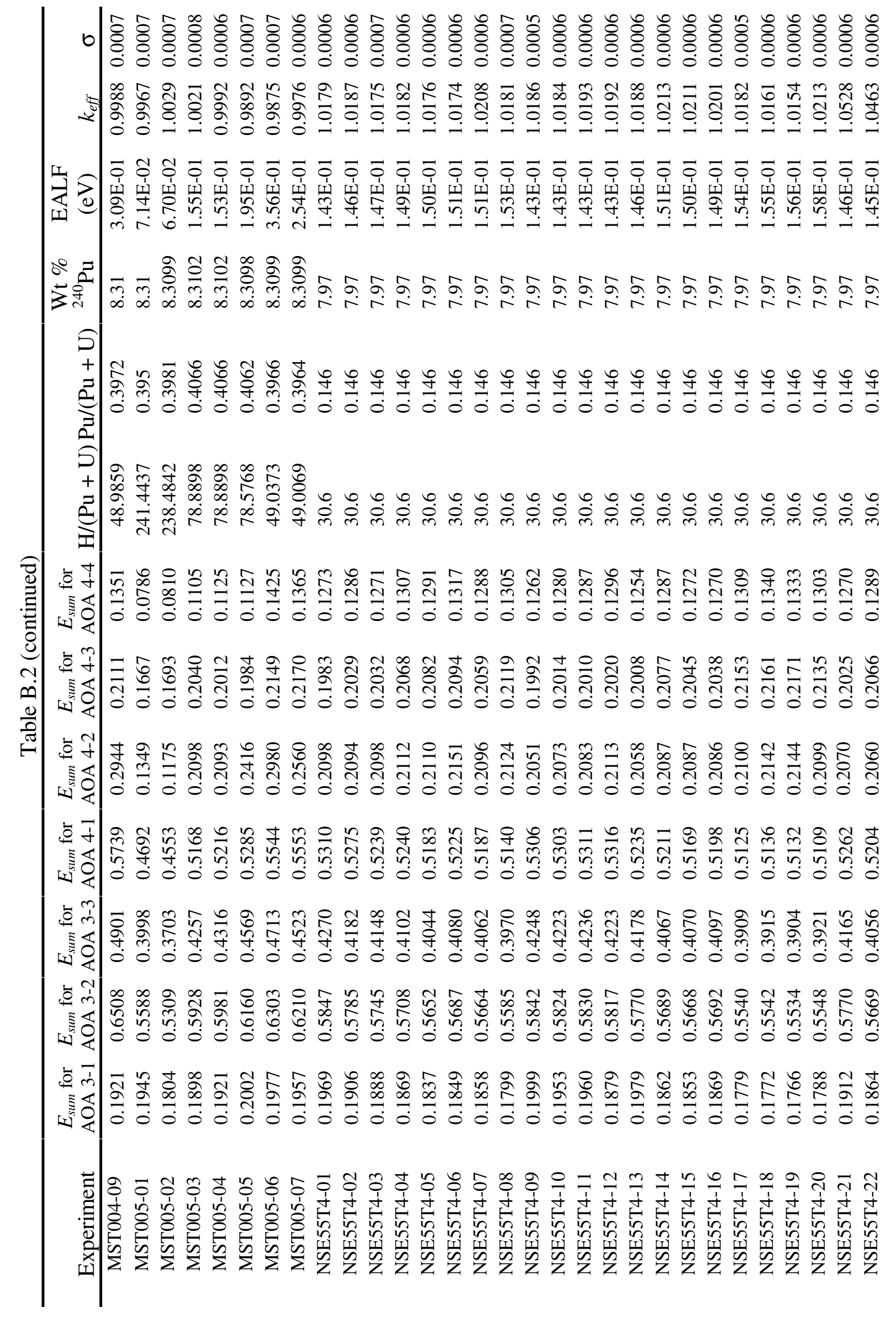




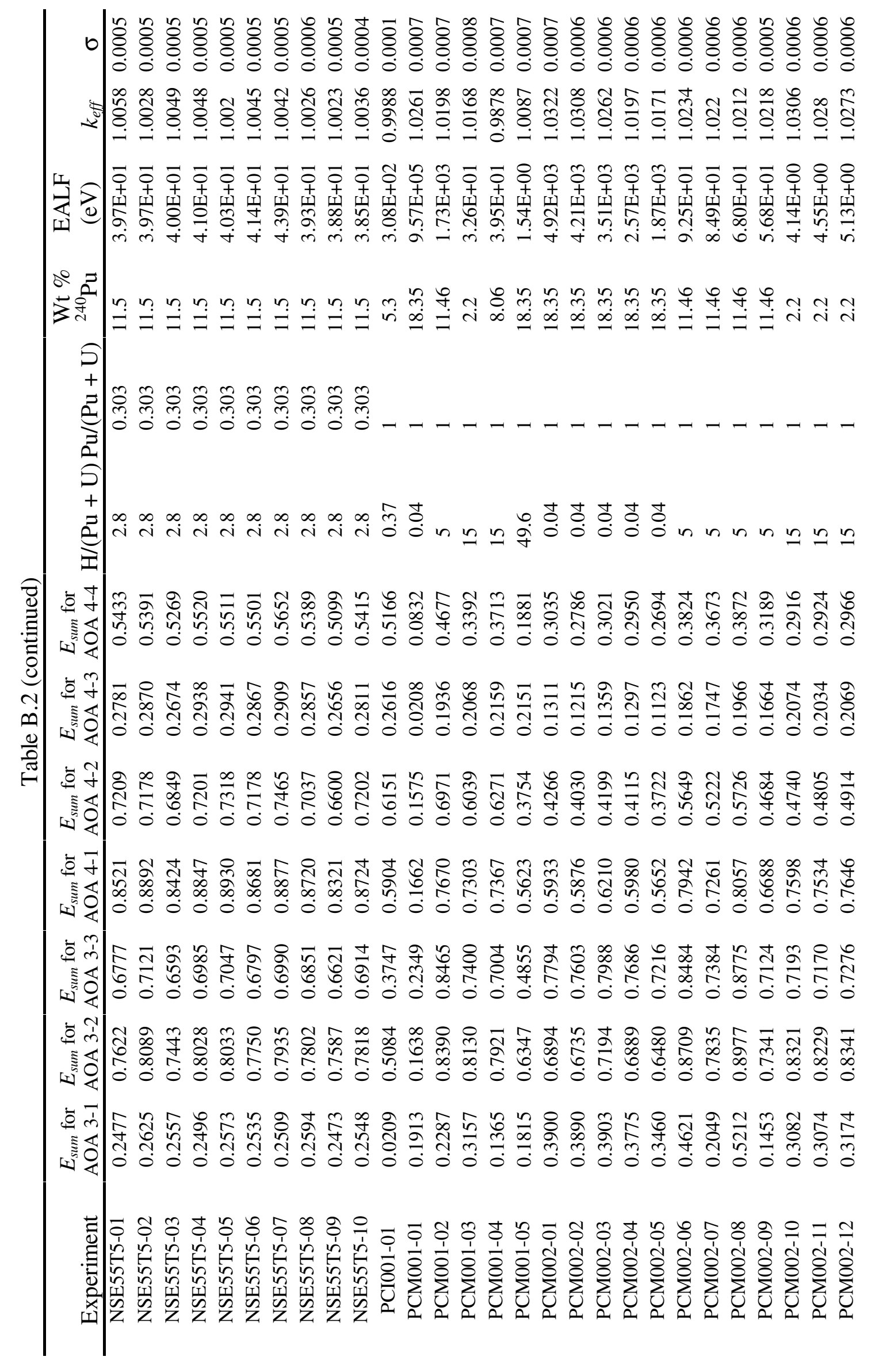




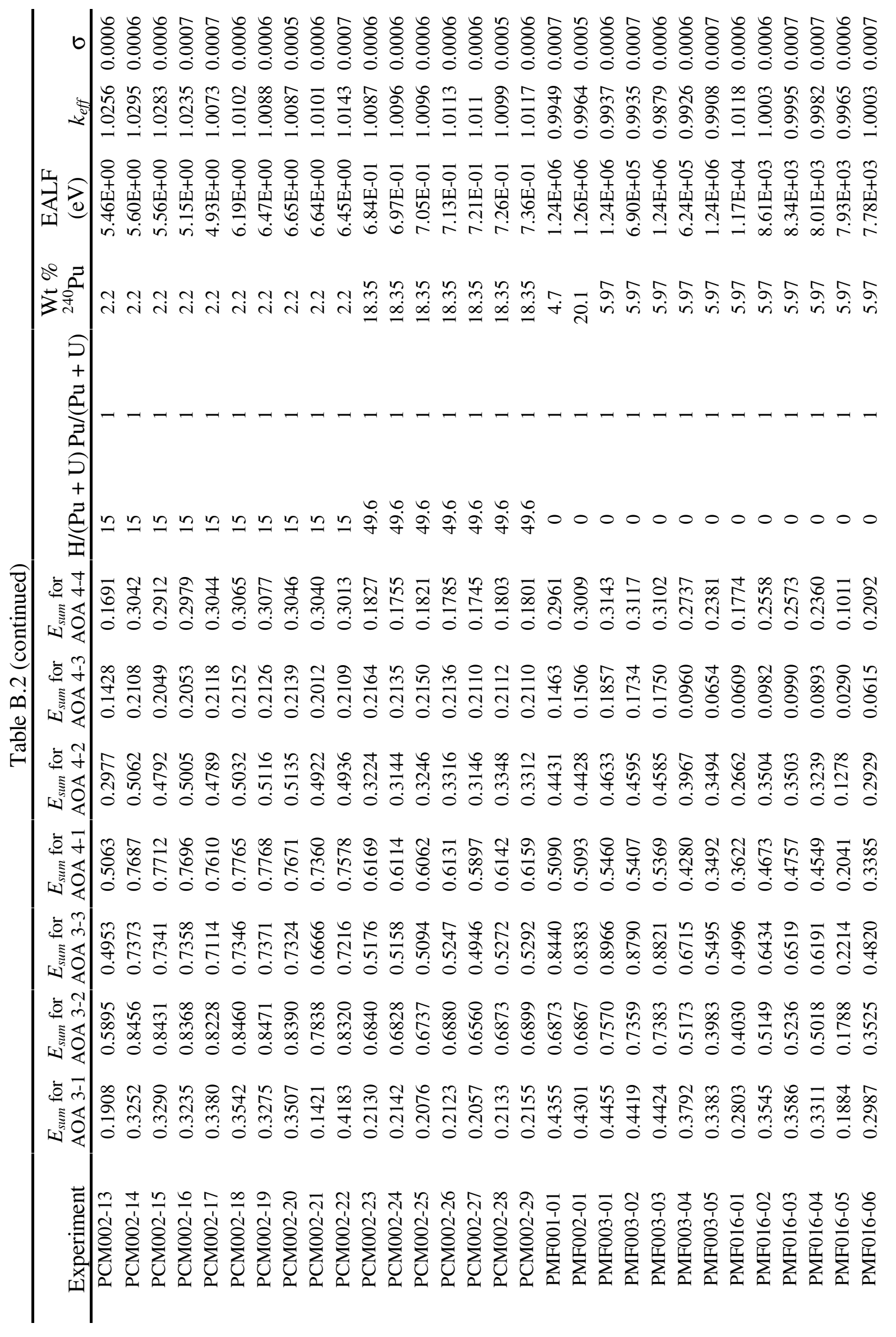




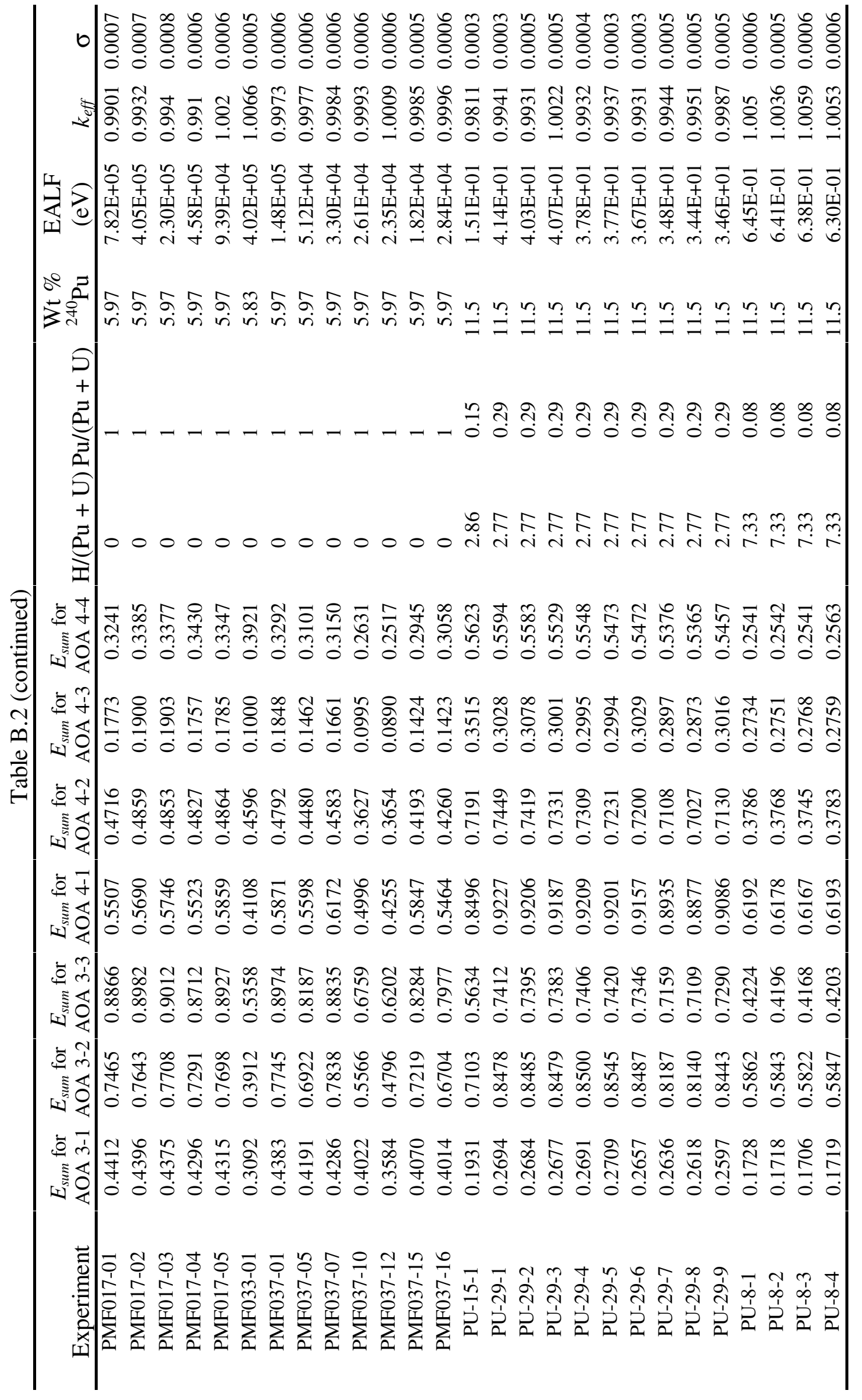


ORNL/TM-2001/262

\section{INTERNAL DISTRIBUTION}

1. W. C. Carter, 6011, MS-6370

2. B. L. Broadhead, 6011 , MS-6370

3. M. D. DeHart, 6022, MS-6370

4. M. E. Dunn, 6011, MS-6370

5-9. K. R. Elam, 6011, MS-6370

10. S. Goluoglu, 6011, MS-6370

11. J. N. Herndon, $4500 \mathrm{~N}$, MS-6228

12. D. F. Hollenbach, 6011, MS-6370

13. C. M. Hopper, 6011, MS-6370

14. C. V. Parks, 6011, MS-6370

15. L. M. Petrie, 6011, MS-6370
16. R. T. Primm, III, 6025, MS-6370

17-21. B. T. Rearden, 6011, MS-6370

22. D. A. Reed, $4500 \mathrm{~S}, \mathrm{MS}-6127$

23. R. M. Westfall, 6011, MS-6370

24. ORNL Laboratory Records $4500 \mathrm{~N}, \mathrm{MS}-6254$

25. ORNL Central Research Library $4500 \mathrm{~N}, \mathrm{MS}-6191$

\section{EXTERNAL DISTRIBUTION}

26. C. E. Apperson, Jr., WSMS - Savannah River, PO Box 5388, Aiken, SC 29804-5388

27. J. M. Belmont, Duke, Cogema, Stone and Webster, 128 South Tyrone Street, PO Box 31847, MS FC12A, Charlotte, NC 28231-1847

28. E. J. Brabazon, Duke, Cogema, Stone and Webster, 128 South Tyrone Street, PO Box 31847, MS FC12A, Charlotte, NC 28231-1847

29. Blair J. Briggs, INEEL, Radiation Physics, Post Office Box 1625, MS 3855, Idaho Falls, ID 83415

30. M. P. Brossard, Duke, Cogema, Stone and Webster, 128 South Tyrone Street, PO Box 31847, MS FC12A, Charlotte, NC 28231-1847

31. K. J. Carroll, BWXT Y-12, Y-12 National Security Complex, PO Box 2009, MS 8238, Oak Ridge, TN 37831-8238

32. J. Chandler, Rocky Flats (RFETS), 10808 Hwy 93, Unit A, Golden, CO 80403-8200

33. M. S. Chatterton, U.S. Nuclear Regulatory Commission, NMSS/FCSS/FSPB, MS T8-A33, Washington, DC 20555-0001

34. D. H. Crandall, U.S. Department of Energy, NA-11, FOR, Washington DC 20585

35. M. Dayani, U.S. Department of Energy, Savannah River Operations Office, Road 1A, Aiken, SC 29801

36. J. R. Felty, Science Applications Int'l Corp., 2418 N. Dickerson St., Arlington, VA 22207

37. I. E. Fergus, U.S. Department of Energy, QA-50, Headquarters Germantown, 19901 Germantown Road, Germantown, MD 20874-1290

38. R. F. Foster, Duke, Cogema, Stone and Webster, 128 South Tyrone Street, PO Box 31847, MS FC12A, Charlotte, NC 28231-1847 
39. A. Garcia, Idaho National Engineering and Environmental Laboratory, 2525 North Fremont Avenue, Idaho Falls, ID 83401

40. P. S. Hastings, Duke, Cogema, Stone and Webster, 128 South Tyrone Street, PO Box 31847, MS FC12A, Charlotte, NC 28231-1847

41. B. Hawks, U.S. Department of Energy, Oak Ridge Operations Office, 200 Administration Road, Oak Ridge, TN 37831

42. C. S. Henkel, Duke, Cogema, Stone and Webster, 128 South Tyrone Street, PO Box 31847, MS FC12A, Charlotte, NC 28231-1847

43. W. G. Hennessy, Duke, Cogema, Stone and Webster, 128 South Tyrone Street, PO Box 31847, MS FC12A, Charlotte, NC 28231-1847

44. S. Huang, LLNL, 7000 East Avenue, MS L-128, Livermore, CA 94550

45. J. V. Johnson, U.S. Department of Energy, 1000 Independence Avenue, Washington, DC 20585

46. E. Kendall, BWXT Y-12, PO Box 2009, Bldg. 9704-2, Oak Ridge, TN 37831

47. K. D. Kimball, NISYS Corporation, 4233 Pleasant Hill Rd (Suite 200), Duluth, GA 30096

48. R. Knief, 10036 Wellington NE, Albuquerque, NM 87111

49. B. L. Lee, Jr., Bechtel Jacobs Company LLC, ETTP, Bldg. K-1320, MS-7583, PO Box 4699, Oak Ridge, TN 37831-7583

50. M. Lee, University of California, Lawrence Livermore National Laboratory, 7000 East Avenue, PO Box 808, L-1, Livermore, CA 94550

51. M. A. Lein, Duke, Cogema, Stone and Webster, 128 South Tyrone Street, PO Box 31847, MS FC12A, Charlotte, NC 28231-1847

52. E. Lipke, RL, PO Box 550, MS A0-26, Richland, WA 99352

53. C. D. Manning, Framatome Advanced Nuclear Power, 2101 Horn Rapids Road, Richland, WA 99352-5102

54. R. McBroom, U.S. Department of Energy, Oak Ridge Operations Office, 200 Administration Road, Oak Ridge, TN 37831

55. J. McKamy, U.S. Department of Energy, Headquarters Germantown, HQ EH-21, Bldg. 270, 19901 Germantown Road, Germantown, MD 20874-1290

56. T. P. McLaughlin, LANL, Bikini Atoll Rd., SM 30, PO Box 1663 (MS F691), Los Alamos, NM 87545

57. J. Mormon, Argonne National Laboratory, 9700 South Cass Avenue, Argonne IL 60439

58. F. Motley, Los Alamos National Laboratory, PO Box 1663 MS K551, Los Alamos, NM 87545

59-70. K. A. Niemer, Duke, Cogema, Stone and Webster, 128 South Tyrone Street, PO Box 31847, MS FC12A, Charlotte, NC 28231-1847

71. T. Nirider, U.S. Department of Energy, Richland Operations Office, 825 Jadwin Avenue, PO Box 550, Richland, WA 99352

72. L. E. Paulson, M/C K-26, Global Nuclear Fuel, 3901 Castle Hayne Road, Wilmington, NC 28402 
73. S. Payne, U.S. Department of Energy Albuquerque Operations Office, Pennnsylvania \& H Street, Kirtland Air Force Base, Albuquerque, NM 87116

74. J. Philbin, Sandia National Laboratory, PO Box 5800, MS 1141, Albuquerque, NM 87185

75. F. L. Pignol, Duke, Cogema, Stone and Webster, 128 South Tyrone Street, PO Box 31847, MS FC12A, Charlotte, NC 28231-1847

76. M. Brady-Raap, Pacific Northwest Laboratory, PO Box 999, MS K8-34, Richland, WA 99352

77. T. Reilly, Westinghouse Savannah River Co., PO Box 616, Routing WSMS, Aiken, SC 29808

78. K. Reynolds, U.S. Department of Energy, Oak Ridge Operations Office, 200 Administration Road, Oak Ridge, TN 37831

79. P. Rhoades, U.S. Department of Energy, 1000 Independence Avenue, Washington, DC 20585

80. N. Shepard, Westinghouse Savannah River Co., PO Box 616, Aiken, SC 29808

81. T. Taylor, INEEL, PO Box 1625, MS 3458, Idaho Falls, ID 83415-3458

82. J. R. Thornton, Duke, Cogema, Stone and Webster, 128 South Tyrone Street, PO Box 31847, MS FC12A, Charlotte, NC 28231-1847

83. Hans Toffer, U.S. Department of Energy, Richland Operations Office, 825 Jadwin Avenue, PO Box 550, Richland, WA 99352

84-85. C. Tripp, U.S. Nuclear Regulatory Commission, NMSS/FCSS/FSPB, MS T8-A33, Washington, DC 20555-0001

86. F. Trumble, Westinghouse Safety Management Solutions, 1993 South Centennial Drive, Aiken, SC 29803

87. D. W. Williams, Westinghouse NFD - MS 15, 5801 Bluff Road, Columbia, SC 29209

88. R. E. Wilson, U.S. Department of Energy, Rocky Flats Field Office, 10808 Highway 93, Unit A, Golden, CO 80403-8200

89. B. A. Wilson, Bechtel Jacobs Company LLC, PO Box 4699 (MS 7583), Oak Ridge, TN 37831-7583

90. C. J. Withee, U.S. Nuclear Regulatory Commission, NMSS/SFPO/TRD, MS O13 D13, Washington, DC 20555-0001 
